\title{
ENSURING UNCERTAINTY? THE INTERNATIONAL POLITICAL ECONOMY OF OVER-THE- COUNTER DERIVATIVES TRADING
}

\author{
by \\ Seth Bateman \\ A thesis submitted in fulfilment of the \\ requirements for the degree of
}

Master of Arts

Victoria University of Wellington 


\begin{abstract}
Over-the-counter (OTC) financial derivatives are increasingly used in a globalising financial market as tools for risk management. However, the advent of large financial crises as a result of their use raises issue as to the risks derivatives themselves might pose to the players who use them, as well as to the international financial system as a whole. It is, therefore, a key question to ask what regulation might be apt for trade in OTC derivatives. This thesis considers how a post-structuralist account might offer important insight into how this question is understood. Post-structuralist, as well as broader social constructivist and non-rationalist critiques help illustrate some of the limits to objectivist rationalism in practices of financial risk management. This thesis argues that the danger of ignoring such critiques include a continued "illusion" of individual and state-actor control over macro-economic processes, such as the phenomenal volume of trade in OTC derivatives contracts today. In this light, therefore, the regulation of OTC derivatives is not just a political question of who does and should have explicit policy control over economic and regulatory processes; but it is also a political question over knowledge constructs, and how particular technologies and specialist discourses are developed that enable "experts" legitimacy and power where it is not necessarily justified.
\end{abstract}




\section{TABLE OF CONTENTS}

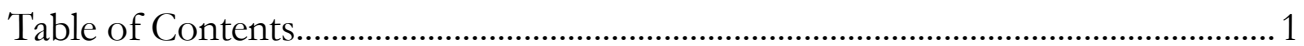

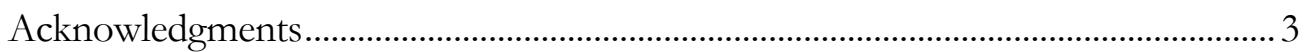

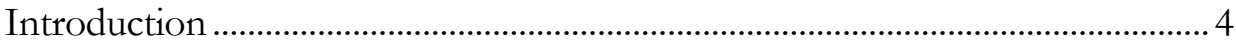

How Should The Question Of Regulating OTC Derivatives Be Framed? ........................ 4

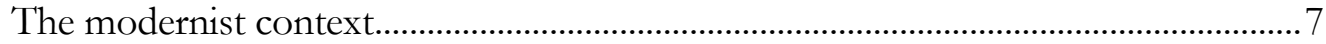

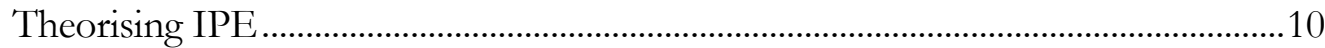

How will this thesis address the question of regulating OTC

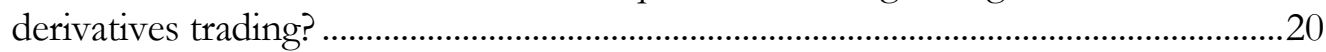

Chapter 1

Framing Uncertainty? Understanding Market Risk...........................................................22

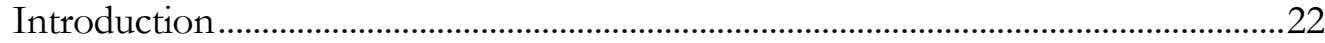

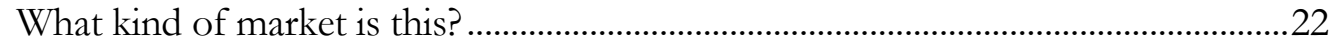

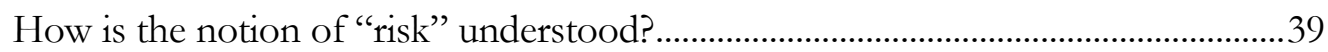

When is "market intervention" justified according to liberal logic?...........................43

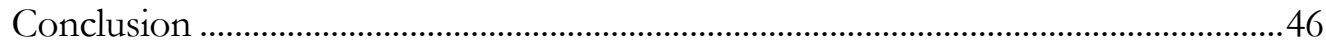

Chapter 2

How Are We To Understand Derivatives? ....................................................................48

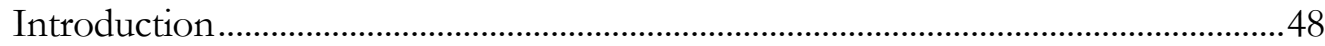

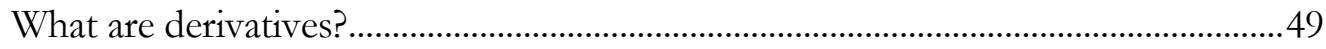

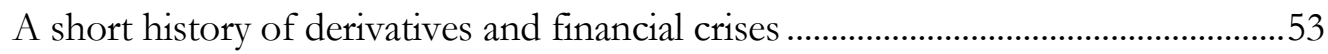

More recent history of derivatives - the age of derivatives? ........................................61

Theorising derivatives: how are they to be understood? ...............................................64

How justified are financial "experts" in their claim to such a title? .............................74

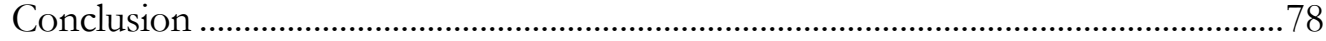

Chapter 3

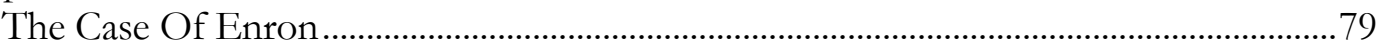

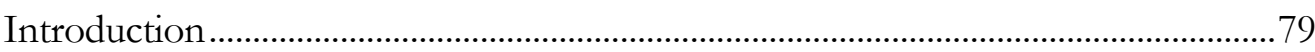

Why choose Enron as a case study?............................................................................. 80

How did Enron come to trade in derivatives? A brief history of

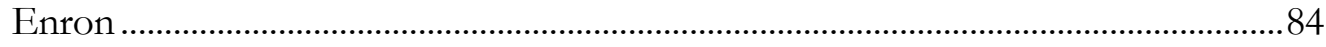

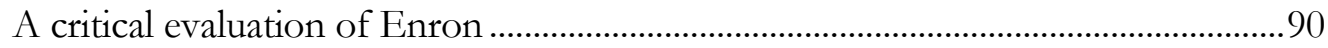

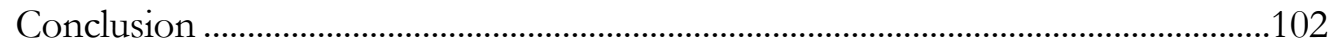

Chapter 4 104

How Is The Question of Regulation To Be Framed? ...................................................104

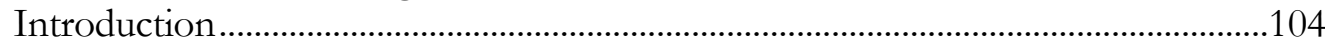

What does regulation mean in global finance? ..............................................................104

The question of control: structure or agency?........................................................112

What other criteria for regulation? ...............................................................................118 


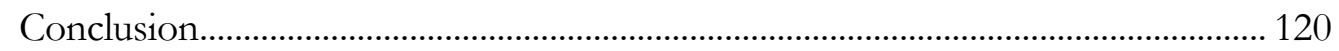

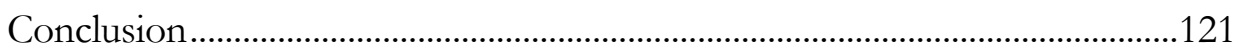

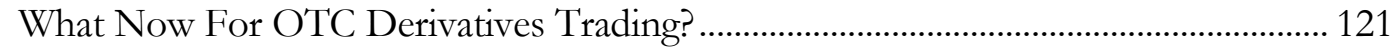

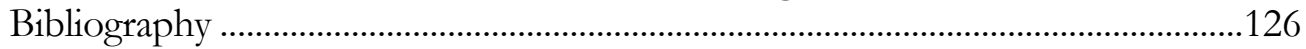




\section{ACKNOWLEDGMENTS}

The process of writing this thesis has involved much more than can be indicated in the finished product. Therefore, for making this challenging experience an ultimately rewarding one, the author wishes to thank the following people:

For collegial support and general good times: Georgina Matheson, James Gray, Teresa Tivayanond, Margaret Haywood, Keith Bollard, Jen Porter, Andre Broome, and everyone else who saw the value and entertainment in combining debate and socialising.

For academic inspiration and guidance: Ralph Pettman and Robert Deuchars.

For the numerous tutoring positions that have allowed me to share my passion for ideas and world affairs with an otherwise unreachable audience: Pat Maloney (POLS112), Margaret Clark (POLS111), Anne Rahming (POLS113), David Capie, Rod Alley, Ray Goldstein (POLS244), Robert Deuchars (POLS248), and Ralph Pettman (POLS374). And thanks also to the many students who have provided energetic debate in return.

And for personal support that has really mattered, from those beyond the ivory tower, who haven't necessarily a clue what this thesis is about: the Wedde clan, the Fox clan, Sarah Duignan, Dave (whistling) Turnbull, to Chris Fisher for his warped sense of humour and shared enjoyment of galleria coffee and to Frances Wedde and Fionna Cumming for their encouragement. 
Introduction

\section{HOW SHOULD THE QUESTION OF REGULATING OTC DERIVATIVES BE FRAMED?}

Trade in over-the-counter (OTC) derivatives now accounts for nearly \$US2 trillion per day in international financial transactions. ${ }^{1}$ Increasingly abstracted from real commodities and securities, such as those assets that are actually traded and consumed, the value of these financial instruments is the subject of much speculation. Derivatives are noted by proponents for their impressive function of limiting the risks a company is exposed to, providing a kind of insurance policy against various forms of market uncertainty. Critics, however, point out that OTC derivatives in particular are not only used to offset risk, but are in fact exploited as tools for speculation on future prices driven by "healthy desires for profit", showing little regard to the various social, economic, environmental and political costs that may ensue. For example, large financial crises such as those of Barings Bank, Long-Term-Capital-Management (LTCM), Orange County and Enron, have had both catastrophic impact for each organisation as well as significant impacts on associated workers, bank and credit networks, and government expenditure and investment plans (such as superannuation funds, for example) - in other words: the wider international financial system and beyond. Furthermore, OTC derivatives - by definition, those outside of formal exchanges - are such an obvious focus for financial speculation due to the lack of any real systematic regulation of their use. Regulation of OTC derivatives does exist, though a culture of "self-regulation" is prevalent due to the predominance of

\footnotetext{
${ }^{1}$ Statistics as at the final quarter of 2003 according to the Bank of International Settlements. See Bank of International Settlements, September, BIS Quarterly Review, Geneva. Note that this value is calculated in notional amounts. See notes to report on p. A108.
} 
neo-liberal logic, and the liberalisation and deregulation of financial markets that follows from this.

The most significant concern raised by global trade in OTC derivatives (i.e. trade that is across national boundaries and encompassing a multitude of currency and credit networks) is that of systemic risk. A concern with systemic risk is a concern over the role OTC derivatives trading might play in the occurrence of not only large corporations over-extending themselves and becoming bankrupt, but also the follow-on effects such an event might have for the entire international financial system. The likelihood of such an event is increased due to the large volumes of trade that exist between a relatively small number of tightly interconnected financial players. Also, because the financial system is no longer just a national one, nor even one between a small number of states, systemic risk is a truly important concern for the global financial market and the vast array of world affairs that are tied up with these processes. A key question has therefore been raised, by those across the political spectrum, as to the apt regulation of OTC derivatives trading. This thesis explores the question of whether OTC derivatives should be regulated, and how they should be regulated.

This is not a question ignored by scholars of international political economy (IPE), as the international financial sector and its abstract, but all too real, power, is considered a subject of critical importance. However, many conventional IPE accounts of international financial markets treat them as an homogenous external force that constrains policy devices in a straightforward way, rendering the matter of "finance" a set and neatly bounded subject to be studied as separate from wider politico-strategic, politico-social, and even other politico-economic processes. Many "new" scholars of IPE argue that the comprehensive nature and impact of this subject make it one that deserves better cultural, political and 
social, as well as economic, understanding, than it often receives in the more "orthodox" accounts (taken here to be predominantly neo-liberal and neo-realist) from scholars of IPE and economics.

Trade in OTC derivatives provides an important case where more socially constructivist accounts prove fruitful in terms of understanding the nature of human behaviour. Take, for instance, the question of systemic risk raised above. This question of systemic risk is not ignored by orthodox economists and political economists, and, in fact, their analyses become highly sophisticated, in many instances utilising complex mathematical formula and statistical modelling to outline what hypothetical situations might lead to systemic collapse. For example, there has been much discussion and analysis of "contagion" in the "Asian Financial Crisis" of 1997, and the spectacular demise of the "superstar" hedge fund LTCM has received much attention from IPE scholars also. However, an important question remains as to whether such systemic risks can actually be known, or predictable, in a calculable sense. This is partly an epistemological query over the nature of social practices in global finance, and how these processes might be rendered knowable, calculable, and therefore predictable. Without rushing into the intricate methodological debates that exist within the discipline of IPE, however, it is clear that how the "risks" in derivatives trading are understood is a key point to assess. Therefore, because there is contention over what kind of knowledge is to best allow us to explain and understand the social interactions that make up the complicated world of global derivatives markets, the question over who is "expert" in this field, and whose knowledge is to be relied on for questions of regulation, are also key queries that need raising. 
IPE does offer many interesting and insightful contributions to understanding financial practices and their roles in broader politico-economic practices. However, until recently a serious gap in the literature has existed with regard to the notion of "risk".

Before assessing the IPE literature that exists on this subject, however, we need to better understand the relevance of the theoretical debate that exists between "rationalist" and "non-rationalist" (note: not anti-rationalist) accounts of IPE, by understanding the context to the academic discipline of IPE and IR more generally. It is important to do so, as the way in which this discipline has developed provides the basis for what questions are asked and how it is deemed best to answer them.

\section{The modernist context}

One consequence of the way modernist society has developed is that modernist thinkers have divided various social processes into different groups, such as politics, sociology and economics. Perhaps the ultimate modernist example of this search for a rational and total way of mapping knowledge comes from the great Enlightenment project, the Encyclopedie, edited by Diderot and d'Alambert and supported by the intellectual weight of eighteenth-century French philosophes. ${ }^{23}$ As they struggled to map all knowledge according to what they believed to be the "natural" division of the faculties of the mind, they displayed the extreme faith that many have in the power of rationalist ways of knowing to

\footnotetext{
2 See, for instance, J. L. R. d'Alambert, Preliminary Discourse to the Encyclopedia of Diderot, trans. Richard N. Scwab (Chicago: University of Chicago Press, 1995).

${ }^{3}$ There is some disagreement over when exactly the period of modernity (if it can indeed be described as a discrete period) "began", and some argue that the European Enlightenment precedes modernity proper. However, this author takes the view that the development of rationalist ways of knowing in the Enlightenment (and preceding it) provide core philosophical and cultural components of modernist practices.
} 
provide an objective and true account of the world "out there". They failed, as the task they set themselves was incredibly far-reaching for the time (and arguably too far-reaching for any time), but the intellectual search for the way to explain the world around us has continued, and the key legacy of the Enlightenment search for truth has continued in this modernist division of academic labour. ${ }^{4}$

The above-mentioned intellectual division of labour has become one of the defining features of the way modernist thinkers attempt to explain and understand their respective "areas of expertise". Therefore, rather than look at world affairs as a whole set of interrelated practices, which would indeed be confusing and would provide less "clarity" than this kind of focus brings, specific analytic languages have been developed that focus and specialise their search for "truth".

It is out of this intellectual history that the study of international relations (IR) has developed as a discipline. This discipline focuses primarily on the politicostrategic dimension to world affairs, that is, the nature of power and how it is exercised by state-actors. The dominant voices in the discipline have traditionally been realist (those who understand human nature in essentially pessimistic terms) and idealist/internationalist (who understand human nature in essentially calculating terms) accounts. ${ }^{5}$

By focusing so heavily on state actors in their pursuit of explanations for war and peace, realist and idealist scholars neglected a whole range of non-state actors, as

\footnotetext{
${ }^{4}$ See Milbank for an account of the religious context that this division of labour has developed out of in the Western tradition. J. Milbank, Theology and Social Theory: Beyond Secular Reason (Cambridge, Massachusetts: Blackwell, 1990; reprint, 1994). Also see

${ }^{5}$ For an account of the methodological history of the discipline of IR, see M. Hollis and S. Smith, Explaining and Understanding International Relations (Oxford: Clarendon Press, 1990).
} 
well as politico-economic and politico-social processes. It was not until the 1970s that the study of international political economy (IPE) began to gain traction in IR circles as an important complement to and component of a comprehensive explanation of international political processes. ${ }^{6}$ The result was not so much a rejection of realist and idealist theories, but rather a modification of these theories to include economic factors in their consideration of the decision-making processes of states.

There are two key points to note here. First, academic study of world affairs has become more specialised and focused on specific "problems" that are viewed to have more in common than other problems. For instance, "power" (understood primarily in material and coercive terms) has been considered the key aspect that defines the study of politics, as opposed to that of wealth and scarcity in economics. Second, the study of international relations, along with much else endeavour in the social sciences, has seen a dramatic shift to reliance on what can be called "rationalist" ways of knowing. This shift relies on the epistemological belief that "science" should underpin all social enquiry, providing verifiable knowledge that lays the foundation for a more "objective" understanding of the world "out there", a theoretical position mapped out by Descartes and developed according to his objectivist and enumerated principles some four hundred years earlier ${ }^{7}$. The study of IR, and the sub-discipline of IPE it has spawned, are tantamount to the methodological dominance of objectivist rationalism. A brief

\footnotetext{
${ }^{6}$ Gill and Law are correct to assert that political economy has long been an important component to Western accounts of world affairs, an intellectual history that precedes the discipline of IR altogether. S. Gill and D. Law, The Global Political Economy: Perspectives, Problems, and Policies (Baltimore: The John Hopkins University Press, 1988) p. 3. However, for an account of more recent developments of the discipline of IPE, see S. Strange, "Political Economy and International Relations," in International Relations Theory Today, ed. Ken Booth and Steve Smith (Pennsylvania: The Pennsylvania State University Press, 1995).
}

${ }^{7}$ R. Descartes, Discourse on Method, trans. John Veitch (London and New York: J. M. Dent, Dutton, 1975). 
analysis of the IPE literature makes clear what types of questions and enquiry this type of analysis leads to, and consequently, what questions it does not ask.

\section{Theorising IPE}

So, what has been the contribution to the discipline from the scholars of IPE? For starters, we can divide most of the IPE literature into two broad groups of "traditional" approaches and "new" approaches. ${ }^{8}$ The traditional approaches are the "trusty trio" of liberalism, mercantilism and Marxism. The most prominent of these voices are those belonging to the liberals who support a "free market" model, viewing free trade and the free movement of capital as essential to the functioning of "fair" and "efficient" markets." According to liberal logic, " $t$ the economy is oiled by freely exchangeable currencies and open markets which create a global system of prices which, like an invisible hand, ensures an efficient and equitable distribution of goods and services across the world economy., ${ }^{10}$ For liberals, the assumption that people are to be understood as rational selfmaximising individuals is paramount.

Liberals of all kinds are concerned about "market failure" and the economic depression that might result. Financial poverty and uncertainty is also likely to manifest itself in internal and international conflict, and can affect the collective security pacts that concern liberal internationalists, and the interdependent economic relations that concern liberal institutionalists. Whatever liberal approach is adopted (moderate or extreme), individual actors, such as the firm, are the key. Any rational description of economic processes must take seriously

\footnotetext{
${ }^{8}$ N. Woods, "International Political Economy in an Age of Globalization," in The Globalization of World Politics, ed. John Baylis and Steve Smith (Oxford: Oxford University Press, 2001), p. 285.

${ }_{9}^{9}$ See, for instance, J. G. Ruggie, "International Regimes, Transactions, and Change: Embedded Liberalism in the Postwar Economic Order," International Organizations 36, no. 2 (1982).

10 Woods, "International Political Economy in an Age of Globalization," p. 285.
} 
the motivations of the individual firms involved, primarily in terms of the monetary incentives to which they respond.

The mercantilist's focus, by contrast, is still very much that of the state. For mercantilists, supra-territorial financial capital is potentially a "threat" to state autonomy. Hegemonic stability theory looms large here, as the importance of international economic processes is to be understood in terms of the "balance of power" that it is part of. Without cash, governments cannot buy military capabilities, which are necessary in a zero-sum world of self-interested state actors - the key assumption of realists and mercantilists alike.

Marxists are, like mercantilists, sceptical of the positive-sum game put forward by liberals. But unlike realists, whose main actor is that of the state, Marxists emphasise the class struggle that is part and parcel of capitalist processes. Following the logic of historical materialism, financial instruments such as derivatives are viewed as tools to be used by bourgeois elites to further the expansion of capitalist markets, and to "exploit" the value found in all labour practices. It is no surprise, then, that those who trade in financial derivatives are primarily viewed by Marxists in parasitic terms, as providing little, if any, creative input to economic processes.

The upside for Marxists is that a historical materialist analysis leads one to "realise" the unsustainable nature of capitalist processes. The further the expansion of capitalism and its reliance on abstract notions of value, the more imminent the "inevitable" collapse of the entire financial system. Regardless of one's political perspective, the Marxists' focus on financial capitalism at the systemic level of analysis, provides some credence given the global nature of the processes involved. 
The "new" approaches to the study of IPE build on these traditional approaches, by incorporating the results of methodological debates within the discipline over how the motivations of actors (as well as which actors are to be considered important) are to be understood and explained. The new approaches can be broadly categorised as rationalist, like neo-realism and neo-liberalism, and social constructivist, like critical theory and neo-gramscianism.

Ronen Palan notes the 'rising in significance of the methodological debate between, on the one hand, rationalist and methodologically individualist approaches, and on the other, the critical or post-rationalist traditions. ${ }^{11}$ A key point raised by the post-rationalist tradition, is that the distinction between the political and the economic is not as clear as theorists such as Gilpin have made out. This is due to substantial changes due to a 'profound restructuring of the environment of accumulation through economic globalisation., ${ }^{12}$

The two main rationalist approaches to the study of IPE are the neorealist and neoliberal takes, such as those of $\operatorname{Krasner}^{13}$ on the one hand, and of Cohen, Cerny and Pauly on the other. ${ }^{14}$ Both of these accounts have refined their technical analysis of the behaviour of their respective actors, with the main assumption being that individuals act according to laws of utility-maximising selfinterest. Importantly, for neo-liberal theory, 'the state is disaggregated while

\footnotetext{
11 R. Palan, ed., Global Political Economy: Contemporary Theories (London: Routledge, 2000) p. 2.

12 Ibid. p. 3.

${ }^{13}$ S. Krasner, "The Accomplishments of International Political Economy," in International Theory: Positivism and Beyond, ed. Steve Smith, Ken Booth, and Marysia Zalewski (Cambridge: Cambridge University Press, 1996). This particular article outlines both the position of Krasner's own neo-realist work as well as other predominantly rationalist accounts of IPE.

${ }^{14}$ B. Cohen, "Money in a Globalized World," in The Political Economy of Globalization, ed. Ngaire Woods (New York: St Martins Press, 2000).
} 
normative consideration of system optimisation through the tools of rational choice is advanced. ${ }^{15}$

Three main criticisms to these rationalist approaches are outlined in approaches that emphasise epistemic communities ${ }^{16}$, Gramscian IPE $^{17}$, and the importance of information ${ }^{18}$. Other reasons for challenging these dominant discourses of rationalist accounts include the numerous voices that are not heard through their analysis of the global political economy. For instance, the gendered nature of the global political economy, such as the masculinist financial practices and female under-representation that are evident in popular accounts, like the non-fiction book Liar's Poker and the fictional movies of Wall Street and American Psycho. ${ }^{19}$ Environmentalists also note the inattention ecological concerns receive in the constant call for economic growth through increased production and consumption of non-renewable (and often non-recyclable) resources. ${ }^{20}$

There is also a growing literature establishing a post-rationalist approach to IPE, or GPE (global political economy as it is termed by authors such as Palan and Peterson).

\footnotetext{
15 Palan, ed., Global Political Economy: Contemporary Theories p. 6.

${ }^{16}$ E. Helleiner, States and the Re-emergence of Global Finance (Ithaca, New York: Cornell University Press, 1994).

17

18 T. Porter, States, Markets and Regimes in Global Finance (Basingstoke: Macmillan, 1993). And more recently, T. Porter, "The Late-Modern Knowledge Structure and World Politics," in Approaches to Global Governance, ed. Martin Hewson and Timothy J. Sinclair, SUNY series in Global Politics (Albany: State University of New York Press, 1999), S. Strange, States and Markets: An Introduction to International Political Economy, 2nd ed. (New York: Basil Blackwell, 1997).

${ }^{19}$ Important feminist contributions to IPE include C. Enloe, Bananas, Beaches and Bases: Making Feminist Sense of International Politics (Berkeley: University of California Press, 1989), V. S. Peterson, A Critical Rewriting of Global Political Economy: Integrating Reproductive, Productive, and Virtual Economies (London: Routledge, 2003).

${ }^{20}$ Nor are these voices particularly new. See, for instance, E. F. Schumacher, Small Is Beautiful: A Study of Economics as if People Mattered (London: Vintage, 1973).
} 
Broadly speaking, post-rationalist GPE adopts an open-ended historical narrative in which outcomes are not predictable, but negotiated and contested, with each actor-network perpetually frightened of loss or stasis. States and multinational enterprises are viewed no longer simply as instrumentalist advantage-maximising institutions, but as complex organisations which exceed their goals and functions, but in non-utilitarian ways. Their language, their scripts, their histories, their techno-structures and artefacts matter; analysis of which reveals them to be trapped in their own evolutionary logic but also constantly at work to renew themselves. Consequently, we have witnessed the "opening up" of GPE from its economistic and material base to broader questions of history and culture. ${ }^{21}$

Key to all of this debate is the issue of what questions IPE should address. Palan also notes that "three crucial questions" of political economy are those relating to power, capital and labour. He argues that, '[m]ore than any other branch of political economy, GPE centres on power, and yet, it does not really know how to conceptualise power. ${ }^{22}$ The notion of power is one that post-structuralists are particularly interested, though the type of power they focus on has more to do with the relationship between knowledge and constructed social practices than it does with physical force or outright coercion. The importance of this analysis lies in its recognition of not just the continually politically contested nature of global social structures, but it also provides insight into the limits of more rationalist accounts. This is not to reject that rationalist accounts offer powerful explanatory tools, but it does argue that these explanations have their limits, and that the meaning of such social practices is often overlooked and misunderstood. Importantly, this meaning is crucial to understand, if one believes an epistemologically constructed interpretation is apt. Post-structuralists consider

\footnotetext{
${ }^{21}$ Palan, ed., Global Political Economy: Contemporary Theories p. 15.

22 Ibid. p. 4.
} 
such an investigation apt due to the contested nature of truth-claims, that rely heavily on the connection of particular types of knowledge (such as statistical knowledge and mathematical models) and hierarchical positions of decisionmakers. In the global political economy, the question of power is so important due to the global scope and nature of the impact the decision of such a relatively few can have.

The point of a postmodernist account is to turn reason back on itself. ${ }^{23}$ Postmodernists believe that reason gets caught up in its own logic. To the postmodernist, truth is essentially relative and depends on the socio-cultural context and perspective one has. Going too far down this path can lead to a point of no return, a point where one is no longer able to verify any "truth" whatsoever. Stopping short of this point, however, valuable lessons can be gained. In the study of IPE, this means that

[w]e need to think more productively about: the world as the economic unit, information and signs as what is exchanged, and the meaning and value of exchanges that are virtual but systematically consequential. At the same time, we need to be able to link the exchange of symbols and intangibles to expectations, identities, and practices of the virtual economy and relate these to the productive and reproductive economies. ${ }^{24}$

As Peterson notes, the 'role of subjective opinions in financial matters is hardly new, though (beyond a narrow construction of "rationality") it has rarely been a focal point of liberal and/or positivist analyses. ${ }^{25}$ This is particularly important for our understanding of derivatives trading, where abstract contracts are

\footnotetext{
23

${ }^{24}$ Peterson, A Critical Rewriting of Global Political Economy: Integrating Reproductive, Productive, and Virtual Economies pp. 115-116.

25 Ibid. p. 115.
} 
contingent on shared meanings of value. Indeed, 'most scholars writing on global finance do so from positivist, productivist, or constructivist orientations that tend to marginalize subjectivities, signs, and semiotics' ${ }^{26}$.

Post-structuralist and social constructivist ${ }^{27}$ accounts offer a very different and critical position in this regard, arguing that neo-liberal and neo-realist approaches make false distinctions between "fact" and "value", and ignore the power/knowledge relationships that exist at the heart of all modernist social practices. Their critique of what are essentially viewed as "positivist" accounts of global finance, points to the limits of scientific risk management in areas of social processes where theory informs practice such that mathematical models and statistical knowledge become part of and alter the practices of global finance. In the case of derivatives trading, models such as the Black-Scholes options-pricing formula influence the behaviour of financial traders. This, in itself, does not present a fundamental problem to "positivist" risk analyses. But, it does belie the importance of understanding social processes in their cultural and social context.

If, as post-structuralists suggest, theory does inform practice through a complex nexus of power/knowledge relations (such as those that exist between the construction of statistical knowledge, issues of classification, interpretive representation of social processes presented as social "fact", education of "experts" and the construction of a technocratic society that supports their legitimacy, and that legitimacy as viewed to be based on their superior apolitical and objective knowledge, as opposed to knowledge that might be political and

\footnotetext{
26 Ibid.

27 This is a very broad category in IR/IPE theory, and includes those from more "soft" rational choice camps as well as other more radical constructivist approaches. For instance, see J. K. Jacobsen, "Much Ado About Ideas: The Cognitive Factor in Economic Policy," World Politics 47, no. 2 (1995), M. Laffey and J. Weldis, "Beyond Belief: Ideas and Symbolic Technologies in the Study of International Relations," European Journal of International Relations 3, no. 2 (2000).
} 
with vested interest), then the position of the "expert" in scientific financial risk management might well be undermined. Interestingly, in this regard, is that there is a 'curious inattentiveness to the question of risk ${ }^{28}$ in IPE.

While much of the IPE literature offers criticisms of economic and financial practices, these criticisms are limited by those "facts" that are taken as given, those arguments that are taken as "truths". A genealogy of finance and a genealogy of risk highlight the politically contestable nature of these "facts" and "truths", and are one way, therefore, of allowing for a critique of these practices, including a critique of derivatives trading.

The intention of this thesis is not to discard the often-fruitful investigations provided by Marxist, neoliberal and neorealist accounts of the global political economy, however. This is to incorporate these "stories" as part of a more comprehensive explanation and understanding of the processes involved. Two recent studies of the international political economy of finance are worth dwelling on here to provide a clearer idea of what such a critical study might look like.

Genealogical studies, or "critical histories" of this sort are still relatively new to the discipline of IPE. Marieke de Goede, for example, has written a genealogy of finance that traces key contentions and shifts in the development of financial practices and their cultural contexts. She argues that 'understanding the politics of modern finance requires a rejection of the dichotomy between the ideal and the material, and starts with a consideration [of] how current discourses of financial rectitude and economic necessity have taken shape at the expense of

${ }^{28}$ R. Deuchars, The International Political Economy of Risk: Rationalism, Calculation and Power (Ashgate, 2004) p. 1. 
other possible financial representations. ${ }^{29}$ This analysis includes investigating the gendered discourse of credit and credibility, the morality of speculation, the differences between gambling and finance, and the imagination of finance as a rational and scientific practice. This work is but one example of the nonrationalist research advocated by Palan and Amin, though it is different to the constructivist approaches they prefer to pursue. ${ }^{30}$ Furthermore, Robert Deuchars' study of the IPE of risk maps the rise of insurance technologies and financial rationalities made possible by the contingent developments of probabilistic technologies, by the advent of statistical knowledge, and by the employment of this technology and knowledge in early political economy. Both de Goede and Deuchars, building on critical historical work from outside the discipline of IPE (and well beyond the discipline of IR), provide a launch pad from which a critical history of derivatives might be told.

Discourse analysis, like that provided by de Goede and Deuchars, is a meta-meta critique. This means that it is a critique that situates itself outside the realm of meta-narrative of rationalism, showing how the reliance on objectivist rationalism limits understanding of social practices in general, and of financial practices in particular. By illustrating the important contribution these accounts offer, is not to say that this is the "whole story", as it were. But it does offer an important limitation to what are otherwise purported to be uncontested "expert", and apolitical, opinions in highly important politico-economic processes and institutions. Also, if we are to provide not just problem solving theories, but critical theories, as Cox discusses $i t^{31}$, we need to account for change - how this

\footnotetext{
${ }^{29}$ M. D. Goede, "Beyond Economism in International Political Economy," Review of International Political Economy 29 (2003): p. 81.

${ }^{30}$ A. Amin and R. Palan, "Towards a Non-Rationalist International Political Economy," Ibid.8, no. 4 (2001).

31 R. W. Cox, "Critical Political Economy," in International Political Economy, ed. Bjorn Hettne (Halifax: Fernwood Books Ltd, 1995).
} 
particular set of social practices has come into being, and how it is likely to change in the future - let alone how it might be possibly to change it, depending on one's perspective and aims.

These critical histories of finance and IPE follow Foucault in their analysis of power/knowledge contests. ${ }^{32}$ They contest the agenda-setting affect power as knowledge has on contemporary social practices. The implications of the consequent social constructivist approach is to question the legitimacy of the expertise that is proffered by those specialists that focus narrowly on particular sets of practices without showing an understanding of the context of their subject - the complex, social relations they are part of but not separate from. With regard to derivatives trading as risk management, one needs to question the role of the "expert", therefore, and how much control experts have over global finance.

Following the above analysis, one key argument of this thesis is that there is an "illusion of control" over the financial market generally, and over the OTC derivatives market in particular. Whilst it is obvious that there are various political stances apropos the need to (not) regulate derivatives trading, this essay investigates the question of control from a slightly different angle: do those who suppose to understand, predict, explain and control financial "risk" really know how to do so at the systemic level? In other words, are the financial "risks" of derivatives trading understood well enough to enable us to regulate them (in reformist or extreme liberal form) properly, such that the systemic threats they pose to the international financial system are kept under control? Reasons for this "illusion of control" include the ideological nature of the supposedly value-

\footnotetext{
32 See M. Foucault, Power/Knowledge: Selected Interviews and Other Writings 1972-1977, trans. Colin Gordon, et al. (Brighton: Harvester Press, 1980).
} 
neutral tools of modern risk management. Any claims to objectivity in this regard are in very real danger of fostering misunderstanding of the nature and consequence of using models and modern risk technologies such as those employed in OTC derivatives trading.

\section{How will this thesis address the question of regulating OTC derivatives trading?}

This thesis takes as its starting point the critical assessment of the liberal understanding of what is "market risk". In doing so it explores the liberal definition of what constitutes a market, and how "risks" to this market might be understood. This leads to the question of how "market failure" is understood and when market intervention is justified according to (neo-) liberal logic. This critical overview of market risk provides the context to how we are to understand trade in OTC financial derivatives.

The second chapter explores financial derivatives trading as an example of risk management. The chapter briefly provides a critical history of derivatives trading as risk management. This provides, in turn, context to the practice of contemporary OTC derivatives trading and, in doing so, briefly examines the assumptions that underpin the key mathematical models used for predicting OTC derivatives contracts. By outlining the literature on derivatives trading in general, and OTC derivatives in particular, an understanding of how these tools are used is developed. This leads to the question as to whether the practice of OTC derivatives trading is adequately understood within liberal "market risk" models.

A case study of the giant American energy corporation Enron, and its use of OTC derivatives trading, provides evidence of how market risk can be (mis)understood, and how regulatory mechanisms of the state do not provide the kind of safe-guards required to prevent "risk" spreading from such a corporation 
to the rest of the international financial system. What is particularly interesting about this case is the way the fallout from the Enron bankruptcy has, like many bankruptcies involving OTC derivatives trading, been a focus for studies of fraudulent accounting and improvements of transparency. However, the basic assumptions underpinning the use of financial derivatives, and the ability to use them "safely", are left relatively unquestioned by most commentators. This case study illustrates the distance between liberal accounts of theory and practice.

If OTC derivatives are a source of "systemic risk", then regulation is a key concern for liberals and other politico-economic ideologies. This makes the case for regulation more convincing than many liberal commentators might think it is. The fourth chapter accounts for how the notion of regulation, as raised by the question of risk, is understood and developed according to various theories of international political economy. Examining the notion of governance in the international financial sector points to the crucial question of structure versus agency in the OTC derivatives market, thereby placing talk of financial regulation in a philosophical, as well as political, framework. 


$$
\text { Chapter } 1
$$

\section{FRAMING UNCERTAINTY? UNDERSTANDING MARKET RISK}

\section{Introduction}

The introductory chapter outlined the problem of systemic risk that trade in OTC derivatives trading poses, and assessed various analytic languages employed by theorists of IPE to assess such risks. It established that IPE needs to be understood in terms of a more critical approach than that offered by the "problem solving" theory of rationalist approaches such as neo-liberalism, and that post-structuralism offers one such useful approach. This chapter elaborates on and explores the nature of financial market practices and the logic of regulatory policy options in this context. The first section outlines what kind of market the financial market is, how it is supposed to function and what it is meant to do, based on the assumptions made by those who support the logic of it. The second section outlines what constitutes a "risk" to this market, and therefore, how "market failure" is assessed. The third section focuses on how the question of "market intervention" is framed as a result of this particular understanding of "risk" to market structure.

\section{What kind of market is this?}

A market is generally defined as a place in which trade is conducted, or that set of social interactions regarding the exchange of goods and services. ${ }^{33}$ History and geography illustrate the variety of the different types of markets that humans have constructed through their desires to meet needs and wants of material goods. Importantly, though, the global political economy is increasingly a capitalist one.

\footnotetext{
33 OED, ([cited 21 October 2004]); available from http://www.oed.com.
} 
While some argue the importance of recognising "varieties of capitalism" 34 , for the sake of clarity it is easy to see central tenets of capitalism as a way of organising economy and society in general.

First and foremost, the capitalist system is one that relies on the concept of "capital". Although originally associated with land and personal property, capital is essentially anything that is said to be owned, saleable and transferable (usually by an individual, but also including groups). While sounding obvious (to Western ears in particular) today, these qualities are not natural givens - especially to something so central to the survival and livelihood of societies as land - and the institutionalised prominence of these particular values in society is historically unique. This is, of course, a central and large subject to note (after all, Marx devoted three entire volumes to the subject), and much could be said about the notion of capital that cannot be covered here. What we do need to note, however, is that the fact that this is a capitalist system means that it is one that privileges the role of capital and the conceptual and practical basis from which its exchange has been able to take a central part of modernist social practices.

Second, the development of the notion of capital is historically and intricately tied up with the notion of individual freedom to own, buy and sell it. Liberalism, in other words, provides the social and "moral" basis that underpins the logic in which capital should be used in society. It is believed that by privileging the role of the individual, their self-interested pursuit of material gain will likely lead to a

\footnotetext{
34 See P. A. Hall and D. Soskice, Varieties of Capitalism: The Institutional Foundations of Comparative Advantage (Cambridge: Cambridge University Press, 2001), J. R. Hollingsworth and R. Boyer, eds., Contemporary Capitalism: The Embededdness of Institutions (New York: Cambridge University Press, 1997), P. L. Kitschell, G. Marks, and J. D. Stephens, eds., Continuity and Change in Contemporary Capitalism (Cambridge: Cambridge University Press, 2000). Referred to here are primarily the distinctions between Liberal Market Economies (LMEs) and Coordinated Market Economies (CMEs). Though, some have noted problems with this distinction. See M. Blyth, "Same as it Never Was: Temporality and Typology in Varieties of Capitalism," Comparative European Politics, no. 1 (2003).
} 
more efficient and "progressive" economic system overall. "Freedom", in this regard, is assessed by the "right" for individuals to own property or other forms of capital, and to sell them to whomever they choose for whatever price is agreed under rational contract; to be able to sell one's labour for a wage; and to be able to enter/exit the market with relative ease.

Adam Smith outlined what he, and many liberals following him, consider to be the "basic laws" of the market:

They tell us that the outcome of a certain kind of behavior [sic] in a certain social framework will bring about perfectly definite and foreseeable results. Specifically they show us how the drive of individual self-interest in an environment of similarly motivated individuals will result in competition and they further demonstrate how competition will result in the provision of those goods that society wants, in the quantities that society desires, and at the prices society is prepared to pay. ${ }^{36}$

The assumption that humans are essentially calculating is paramount here, and core to all liberal accounts of human behaviour and decision making. Clear, too, is the importance of 'individuated individuals, promoting their personal economic advantage, and this being "naturally" and "necessarily" the best for everyone else. ${ }^{37}$ Not only did Smith make this central to his thesis, but some two hundred years later Fredrick von Hayek espoused the normative value of such an account, as well as its descriptive accuracy. ${ }^{38}$ The twentieth century neo-classical

\footnotetext{
35 A strong moral component also exists here, as the contribution an individual makes to society has become increasingly linked to their success in economic terms. This is in contrast to previous Western social norms informed by Christian values that denounced the accumulation of wealth and also linked hierarchy and esteem with "God-given" social divisions.

${ }^{36}$ R. Heilbroner, The Worldly Philosophers: The Lives, Times and Ideas of the Great Economic Thinkers, Revised 7th Edition ed. (London: Penguin Books, 2000; reprint, 1999) p. 55.

${ }^{37}$ R. Pettman, World Politics: Rationalism and Beyond (New York: Palgrave, 2001) p. 109.

${ }^{38}$ F. A. Hayek, Road to Serfdom (London: Routledge and Keegan, 1944).
} 
economist Milton Friedman also made this assumption - of human beings as essentially calculating - the key to his analysis of the market. ${ }^{39}$ The implications of such an assumption is that the market will work most efficiently, where there is little interference from government, or from "outside" forces.

It is the self-interested individual that drives economic growth through entrepreneurial risk-taking ventures. Moreover, and key to liberal theory, the selfinterest of these relative few provides the basis for economic expansion that grows the collective pie for all. Ideally, then, the economic realm should be separate from the political realm, allowing for the "natural" laws of the market to play out (as nature intended). Both moderate and extreme liberals, therefore, 'valorize competition, self-realization and self-maximization, not least because of the way these can be used to promote divisions of labor, both locally and worldwide, with all the productive benefits that then accrue' 40 .

Market efficiency is measured primarily in terms of the increase of production that provides for the consumption that is essential to such a materialist society. Moreover, the market is deemed efficient, according to liberals, if there is as little state interference as possible, and the level of production is increasing from year to year - i.e. that there is material progress. How this productive wealth is distributed is not of such a concern for liberals (extreme market liberals in particular) though there must be provision for those workers who receive least for their labour or else productivity may be adversely affected. This is, of course, the point Marxists dwell on the most, emphasising the fact that a class bias is evident in the capitalist market system, due to the division of labour that

\footnotetext{
${ }^{39}$ M. Friedman, "The Methodology of Positive Economics," in Essays in Positive Economics (Chicago: University of Chicago Press, 1953).

40 Pettman, World Politics: Rationalism and Beyond p. 109.
} 
privileges those who own the means of production (and in this case more specifically, finance capital) over those who sell their labour for a wage.

A key question, in regard to the structure and nature of this market, is "how" this particular type of market came about. $\quad 41$ Scholars differ in their accounts of this, depending on their assumptions about human nature and nurture. For liberals, the evolution of capitalism is a natural outcome of the fact that all people are essentially calculating. How else, they argue, can we explain the resilience of capitalist expansion in spite of so many (economic and political) obstacles and oppositions to it? There are, of course, large disagreements within this liberal stance, from those who proffer different interpretations of human nature, to those who believe material or ideational factors conditions our interpretations and behaviour. A key point to make, however, is that these are repeated human practices, not reified structures that have their own agency. They are an aggregate of human behaviour over time and space, and change to this behaviour must be aware of the many individual components that make up its parts.

In order to understand a phenomenally large aggregate of known behaviour, scholars of IPE have divided their analysis of the global political economy into three main sets of practices: trade, production, and finance. It is finance that we are primarily interested in here. While the nature of trade and production are open to interpretation, these are very concrete practices. Finance, on the other hand, whilst obviously "real" in the sense that it affects the lives of people every day, is made up of far more speculative/imaginary/precipitous stuff. So, what is finance, and how is the financial world structured?

${ }^{41}$ Polanyi is interesting in his discussion of 'market society' here. K. Polanyi, The Great Transformation (New York and Toronto: Farrar and Rinehart, Inc, 1994). 
Exchange of capital is limited if it is not easily transferable or if there is not an agreed medium upon which exchange can be based. This is where the role of money and finance come in. After all, a financial market is a market for the exchange of credit and capital. Money is the means by which debit and credit is measured; it is a means of exchange between large numbers of people who do not necessarily know each other, and would otherwise not trust each other in trade without the formulated and regulated symbol money represents. ${ }^{42}$ This $_{\text {fiat }}{ }^{43}$ money is reliant on the beliefs of the individual and state actors that collectively determine how this symbolic value should best be calculated. This is no mean feat given the wide variety of transactions and the large number of people whose varying preferences must be taken into account.

Finance is concerned with how this meta-realm of wealth determination is to be understood. Practitioners of financial transactions (for example, the exchange between those with debt and those with credit) seek one key thing: money, or wealth. In order to get this money a financial actor needs to understand not so much what something is worth to them, but rather what something is worth to other people. Furthermore, they may need to understand what it is worth to a group of people who live locally, and share similar preferences, needs and wants, or they may need to understand what something is worth to people on the other side of the world. This is increasingly the case in markets that are no longer limited locally, but transcend local, national, regional and international boundaries. Furthermore, they may need to understand what that something is

\footnotetext{
${ }^{42}$ For a further formal definition and discussion of money, see J. Tobin, "Money," in The New Palgrave Dictionary of Money and Finance, ed. Peter Newmann, Murray Milgrage, and John Eatwell (London: The Macmillan Press Ltd., 1992).

${ }^{43}$ Fiat money is symbol money backed with the authority of the state to give credence and help trust in public usage. See Ibid.
} 
worth now or they may need to understand what it is worth at some point in the future.

To work out the "value" of something in the future requires a complicated set of assumptions about human behaviour, and mathematical and statistical models able to approximate what the future value is likely to be. As with all liberal market practices, one has to get at least one other person to agree that yours is a reasonable approximation of what the value is likely to be at the designated time in the future. There are now thousands of people who use these techniques to predict and place financial "bets" on the future value of assets and securities.

This system relies on the mediated "trust" offered in the form of credit being reciprocated and maintained. Therefore, the logic of this system is one that is automatically biased against those who are not actively productive or "creditworthy". This system is now global, and credit risk analysis is a huge market in its own right. Credit risk is one of the main types of risk in derivatives trading, as a default on a contract can leave the other contracted party out of pocket, not to mention the follow-on effects of other parties involved.

The growing importance of finance in an increasingly globalised and liberalised economy has gained the attention of more scholars to the study of global finance. To some extent, the question of prioritising the study of these three components of the IPE is still an important question. Many believe finance to be the area of the global economy that flows from trade and production, merely providing the liquidity to "grease the wheels" of production, as it were. Meanwhile, others argue that capitalist expansion and economic structure would not only not be possible without financial capital, but that it is the very driving force behind the historical development of capitalism in general. This is an 
interesting debate to dwell on, as it is ultimately a philosophical question as to how to best understand historical change in political economy: is it driven by the material forces of production, as Marxists assert? Or is it driven more by the creation of ideas, by the "invention" of the notion of credit and financial instruments, that has allowed calculating individuals (constructed or otherwise) to pursue capitalist expansion?

According to V. Spike Peterson 'Global finance broadly defined is a reference to cross-border capital flows of credit (bonds, loans), money (currency exchange), and investment (equities, capital transfers). ${ }^{, 44}$ Further, Strange explores financial exchange by noting that it

comprises not just the structures of the political economy through which credit is created but also the monetary system or systems which determine the relative values of the different moneys in which credit is denominated; in the first the power to create credit is shared by governments and banks (and much will depend therefore on the political and regulatory relation of the one to the other). In the second, the exchange rates between the different moneys, or currencies, are determined by the policies of governments and by markets (and again much will depend on how much freedom governments allow markets). A financial structure, therefore, can be defined as the sum of all the arrangements governing the availability of credit plus all the factors determining the terms on which currencies are exchanged for another. ${ }^{45}$

In a discussion of the financial market practice it is important to recognise and address the large scale and velocity of international capital flows. Importantly,

\footnotetext{
${ }^{44}$ Peterson, A Critical Rewriting of Global Political Economy: Integrating Reproductive, Productive, and Virtual Economies p. 114.

45 Strange, States and Markets: An Introduction to International Political Economy p. 90.
} 
though, as Peterson notes, 'analyses must acknowledge and address the nature of these transactions and their effects on more conventional forms of exchange. ${ }^{46}$

Though the role of finance has traditionally been given less importance than the other dimensions of the international political economy, such as trade and production, the importance of finance cannot really be underestimated in the context of current market structures. As Peterson notes, 'the dictates of interdependent global financial markets increasingly shape the policy options and hence politics of territorially bounded nation-states. ${ }^{47}$

For Susan Strange the key point to be taken from a discussion of finance is the notion of credit. ${ }^{48}$ To Strange, this is an important point to note as,

The power to create credit implies the power to allow or to deny other people the possibility of spending today and paying back tomorrow, the power to let them exercise purchasing power and thus influence markets for production, and also the power to manage or mismanage the currency in which credit is denominated, thus affecting rates of exchange with credit denominated in other currencies. ${ }^{49}$

Marxists disagree with Strange's attributing so much importance to credit in an understanding of the financial sphere of the international political economy. For Marxists, finance, including credit, is to be understood as a logical extension of the accumulation of capital that is central to a "capitalist" system. Stephen Gill and David Law outline the key differences between a Marxist and a liberal

\footnotetext{
${ }^{46}$ Peterson, A Critical Rewriting of Global Political Economy: Integrating Reproductive, Productive, and Virtual Economies p. 113.

${ }^{47}$ Ibid. p. 130.

48 Strange, States and Markets: An Introduction to International Political Economy.

${ }^{49}$ Ibid. p. 90.
} 
approach to the importance of finance, by noting how 'Neoclassical economists often treat the three factors of production as similar, that is as productive inputs which are equally necessary.' Marxists, on the other hand, 'whist acknowledging the productive character of capital equipment, also focuses on capital as a social relation. In this relationship, capital exploits labour by extracting surplus. Thus in the Marxist formulation, capital and labour are social and political concepts, as well as purely technical, economic ones. ${ }^{, 50}$

Marxists are not the only ones to argue that money is a political concept in this regard. ${ }^{51}$ The critical financial economist, Elton McGoun, stakes out at least five different functions of money in a modern financial economy, with particular emphasis being given to the way in which money has provided the basis from which the "financial" economy has become separated from the "real" economy. The study of money is the examination of a range of complex interconnected social processes, and certainly not all (if any) can be understood in scientifically economic terms alone. It is not surprising, therefore, that Peterson argues that contrary to liberal accounts "money is not neutral". Furthermore, 'The key issue here is how fundamentally value is determined not by any inherent measure of labor inputs or material needs but by reference to positioning within a system of signs/values. ${ }^{5253}$ That the role of subjective opinions in financial matters is

\footnotetext{
${ }^{50}$ Gill and Law, The Global Political Economy: Perspectives, Problems, and Policies p. 83.

${ }^{51}$ J. Kirshner, "Money is Politics," Review of International Political Economy 10, no. 4 (2003).

52 Peterson, A Critical Rewriting of Global Political Economy: Integrating Reproductive, Productive, and Virtual Economies p. 117.

${ }^{3}$ This is also a point that the French philosopher Jean Baudrillard has made clear in his discussions of the symbol value of money and commodities in general. See: J. Baudrillard, The Mirror of Production, trans. Mark Poster (St. Loius: Telos Press, 1975), J. Baudrillard, For a Critique of the Political Economy of the Sign, trans. Charles Levin (St Louis: Telos Press, 1981).
} 
important is hardly new, notes Peterson, but '(beyond a narrow construction of "rationality") it has rarely been a focal point of liberal and/or positivist analyses. ${ }^{54}$

It helps to place these theoretical accounts of international finance in some context. As Gilpin notes, 'International finance is the one area to which the term "economic globalization" clearly applies. ${ }^{55}$ The market type of financial structure is now pervasive. Woods identifies three unique aspects to the process termed "globalization": internationalization, the technological revolution, and liberalization. ${ }^{56}$ Internationalization 'describes the increase in economic transactions across boarders which has been taking place since the turn of the century but some argue has undergone a quantitative leap in recent debates. ${ }^{57}$

The final point about liberalization is a particularly important one to dwell on for a discussion of the financial market place. The previous thirty years have seen a dramatic shift from a world financial system largely informed by Keynesian liberal economic policy. The post-World War II period operated under a system of state-regulated currency markets, strict regulation of capital flows, and largely restricted (in the form of protectionist) policies on international trade. While the Bretton Woods agreement instigated a more moderate liberal approach to the international financial system, influenced mainly by Keynes, there were important trade-offs with the US that allowed for significant US control of international monetary policy. Since Nixon's devaluing of the US dollar in 1973 and the subsequent ideological moves (first) from many Western and then (later) from

\footnotetext{
${ }^{54}$ Peterson, A Critical Rewriting of Global Political Economy: Integrating Reproductive, Productive, and Virtual Economies p. 115.

55 R. Gilpin, Global Political Economy: Understanding the International Economic Order (Princeton and Oxford: Princeton University Press, 2001) p. 261.

56 Woods, "International Political Economy in an Age of Globalization," p. 290.

${ }^{57}$ Ibid.
} 
many developing countries has seen a rise in less regulated financial markets under the "informed" logic of neo-liberalism. As O'Brien and Williams point out, 'In the global credit system, the creation and supply of credit has moved from being the responsibility of public authorities (governments) to being provided by corporations. ${ }^{58}$

The dramatic increase in OTC derivatives trading can be seen as a reflection of the expansion of financial capital markets. Financial markets are no longer confined to a relatively small number of Western-based financial centres. They are now an integral part of economic processes in most parts of the world. OTC trading in derivatives is, by definition, trade that happens outside of formally regulated exchanges, however.

Developments in communications technologies as well as the ideological shifts by many governments towards the "freeing of capital" have resulted in increasingly interconnected markets. A consequence of this interconnectedness is that the prices of commodities, interest rates and currencies are affected by the financial exchanges of people all over the world.

While financial markets have become more homogenous and widespread, however, the development of contemporary global financial practices reflects their Western origins. There has also been a marked concentration of wealth and trade among a small number of large actors (mostly large American and European based banks and firms). ${ }^{59}$

\footnotetext{
58 R. O'Brien and M. Williams, Global Political Economy: Evolution and Dynamics (New York: Palgrave Macmillan, 2004) p. 224.

59 J. A. Scholte, "Global Trade and Finance," in The Globalization of World Politics, ed. John Baylis and Steve Smith (Oxford: Oxford University Press, 2001), pp. 528-532.
} 
This system of abstract self-reference is exacerbated by a process of financial money is a form of social power that has assumed new forms with the expansion, integration, and transformation of financial markets. The flow of capital in these markets increasingly determines the fate of national economies and hence their domestic populations. At the same time, these flows of symbolic money are increasingly delinked from the "real" (material, productive) economy of goods and services.

Langley points out that the distinction between the financial/real markets is a false dichotomy. This observation is not new, as he notes that 'scholars writing in the Marxist tradition have characterised global finance as a period in which the speculative accumulation of capital through the creation, buying and selling of credit instruments has become a structural feature of capitalism. ${ }^{, 60}$

"Financialisation" is also viewed to be an important component of the modern global political economy by Langley. This term represents the notion that speculative practices of finance are growing and are becoming more interwoven with the everyday lives of people in their more "basic" market practices. Importantly, he notes that this is process of finance 'feeding on itself rather than nourishing the real economy". ${ }^{61}$ This is not just an "academic" point of difference with liberals over their understanding of financial and economic processes, but a fundamental difference of opinion of how we understand the likelihood of financial market failure in some lesser or greater form. For,

'Under conditions of financialisation, promises to pay carry with them the assumption that socio-economic relations are commodified. However, as Polanyi's inspirational analysis serves to remind us, the adjustment of social

\footnotetext{
60 P. Langley, "The Everyday Life of Global Finance," IPEG Papers in Global Political Economy (2003): p. 15. Also, see P. Langley, World Financial Orders: An Historical International Political Economy (London: Routledge, 2002).

${ }^{61}$ Langley, "The Everyday Life of Global Finance," p. 16.
} 
relations in the face of pressures for commodification encounters significant social, political and embedded institutional forces. It follows that a contradiction present between credit practices that are subject or respond to speculative motivations on the one hand, and the tensions generated by credit obligations that assume the commodification of "real" socio-economic relations on the other. Panics, asset price volatility and ultimately crises break out as the assumptions of commodification cannot be consistently met. ${ }^{62}$

In other words, the tenuous creation of trust between a large number of people requires continued faith and re-evaluation that the value placed in the symbol of money/finance is justified. As money becomes more "abstract", its relationship to the everyday transactions in the "real" economy must be reinforced by a complex set of socio-economic norms to ensure that these symbol-values maintain worth and legitimacy. Global finance 'thus systematically affects the "real" economy but the value of financial instruments is determined by making money from money, not by growth or productivity in the economy of goods and services. The result is the "virtual" economy, where the vast preponderance of value in the global economy - which affects the entire system - is determined less by "objective" than subjective factors. ${ }^{63}$

Tied up with these processes is securitisation, that is, "the "bundling", pricing, and secondary trading of formerly illiquid claims and obligations arising from the creation of credit,' has focused on displacing the 'risks arising from outstanding claims and obligations including exchange rate, interest rate and credit risks. Global finance has witnessed a rapid increase in practices that seek the

62 Ibid.

${ }^{63}$ Peterson, A Critical Rewriting of Global Political Economy: Integrating Reproductive, Productive, and Virtual Economies p. 131. Also see: Kirshner, "Money is Politics.", E. McGoun, "Hyperreal Finance," Critical Perspectives on Accounting 8, no. 1/2 (1997). 
displacement of such risks by hedging price fluctuations, utilising an everwidening range of derivatives instruments. ${ }^{, 64}$

In an account of the IPE it is always important to ask the question: for whom? So, for whom is finance capital for, and for whom is financial globalisation for? We have already established that this is essentially a liberal market order, albeit one that works within the confines of statist politico-strategic world. These practices are essentially for those people who implement the neo-liberal model. According to neo-liberal theory, they ultimately benefit everyone as they increase the whole pie, and even if those who are "responsible" for the increase enjoy most of this increase, everybody's material gain can be measured in "real" terms. Marxists are traditionally the biggest critics of this process, as they argue that those who are responsible for productive processes, the labourers who add value to capital in the process of production, are exploited by those who own the means of production. Peterson also illustrates the link between production and finance in stating that 'the wildfire growth in financial markets is structurally linked to the shift from manufacturing jobs and Fordist practices to less secure work associated with flexibilization. These labor market dynamics entail not only differently valorized activities but differently gendered, raced, and classed identities. $^{65}$

However, 'Although internationalization of finance has become an important feature of the global economy, the international financial system continues to be largely nationally based and consists of closely interconnected, discrete national financial systems. ${ }^{66}$ Therefore, the state is certainly not rendered meaningless in

\footnotetext{
${ }^{64}$ Langley, "The Everyday Life of Global Finance," p. 11.

${ }^{65}$ Peterson, A Critical Rewriting of Global Political Economy: Integrating Reproductive, Productive, and Virtual Economies p. 130.

${ }^{66}$ Gilpin, Global Political Economy: Understanding the International Economic Order p. 262.
} 
analyses of IPE, though states vary greatly in terms of the benefits they receive from such processes. It is no coincidence that those who enjoy the benefits of extreme monetary wealth are predominantly from Western countries, are individually motivated, and privilege reason as an end in itself. They are also likely to be "risk-taking" types. Therefore, this type of market 'necessarily increases inequality ${ }^{67}$, both within and between states, as bankers and financial speculators make money out of money.

This is a significant shift in the privileging of "risk-taking" as central to the "progress" of economic growth worldwide. It is important to note that this system of credit creation necessarily increases economic instability. As strange notes 'The market system may be more efficient and flexible and better adapted to change and innovation but it is also apt to be more unstable. It suffers bankruptcies and bank failures. It experiences financial crises both national and international. $^{, 68}$

The idea of security is important here. The economic security of the individual is paramount for the liberal, and is privileged above those mercantilist accounts of economic security for the state. Of course, this is the ideal for extreme liberals, and a few countries have moved significantly towards this model, but most countries are not yet willing to give up key regulatory controls over economic and financial practices. In many regards, and despite the overtly neo-liberal economic policies they put forward for other countries, the USA adopts many policy options that reflect a strong mercantilist bias, thereby recognising the term security in economic as well as strategic terms. However, within the US, neoliberal market logic has certainly informed most policy moves towards the

\footnotetext{
${ }^{67}$ Strange, States and Markets: An Introduction to International Political Economy p. 93.

68 Ibid. p. 92.
} 
deregulation of many industries (such as the energy market, as will be discussed further in relation to the case of Enron in chapter three) so that they will be open to the competition and "efficiency" of the open market.

Financial instruments like derivatives have flourished in this liberal market economy. The reason so many people partake in such transactions is simple and obvious, given the liberal logic of the market. If one can predict the future price of an asset, then one can eliminate price variables from calculations of future costs, thereby allowing for a greater degree of financial planning. In other words, tools of "risk management", such as derivatives, are a way of providing some degree of certainty in what is an otherwise uncertain economic world. 'It is also worth noting that derivatives operate not just at the level of world capitalism in a Braudellian sense - amongst the large transnational corporations, institutional investors and hedge funds that operate within and raise funds in the wholesale financial markets - they also have begun [to] pervade the economics of everyday life, although most people are unaware of this. ${ }^{69}$ This is a point that Langley focuses on in his discussion of the everyday life of finance. $\mathrm{He}$, as well as Peterson, calls this process the disintermediation of finance. ${ }^{70}$

As Pauly notes, 'the more open economies become to inward and outward capital flows, the more difficult it is for governments to maintain stable exchange rates and monetary policies fully sensitive to national priorities. ${ }^{71}$ In this regard, as the financial market has become more globally integrated, and capital controls have

\footnotetext{
${ }^{69}$ S. Gill, "Finance, Production and Panopticism: Inequality, Risk and Resistance in an Era of Disciplinary Neo-Liberalism," in Globalization, Democratization and Multilateralism, ed. Stephen Gill (Basingstoke: Macmillan, 1997), p. 71.

70 See Langley, "The Everyday Life of Global Finance.", Peterson, A Critical Rewriting of Global Political Economy: Integrating Reproductive, Productive, and Virtual Economies.

${ }^{71}$ Pauly, Who Elected the Bankers? Surveillance and Control in the World Economy p. 24.
} 
become less state-controlled, state policies have become more aligned with the interests of capital. According to liberal logic, this will serve everyone, albeit unevenly. It will reward those who own the capital and put it to the most "productive" use.

Risk, in this regard, is both privatised and individualised, as it takes a predominantly market form (such as the provision of private health care arrangements, private security guards, etc.). People are encouraged to think of themselves as prudential individuals that need to be responsible for their financial future. But contradictorily, risk is increasingly generalised (e.g. environmental risks or market risks, such as a fall in the stock market undermining the lifesavings of people), as the role of the state, the formal democratic representation of the interests of its people, plays a more ambiguous and marginalised role. Legal responsibility become salient here, as insurance markets flourish, but ultimately, however, it is still the state, and its citizens, who pay for many social, environmental and economic costs that are not borne by the private sector.

\section{How is the notion of "risk" understood?}

That the notion of "risk" should be so central to this type of financial market, then, raises the question of how this "risk" is qualified and understood, and how this approach matches up with the nature of the financial market itself. A risk to the market is considered to be a threat to the continued system of credit creation and monetary exchange. These threats are considered in lesser or greater quantitative terms, and are categorised accordingly. For instance, financial analysts divide the risks associated with derivatives trading into as many as nine categories: credit risk (the risk that one of the parties will default on payment according to the contract), market risk (that the market itself will alter considerably affecting key variables such as exchange rates), legal risks and 
systemic risk (the threat of one large financial collapse leading to the demise of the entire financial system to a greater or lesser extent).

It is important to point out that risk is a way of framing uncertainty. The uncertainty of human behaviour is the subject with which every person in business is concerned, whether they are aware of it or not. To know the future of the market is to provide a framework for decision-making in the present. Thus, "risk" is a concern for the future expressed in the present. The possibilities of the future are best measured, according to most liberal economics texts, as the probability of an event occurring, multiplied by the cost of that event occurring (risk $=$ probability $\mathrm{x}$ cost). This is a key point: risk, for liberal economists, is always uncertainty made into a calculable concept, and it is always defined in terms of a probabilistic calculus (i.e. quantified).

In liberal economic terms, that is, risk is understood in calculable terms, and is seen as distinct from the "uncertainty". Frank Knight, now recognised as a key contributor to the economic understanding of risk in business practices, outlines this distinction in his 1931 book, Risk, Uncertainty and Profit.

... uncertainty must be taken in a sense radically distinct from the familiar notion of Risk, from which it has never properly been separated. The term "risk," as loosely used in everyday speech and in economic discussion, really covers two things which, functionally at least, in their causal relations to the phenomena of economic organization, are categorically different. ... The essential fact is that "risk" means in some cases a quantity susceptible of measurement, while at other times it is something distinctly not of this character; and there are far-reaching and crucial differences in the bearings of the phenomena depending on which of the two is really present and operating. ${ }^{72}$

\footnotetext{
${ }^{72}$ F. H. Knight, Risk, Uncertainty and Profit (New York: Sentry Press, 1964) pp. 19-20. Emphasis in the original.
} 
The notion of "risk" is a contested one in contemporary debates across the social sciences. For starters, this account is one that neatly bounds uncertainty in rationalist terms, outlining a clear dichotomy between a future that is not known and a future that is known (at least in probabilistic terms). ${ }^{73}$ How risk is understood depends on a variety of theoretical and ideological stances that all offer different epistemological interpretations. ${ }^{74}$ Underpinning the dominant liberal models of risk analysis is a belief that the scientific methods used to study the "natural" world are apt for study of the social world. In liberal studies of economic behaviour, for instance, methodological individualism, and the assumption that people are essentially calculating, has informed "objective" explanations of the social world "out there". This is an epistemologically realist position, in that "risk" is objectified to be understood as a thing that exists. This relies on the assumption that the social world "out there" can be known as separate and uninfluenced from the language we use to describe it. Risk, therefore, is a real danger, and the best way to explain it is to use scientific methods that, though might not be perfect, do tend towards a "true" account of the "facts".

It is this epistemologically realist position, contextualised within liberal accounts of human nature, that provides the basis for scientific risk management analyses that are prevalent in, and underpin modern financial practices, such as derivatives trading. For instance, the Black-Scholes options pricing model and credit risk analyses play central roles in OTC derivatives markets.

\footnotetext{
${ }^{73}$ Deuchars, The International Political Economy of Risk p. 109.

${ }^{74}$ M. Dean, "Risk, Calculable and Incalculable," in Risk and Sociocultural Theory: New Directions and Perspectives, ed. Deborah Lupton (Cambridge: Cambridge University Press, 1999).
} 
Importantly, in a liberalised market economy risk, these scientific risk analyses provide a more central role that they would in a more regulated financial market. Self-regulation means that these mathematical models and calculative predictive tools provide risk "experts" with the basis for decision-making in private firms.

Derivatives are a good example of how these tools for scientific risk management are used. Derivatives are a double-edged sword in that they are tools for the management of risk, and in many cases, do provide a greater degree of market (and, within the liberal project, even some degree of social) certainty - the task of any form of insurance. However, the highly leveraged and abstracted value of derivatives, coupled with their speculative use, increases volatility, and therefore raises the issue of the need for regulatory mechanisms to bring greater certainty to the market. This argument is analysed in more depth in chapter two, however, the point is an important one for the following discussion of market intervention. Concern for market failure is the key to a liberal understanding of the market. The role of derivatives is an important part of this understanding.

The implications of a financial system that places so much emphasis on reference to itself (as with the use of financial derivatives), render the complex mathematical and "scientific" methods of risk analysis problematic. If scientific methods of risk analysis attempt to look at fundamentals (such as the real economy of trade and exchange in goods and services) and derive the value of derivatives using these methods, then the models that are produced may not have factored in key "variables" that are central to these fundamentals. The "constants" may also be problematic.

As Galbraith succinctly puts it, "[a]ll crises have involved debt that, in one way or another, has become dangerously out of scale in relation to the underlying means 
of payment. ${ }^{, 75}$ The interesting point about derivatives is that they increase the separation between the instruments of debt and the underlying assets and securities that are the basis for the value of debt. Too many people trying to cash in at the same time leads to a financial crash. States try to isolate this so that it does not spread to the rest of the market. The threat of a financial crisis spreading is understood as "systemic risk", and is the subject of much debate, particularly with regard to the use of OTC derivatives.

Predicting financial crises at this level, especially in a globalising financial market, is not small ask. We therefore have to ask how effective tools of scientific risk management are at predicting financial crises. This is a question that both states and private market actors are extremely interested in. It is also a very contentious issue that goes beyond the analysis provided here. However, what needs to be made clear is that scientific risk analysis provides a rationalist basis for liberal policy makers to argue for greater financial freedom from state controls.

\section{When is "market intervention" justified according to liberal logic?}

If, in liberal parlance, market success is assessed by continued material growth, and measured according to increasing profitability, then market failure is said to have occurred if 'a market that is left to itself does not allocate resources efficiently." ${ }^{76}$ Leaving for the moment the contentions of economic "efficiency", we can say that this is very much the ideal from the liberal perspective. Therefore, according to liberalist accounts, the financial market should experience little (if any) "intervention" from the state. The market is understood to work most efficiently, that is, when individuals are allowed to exchange credit and debt,

\footnotetext{
${ }^{75}$ J. K. Galbraith, A Short History of Financial Euphoria (New York: Whittle Books, 1990; reprint, 1993) p. 20.

${ }^{76}$ Definition found at

http://www.economist.com/research/Economics/alphabetic.cfm?TERM=MARKET\%20FAILURE\#M ARKET\%20FAILURE (accessed 3/11/2004).
} 
creating a competitive environment, and keeping prices in line with what they are really "worth", that is, their "natural value". This is perceived to be a "natural" process - one that should not be interfered with - due to the "fact" that individuals act as essentially rational, self-maximising decision-makers. From this premise follows the practice of privileging individuals and their opportunities to make the most of their marketeering skills. The market is seen as the "fairest" assessment of what an individual is worth.

Sticking to the principles of the "free market", however, is only worthwhile if you have a market to keep free. Despite the resistance of liberals to having government intervention in trade and finance, they have their "price". As Balaam and Veseth point out, the nature and significance of finance is compelling from a liberal perspective:

John Maynard Keynes once noted that if he owed the bank a hundred pounds sterling and couldn't pay it, he was in trouble. But if he owed a hundred thousand pounds and couldn't pay, the bank was in trouble. The character of a financial relationship thus depends on the quantities involved as well as the connections it creates. ${ }^{77}$

This relates to the question of "cui bono?", or "for whom". As Marxists have been keen to point out in class terms, the modern state is so closely aligned with the interests of capital (such as laws that protect property and the maintenance of the capitalist market economy) that neo-liberals can take great risks knowing that the system will be propped up by the state. Though systemic risk might be a very real threat, and though "self-management" of this risk is preferred, state intervention is relied on when market failure does occur. This raises the issue of that liberal scholars call "moral hazard".

77 D. N. Balaam, Introduction to International Political Economy (New Jersey: Prentice Hall, 1996) pp. 149-150. Emphasis in the original. 
The trouble is that banks are not like other businesses. They enjoy a privilege not conferred on metal-bashers or greengrocers or anyone else - the right to take deposits. Those deposits are in effect underwritten by the taxpayer, who has to cough up if a bank fails. Should banking regulators be allowing deposittakers to indulge in such huge and complex bets? I think not. ${ }^{78}$

Market intervention where finance capital is concerned (including trade in OTC derivatives) operates according to the above logic. Because finance capital is seen to lubricate the flow of the market more generally, and because it is too complex for states to control anyway, it is best to have as little intervention as possible. This has become the norm for much of the Western world, and increasingly for much of the developed world. Gill points out that the question of market intervention is also important due to the increasing permeation of financial innovation in every day life, and how expectations concerning the future are shaped in part by the new financial structures (for instance, the likelihood of an adequate pension on retirement).

The irony of this free market system, where individual responsibility and reward is supposed to be a cornerstone principle, Gill notes that while the principle of self-regulation as better for all, 'many liberal economists point out that derivatives traders may be taking imprudent risks in anticipation of a government bail out, for example where the central bank acts as lender-of-last-resort: a type of socialization of risk. As Cerny notes, the problem of market intervention is made more problematic by two key issues. First, that of the 'tug-of-war between national governments and transnationalized markets for control of the international financial system' which makes any consistent regulatory regime

78 P. Hosking, "The Business," New Statesman, 24 March 2003. 
difficult. And second, that of the 'relationship between the financial economy and the real economy[, which] is a long way from being resolved. ${ }^{79}$

Furthermore, the fact that this is an increasingly globalised financial economy, that has is becoming further intertwined, gives credence to Cerny's point that 'any future national control would be limited, indirect and constrained to conform to the imperatives of the transnational financial markets. ${ }^{, 80}$

Liberals follow the division of labour to a particular extreme. They believe that those who work most with financial markets are likely to be those who best understand these processes. That people are assumed to be "rational" indicates that these "experts" have a strong basis upon which to lay their claim to expertise. Market intervention is therefore informed by expert discourse, which, as was discussed earlier, has its roots in methodological individualism and objectivist rationalism.

This can be seen in relatively recent policy moves in the US with the Commodity Futures Modernization Act, which has greatly reduced the level of rigorous state regulation. This indicated both a preference for free market principles, and an implicit belief in rationalist methods of risk management. Therefore, the relationship between ideological policy options and supposedly value-free technical analysis is intricately tied up.

\section{Conclusion}

The above discussion makes clear how liberals understand the nature of the financial market. This market is increasingly "going global" and neo-liberal logic 
predominantly informs these market-making practices, as well as the risk management tools and techniques within this structure. It is within this abstract financial economy that derivatives now feature. The logic of extreme liberal market practices dictates that the experts of international finance need to be given free reign to move financial practices toward increasingly "efficient" processes. The role of government, according to liberals, should therefore be limited, and any form of regulation should be ideally left to the "experts" to get it right. The question is: do the "experts" have a critical enough understanding of financial market practices to allow them to predict key challenges, such as systemic risk due to derivatives trading? 
Chapter 2

\section{HOW ARE WE TO UNDERSTAND DERIVATIVES?}

\section{Introduction}

The previous chapter outlined the way in which the financial market operates, who it works for, what is considered a "risk" to this market, how this "risk" is understood, and, therefore, when the question of market intervention is subsequently raised. This chapter outlines the role of OTC derivatives within this market structure, showing how they operate both as tools for risk management as well as increasing risk in the international financial system. First, this chapter defines derivatives, outlining different types of derivatives markets, thereby illustrating the specific role of OTC derivatives. Secondly, the chapter employs a "critical history" of finance in general, and of derivatives more specifically, to clarify the ways in which derivative financial instruments have been used, and have come to be given such prevalence in the modern political economy. In doing so it illustrates how the way they have been considered depends on the politico-economic, politico-social and politico-cultural contexts they have been used within. Moreover, the analysis shows how the modern notion of financial derivatives have been "made thinkable", tied up with the construction of the modernist notion of "risk". Third, this critical interpretation of the construction of derivatives leads in to a literature review of derivatives, raising questions over how best to understand these tools for risk management. In doing so, the chapter examines the key assumptions of the mathematical models that underpin the faith that analysts and traders alike place in the use of these tools. When these assumptions are matched with the speculative and compounding use of derivatives that is in practice today, serious doubts have to be raised as to the control neo-liberal "experts" can be said to have over systemic risks. 


\section{What are derivatives?}

Derivatives are defined as 'financial instruments which derive their value from an underlying asset. ${ }^{91}$ Derivatives can be essentially divided into two main groups: those that are forward-based and those that are option-based. ${ }^{82}$ Forward-based contracts give the right to buy a particular asset or security at a particular time in the future, thereby offering insurance against price (and general market) volatility. Options-based contracts give a person the right, but not the obligation, to buy or sell (named puts or calls, accordingly) an underlying asset or security at a particular time in the future. The benefit of these latter contracts is that if one would have been better off without the contract in the first place there is no obligation to buy/sell the underlying asset or security at a price higher/lower than they can get on the market in "real time".

However, derivatives contracts do get more complicated than this, as derivative products are developed that have other derivatives, instead of an asset or other form of security, as the underlying basis for their abstract value. Abstract is the key word here, as it is not uncommon to have options on futures, futures on options and a wide variety of self-reflective variations. The names are as creative as the financial innovations they represent, with a host of swaps, collars, swaptions, etc., making up a vocabulary that most finance practitioners must struggle to keep up with. ${ }^{83}$

\footnotetext{
${ }^{81}$ R. Beynon, ed., The Icon Critical Dictionary of Global Economics (London: Icon Books, 1999) p. 189.

82 Ibid.

${ }^{83}$ For a discussion of just how complex derivatives instruments can get, see D. Henwood, Wall Street: How it Works and for Whom (New York: Verso, 1997; reprint, 1998) pp. 34-37. Note that though this publication is slightly out of date, this ratio has not altered significantly.
} 
The basis (asset or security) of derivatives contracts can, in theory, be anything. Traditionally, derivatives have been based on commodities, like wheat and grain in nineteenth-century US markets, or rice in eighteenth-century Japan. Today, interest rates and currencies, among other securities such as bonds, make up a far greater proportion of derivatives traded globally. ${ }^{84}$ The importance of financial securities in the contemporary international political economy, as well as their increased volatility since the breakdown of the Bretton Woods era, is obviously one reason for the growth in derivatives contracts in securities rather than commodities markets. However, the fact that less than $1 \%{ }^{85}$ of annual futures trading ends up being consummated in possession-taking raises an important concern over the purpose of these instruments to most people who use them. Derivatives differ to most assets or securities in that they do not generally involve ownership or title. Therefore, it is possible to gain exposure to a relatively large investment/amount while paying a fraction of this cost (at least in the short term). This means that most derivatives contracts are highly leveraged. Therefore, the ability to "hedge" against the future of the market not only provides an opportunity for insurance, but it also allows one the opportunity to gain substantial amounts for relatively little investment. This leverage provides the basis for a great deal of speculation - or, in other words, a form of gambling, the reason for the title of Susan Strange's book Casino Capitalism. ${ }^{86}$

An important point to note is that while many derivatives contracts can be considered speculative activity, the underlying commodity or asset has to be owned by someone at some point. Therefore, while prices do appear to be driven by people who are ultimately very removed from daily lives of many of the

\footnotetext{
${ }^{84}$ See BIS Quarterly Review,

${ }^{85}$ Henwood, Wall Street: How it Works and for Whom p. 29.

${ }^{86}$ S. Strange, Casino Capitalism (Oxford and New York: Basil Blackwell, 1986).
} 
people who use and distribute the assets and securities under consideration, there is still a link to the "real" economy, as it were.

There are essentially two kinds of derivatives markets - exchange traded and over-the-counter. Exchange traded markets are formally regulated markets that are set up for the exchange of specific kinds of derivative-based financial contracts on certain assets and securities. Key exchanges to consider are the Chicago Board of Exchange (CBOE), established in 1973, and the London International Financial Futures Exchange (LIFFE).

OTC derivatives trading, by contrast, are those derivatives contracts that are exchanged outside of the regulated confines of regulated exchanges. OTC derivatives are where the real innovation in financial instruments begins, as a derivatives contract can essentially be constructed on any underlying asset, security or derivative that two or more parties agree upon. Arguably, the only important factor that really matters is whether the two parties think that the contract will be worth something to them.

Exchange-traded derivatives are relatively well regulated, as only registered financial corporations can trade on these exchanges, and most of the derivatives contracts are pre-set. OTC markets, on the other hand, are relatively unregulated. Not only are there a large number (potentially unlimited) of tailor-made derivatives contracts that can be traded, but any company, municipality, government, or bank can trade in them. For instance, look at the cases of Orange County and Enron. Therefore, not only is the variety of derivatives contracts greater on the OTC market, but this number of financial players increases as well. The result is that the overall volume in trade has increased 
markedly with an increase in financial trade and proliferation of neo-liberal market policies as part of economic globalisation.

There are a number of types of risks to consider in a discussion of derivatives trading, though it is systemic risk that amplifies across all politico-economic positions. Market risk dangers arise from the changes in market conditions generally - these are the risks that are associated with general changes in market prices, and therefore encompass a large number of factors. Credit risk (or "counter-party" risk) is the risk of one of the parties involved in a derivatives contract defaulting. This risk is a particularly important one to consider for OTC derivatives trading as due to the lack of regulation, any two parties can agree to enter into a contract together.

Derivatives increase systemic risk in the financial system due to the complexity of derivatives themselves and the sheer volume of transactions. As noted in the introduction, there are roughly $\$ 2$ trillion dollars worth of trade in OTC derivatives per day. This is a number too large to comprehend with any real meaning, especially when compared to the kind of income of most of the people in the world. The question of volume is one of "flow", however, and the fact that almost all contracts end up being worthless - i.e. derivatives trading is essentially a zero-sum game.

A lot of companies use derivatives for good reasons. These instruments provide a greater degree of certainty, in terms of currency markets, commodities, and the like. Many banks, companies and even public municipalities use derivatives contracts in less prudent ways, however. O’Brien and Williams concisely outline the key problematic with these tools of risk management: 
Used wisely, derivatives can insure business and individuals from the risks of falling or rising prices. However, they are also used to make money by betting on the value of a product at some time in the future. If they are correct about the price movement, they can sell at a profit. If they are incorrect, they suffer a financial loss. Since these products can be bought on margin, large sums of money can be pledged without having the ability to pay for it at the time of purchase. This kind of system encourages investors to take risk for potentially large pay-offs. ${ }^{87}$

OTC derivatives markets operate according to self-regulatory principles, informed by expert risk managers. To understand the risk OTC derivatives pose at a systemic level therefore requires an examination of the expert understanding of derivatives, underpinned by objectivist rationalist risk models. However, before discussing the nature of derivatives trading in terms of different analytic languages and critical accounts, it is important to gain some historical understanding of how these instruments of risk management have been developed and used in order to provide context to the power/knowledge relations that are played out in the IPE of OTC derivatives trading.

\section{A short history of derivatives and financial crises}

Of particular interest to international political economy is the way in which derivatives, a form of risk management, have historically come to be so. For, in the Nietzschean/Foucaultian ${ }^{88}$ tradition of critical histories, we find that derivatives have been extant for some time, but their use and development has been restricted and largely determined by particular cultural frameworks of thought. This interpretation of history as contending and non-linear goes against

87 O'Brien and Williams, Global Political Economy: Evolution and Dynamics pp. 236-237. 
the liberal logic of capitalism or the Marxist analysis of historical materialism, for example, where there are grand narratives based on particular assumptions about human nature and nurture. Rather, the history of derivatives, and of finance, capitalism, and modernity more generally, can be viewed as a complex combination of cultural interactions that are non-deterministic and nonevolutionary in nature. The consequences of interpreting history in this fashion is that contemporary practices that we may view as given and beyond critique are opened for debate and thus re-politicised in the context of their ideological nature. Put more simply, these are social systems that are made, and remade by repeated human practices. In order to understand, let alone alter, these practices, one needs to appreciate the many strands that make up the whole of human behaviour.

Mitchell Dean makes these points salient with regard to the notion of "risk", as it has come to be understood in the modernist context:

What is important about risk is not risk itself, but the forms of knowledge that make it thinkable from statistics, sociology and epidemiology to management and accounting, the techniques that discover it from the calculus of probabilities to the interview, the social technologies that seek to govern it from risk screening, case management and social insurance to situational crime prevention, and the political rationalities and programmes that deploy it, from those that dreamt of the welfare state to those that image an advanced liberal society of prudential individuals and communities. ${ }^{89}$

The history of derivatives is often presented as one that is limited to modern developments in the American and British financial settings, and indeed it is only

${ }^{88}$ See M. Foucault, "Nietzsche, Genealogy, History," in The Foucault Reader: A Critical Introduction to Foucault's Thought, ed. Paul Rabinow (London: Penguin, 1991), F. Nietzsche, On the Genealogy of Morals, trans. Douglas Smith (Oxford and New York: Oxford University Press, 1996). 
in the last thirty years that derivatives trading have come to play a major role in a truly international financial environment. However, evidence can be found of basic types of derivatives, such as futures and forwards contracts, as far back as the past 4000 years. Perhaps the earliest record of derivatives trading dates back to the records of the Code of Hammurrabbi, where evidence can be found that futures trading were regulated. As one commentator has noted, '[a] grain merchant was permitted to borrow a fixed amount of gold to pay for a barley crop before the next harvest. If barley fell in price, the merchant came out ahead when he repaid the loan - and the Code stipulated that if this futures contract was duly signed and witnessed, neither party could renege. ${ }^{90}$ One of the interesting points to note regarding the Code is that it offers insight into aspects of capitalism that we usually view as particular to our modern times. This example of futures trading shows "advanced" understandings of money, credit, interest, and insurance; all of which encompass elements of modern day financial capitalism.

The ancient Babylonians were not the only ones to recognise the value of futures contracts as a way to mitigate the uncertainties of unforeseeable natural events. Periclean Athens, Augustan Rome, Abbasid Caliphate, the Ottoman Empire at the death of Suleiman, Mughal India at the death of Akbar, Flemish traders in the $12^{\text {th }}$ century, Medici Florence, Elizabethan England, as well as the United Provinces at the Peace of Münster, used varying types of derivatives financial instruments as a way of mitigating the effects an uncertain world brings to any economy. ${ }^{91}$ Most types of derivatives were simple: futures contracts provided a

\footnotetext{
${ }^{89}$ Dean, "Risk, Calculable and Incalculable," pp. 132-133.

${ }^{90}$ J. W. Michaels, "Did the Babylonians have an SEC?," Forbes, August 151994.

${ }^{91}$ Include all references to pre-modern financial derivatives. J. Buchan, Frozen Desire: The Meaning of Money (New York: Farrar Straus Giroux, 1997), J. Day, Money and Finance in the Age of Merchant Capitalism (Oxford: Blackwell Publishers, 1999), R. Ehrenberg, Capital and Finance in the Age of the Renaissance: A Study of the Fuggers and Their Connections, trans. H. M. Lucas (New York: Augustus M. Kelley, Bookseller, 1963), R. W.
} 
particular mechanism for ensuring the changeability of the weather would not necessitate the same uncertainty for the economy. What I find interesting in these early examples of derivative financial instruments is not so much their "proof" that mankind has always been moving towards capitalism, say. In this regard, there is no origin for financial capitalism in the development of these financial instruments. Rather, that the use of these instruments has been so restrained, not only shows the importance of moral or religious reasons, but it also shows the importance of a complete political and cultural setting that would allow these instruments to be used so widely and such for speculative purpose. An examination of their use in various early to late modern capitalism further highlights this point.

These pre-modern examples of financial instruments are interesting when compared with contemporary practices of derivatives trading in that they appear to be limited both in terms of the types of instruments that were available and their complexity. There are a number of features associated with the emergence of financial capitalism that create favourable conditions for financial instruments to be developed and used. For example, money, credit, debt and interest, are all key developments that could not have been developed in pre-modern times in the way we think of them today, due to cultural restrictions that would not allow their use on a moral basis. Ehrenberg offers us an insight into the cultural mindset of the medieval European and their Christian attitudes towards money:

Penucia pecuniam non parere potest. Money is essentially unproductive. Anyone, therefore, who demands fruits from it, sins not only against positive commandments of divine and secular law, but also against the nature of things. A man profoundly learned in this commercial law of the Middle Ages formulates

Goldsmith, Premodern Financial Systems: A Historical Comparative Study (Cambridge: Cambridge University Press, 1987). 
in these words the principle which for many centuries ruled the undisputed in theory and even attempted to bring practice under its sway.

This ecclesiastical view of money capital had its origin in the leading idea of Christianity directed against the materialism of antiquity - the idea that earthly things were valuable only in so far as they served as the preparation of life to come. It was based on a moral precept from the Bible, and a saying of Aristotle, which apparently was only the statement of an ideal, but which interpreted as a principle, appeared to deny the productivity of money.

It is interesting to note at this early stage one of the key features of financial capitalism: the ability of financial capital to not only be a measure of trade and exchange in the real economy, but also its ability to affect, and to some extent control, the workings of those fundamentals upon which the financial (abstracted) economy relies.

As noted above, derivatives are not new. They have been used in a variety of politico-cultural settings. Second, there have been key periods where derivative financial instruments, and the speculation surrounding them, has resulted in debate over money, gambling and speculation. This history is rife with moral and political assumptions about the role of such instruments in society. ${ }^{92}$ Furthermore, it illustrates the rise of certain ontological, epistemological and methodological views that now constitute a largely uncontested account of what is real, true and factual. This not only results in shortcomings in how "risk" is understood and managed in finance, but also helps re-open debate over issues that are viewed as being beyond political critique.

\footnotetext{
${ }^{92}$ For example, see E. Chancellor, Devil Take The Hindmost: A History of Financial Speculation (New York: Farrar, Straus, Giroux, 1999). and Buchan, Frozen Desire: The Meaning of Money.
} 
This point about re-politicising risk is an important one, but not the only one. The other key point is the social construction of "risk", and therefore the socially contingent nature of risk management practices today. It is also very useful for illustrating how tools for risk management have helped create risk; and how this is politically framed.

The origins of the financial innovations that allowed financial capitalism to eventuate are to be found in the $16^{\text {th }}$ century and the rise of Antwerp as a key city of commerce. The development of the foreign bill of exchange became one of the key financial innovations that allowed a multinational and multilingual marketplace to emerge. ${ }^{93}$

Money, credit and capital are, quite literally, systems of writing. This goes for the earliest forms of credit and book-keeping money as well as for late-modern definitions of capital. For instance, Mary Poovey argues that early-modern book-keeping, which forms the basis of current accountancy practices, was a rule-governed kind of writing which "tended to create what it purported to describe". .4

'Put simply, financial instruments such as options and forward contracts emerged in conjunction with the longer time horizons brought about by voyages of discovery and colonial conquest in early-modern Europe. ${ }^{95}$

For instance, numerical arguments never used to be as convincing as they are today. It was only the development of arguments based on numerical calculation, such as those made by Descartes, that made possible developments in modern

\footnotetext{
${ }^{93}$ L. Neal, The Rise of Financial Capitalism: International Capital Markets in the Age of Reason (Cambridge: Cambridge University Press, 1990) p. 5.

${ }^{94}$ M. d. Goede, "Discourses of Scientific Finance and the Failure of Long-Term Capital Management," New Political Economy 6, no. 2 (2001): pp. 151-152.
} 
forms of insurance in general, and in financial risk management in particular. Ian Hacking has documented the emergence of probability in early modern Europe, for instance, as a significant epistemological challenge to alternative forms of argumentation. What was considered probable, prior to the end of the sixteenth century, had more to do with an oratory argument given by a person associated with authority. Rhetoric and social standing or authority, in this regard, was as, if not more, important than the validity of the argument. This wording is misleading though - the argument was valid if it was attached with authority. ${ }^{96}$ Numerical probability as we know it, was treated with suspicion and caution. Even as mathematics came into its own as the new "proof" of grand design and God Himself, probability appeared to undermine the certainty sought by the likes of Descartes. It was only with the onset of collections of statistical data of state populations in the early nineteenth century that natural laws appeared to be so unevenly distributed, undermining the (until then) solid and God-given concept of human nature, and probability and its "normal" distribution became a useful tool for taming this uneasy new world of chance.

It is dangerous to make this history over-simplistic however. While probability did not come into its own in social analysis until the nineteenth century, growing insurance markets throughout Europe began to make use of the probabilistic calculus to ensure a safe return on chancy mercantile ventures. ${ }^{97}$ This contributed to the growing links between what was considered a lesser form of mathematics

\footnotetext{
95 Ibid.: p. 153.

96 I. Hacking, The Emergence of Probability (London: Cambridge University Press, 1975).

${ }^{97}$ See R. Rosencrance, The Rise of the Trading State: Commerce and Conquest in the Modern World (New York: Basic Books Inc., 1986).
} 
and a growing mercantile class that was struggling for greater economic freedom and social recognition in the seventeenth and eighteenth centuries. ${ }^{98}$

By the mid-nineteenth century, financial trading had started to become backed more closely by "scientific" evidence, making great use of developments probabilistic calculus and the collation of statistical knowledge. Interestingly, De Goede notes that debates over the legitimacy of derivatives in post-civil war USA still centred around moral issues, with many farmers arguing that futures trading was creating too much price volatility, which was seen to be as a result of speculation, understood to be gambling by most. As with earlier examples of speculative use of derivatives 'US farmers argued that professional speculators were trading in "fictitious commodities" or "wind wheat".99

For de Goede, there was a conscious recognition by financial experts at the end of the nineteenth century that 'the dissociating their practices from unproductive gambling was vital for the political legitimacy of their profession. ${ }^{, 100}$ Thus, the emphasis on "scientific" analysis of stock prices took hold in financial circles, especially in early twentieth century. 'It was a way for speculators to assert their productiveness and intelligence in the face of growing opposition to their trades as fraudulent and gambling. Dow, Jevons and Bachelier [all key financial commentators and players] located the cause of price fluctuations as external to the financial system, in contrast to the Dutch shareholders who admitted that

\footnotetext{
98 Poovey provides an excellent analysis of the role of double-entry bookkeeping in the development of early capitalism and modernity. This analysis recognises the growing importance of objectification and enumeration in legitimate economic practices in eighteenth and nineteenth century Britain and France. M. Poovey, A History of the Modern Fact: Problems of Knowledge in the Sciences of Wealth and Society (Chicago and London: The University of Chicago Press, 1998).

${ }_{99}$ Goede, "Discourses of Scientific Finance and the Failure of Long-Term Capital Management," p. 154.

100 Ibid.
} 
price movements depended on speculators' hopes and fears.' ${ }^{101}$ In particular, de Goede notes the era leading up to and following the financial crises of 1929 as a period of normalising practices of scientific finance. Contrasted with the legal debates surrounding lotteries in London and bucketshops in the US, the legal debates in the fourth quarter of the twentieth century were set within the confines of the SEC that was established in the aftermath of the 1929 stock market crash. The SEC was established to regulate the workings of the financial world that would operate according to these more rationalist principles and guidelines. Importantly, the trend towards faith in objectivist rationalist methods of analysing economic and financial processes reflects wider moves to quantify study of social relations.

\section{More recent history of derivatives - the age of derivatives?}

The past 20-30 years has been a period of history characterised financial liberalisation and endorsements of attitudes, policies and rationalities that make this possible. While a title such as "the age of derivatives" is certainly an exaggeration and overstatement, it may also have some merit to it. Derivatives trading has become the most expansive area of financial trade in the past 10-20 years with astronomical growth in volume tantamount to the close relationship these instruments have come to share with financial liberalism. While I would not for a moment suggest that derivatives are the only, or most important, development in the recent era, they nevertheless characterise the ambitions and logic of that time-frame: the expansion of capital and liberal markets through the tools of risk management and its accompanying speculation.

The financial revolutions evaluated in the previous section of this chapter explored how finance became normalised under the guise of mathematised risk

101 Ibid.: p. 156. 
analysis and quantified evaluations of economic behaviours. The positivist turn in the social sciences generally, and finance in particular, fuelled the intellectual environment for quantified models of risk analysis and management.

In 1971 Fischer Black and Merton Scholes published their foundational article on the Journal of Political Economy on the Options Pricing Model. This model was soon recognised as a significant revolution in financial modelling, and the Fischer-Black formula outlined a model for arbitrage - risk-less trading - in options trading.

This is often where the history of derivatives trading begins its narrative. Derivatives trading is born with the volatile markets, financial deregulation and new technologies that provided the environment for their inception. We have seen, however, that derivatives trading, in its basic forms at least, is not a new concept, and has had a tumultuous history of contestation tied up with its association with speculation and gambling. In a sense, though, this history was forgotten $^{102}$ by many who were keen to see the usefulness of a tool for risk management in increasingly uncertain economic times. Derivatives would become an important way of insuring against the wiles of the international financial marketplace.

De Goede's analysis of the normalisation of financial discourse in the 1930's becomes especially relevant here in determining the discourse of financial possibilities available. Derivatives were no longer an issue for moral, social or political concern; they were an issue for technical refinement and practical progress. The debate surrounding the use of derivatives is not one to include these lay concerns, but should be carried out by economists and financial experts

102 Note on the importance of forgetting, via Nietzsche. 
who could work out their role in the new financial era. Therefore, as the financial market has become increasingly liberalised and globalised, neo-liberal arguments to purport this trend have also relied on expert discourse to reject various political (understood to be separate from economic) perspectives.

Furthermore, as the international financial market has become more liberalised there has been more reason for various actors to make use of the insurance qualities of derivative financial instruments. For instance, Exchange rate instability creates systemic risk in the financial system, and derivatives operate as a way of transferring risk from one party to another (importantly, they do not eliminate risk). Another motivator, as discussed above, is also the increased opportunity for profit with the "creation" of new markets that trade in derivatives offer. This has become particularly prominent with the technical developments of complex derivative products and the ability to put them to use in deregulated markets. In particular, currency market turbulence, exchange rate instability, inflation accused price instability and large swings in key financial prices are worth noting here. Pryke and Allen argue that these are new "types" of uncertainty that have to be dealt with. These authors argue that 'the nature of uncertainty and risk stemming from this disorder is qualitatively different' to those previously "experienced" in modern market economies. Thus, a culture of risk taking appears to have grown since the 1970s. ${ }^{103}$ More colourfully, Michael Lewis, author of Liar's Poker, calls this unbridled form of capitalism, "the age of leverage". ${ }^{104}$

\footnotetext{
${ }^{103}$ S. Green, "Negotiating with the Future: The Culture of Modern Risk in Global Financial Markets," Environment and Planning D: Society and Space 18 (2000).

104 M. Lewis, Liar's Poker (London: Hodder and Stoughton, 1989).
} 


\section{Theorising derivatives: how are they to be understood?}

The practice of derivatives trading in particular, as well as the wider politicoeconomic, politico-social and politico-cultural settings within which this practice takes place, have also received increasing attention from social theorists in recent years. Much of this literature examines aspects of the question of "risk", as mentioned above, and is therefore included throughout this section.

First, the liberal account of derivatives is relatively simple, as was outlined in the previous section. Derivatives are a form of risk management that can be used to insure against the uncertainty of the market. In this respect, proper use of derivatives offer the very best in scientific risk management, and this is essential if one wishes to make the most of a globalising and competitive financial market place. Liberals recognise that derivatives are not always used properly, however, this is not the fault of derivatives themselves, or the risk management models they are based on, but rather a question of greater transparency in the process to ensure "market mechanisms" correct any abnormalities before they become too great.

Therefore, for the liberal, it makes sense to focus on the details of derivatives risk analysis, being sure to understand the various credit, operational, legal, etc., risks that exist. ${ }^{105}$ Therefore, much of the "hype" surrounding the various and sensational financial collapses involving derivatives appear very misplaced, from a neo-liberal perspective. 'In conditions of a perfect market derivatives are unable to affect the price of underlying assets (such as exchange or interest rates) and all they can do is to allocate risk between different players in the market. As they spread that risk more widely, derivatives should provide a wider systemic

${ }^{105}$ For example, see H. Ludger and J. Clifford W. Smith, "Controlling Risks in Derivatives Markets," The Journal of Financial Engineering 4, no. 2 (1995). 
stability."106 Many neo-liberals do now acknowledge "market failures" as a result of asymmetric information as well as, in some cases, path dependence, among other things, however, the assumption that human behaviour can be understood in essentially calculating terms informs this interpretation of events as well.

Categorising risk in this way allows the analyser to focus on particular probabilistic calculations that help clarify where the areas of greatest concern come from. However, these classifications are themselves reified concepts. For instance, accounting knowledge and "facts" are not unproblematic, as Mary Poovey has examined. Her analysis of double-entry bookkeeping highlights the way in which "facts" and "truths" are constructed, partly in order to give ontological security to a particular type of knowledge that provides explanation, prediction and control. ${ }^{107}$

Contrasting this epistemologically realist line, Pryke and Allen draw from a sociological interpretation of money to interpret derivatives as a new form of money. According to the sociologist of money, Gorge Simmel, the significance of money is in its bringing about a change in the pace of life. ${ }^{108}$ This is the focus for Pryke and Allen: derivatives represent a qualitative shift in the nature of money. This qualitative change has come about due to the increased speed of their trade and the pervasiveness of these instruments. 'As new forms of money - new means of exchanging temporally and spatially specific risks - derivatives involve the reimagination of seemingly all events as calculable and manageable. ${ }^{109}$

\footnotetext{
106 A. Tickell, "Dangerous Derivatives: Controlling and Creating Risks in International Money," Geoforum 31 (2000): p. 89.

107 See Poovey, A History of the Modern Fact: Problems of Knowledge in the Sciences of Wealth and Society.

108 M. Pryke and J. Allen, "Monetized Time-Space: Derivatives - Money's 'New Imaginary'?," Economy and Society 29, no. 2 (2000): 270.

109 Ibid.: p. 280.
} 
Stephen Green also notes the way in which the "culture of finance" encourages risk taking in modern financial practices. ${ }^{110}$ His analysis of the culture of finance concurs with that of other critical analysts of finance in his recognition of the political nature of such practices. 'Financial markets have produced risk as an attitude to the future not only to cope with threats but to entrench their systems of wealth creation and epistemological authority. Risk management as a system of interlocking technological, institutional, and social forms of action has become entrenched in global markets because of its basic ability to combine the modern ambition for certainty about the future and capitalism's willingness to bring imagined futures into the realm of the market. ${ }^{, 11}$

Stephen Green argues that the literature on risk, through its emphasis on scientific techniques, often glosses the negative qualities of the risk system. These include three main problems; the ways it allows, even encourages, risk-taking; the concentration within the financial system of vulnerability; and the inability of risk models to comprehend the "social" nature of the market."

Green illustrates the importance of critically assessing the notion of "risk" using financial market practices such as OTC derivatives trading. This preludes the discussion of the critical literature that notes the genealogical rise of "risk" as it has come to be thought of the way it is today. For this investigation, I draw on the work of Deuchars and de Goede in particular, as they document the politicoeconomic, politico-strategic, politico-social and politico-cultural settings that have made "risk" thinkable.

\footnotetext{
110 Green, "Negotiating with the Future," p. 82.

111 Ibid.: p. 81.

112 Ibid.: p. 82.
} 
Of key interest with relation to derivatives contracts, is the question of how we create value in this type of market. As McGoun notes, '[o]ne of the primary concerns of finance is the value of financial assets. This sounds simple enough, but since financial assets are a form of money, finance is in effect concerned with the value of money. ${ }^{, 13}$

This "value" of derivatives relies on the construction of monetary processes based on liberal assumptions. For "universal values" to apply, everyone must share the same values. If everyone does have the same values, such as those required for global market prices, this is not so problematic, and the question becomes one of transparency of process, accountability and open access (all central aspects to liberal economics and its assumptions). But, if this liberal assumption of humans as calculating is not universal (both through time and space), the regulation tends towards the construction of normalising disciplinary techniques so that everyone does take on these "values" as their own, by privileging a liberal democratic part-truth as a whole truth.

The questions of who has control and who takes the risks require "repoliticisation," however. Risk and control are concepts that are tied up with the relationship between the knowledge that informs those with the "expertise" and the ideological power that is already culturally embedded in those knowledge structures.

Financial derivatives are essentially a form of 'risk' management, and so the very notion of 'risk' needs to be looked at very closely. As theorists from sociology and anthropology have explored exhaustively, risk has a cultural history particular to Western modernity that can by no means claim universal applicability. The

113 McGoun, "Hyperreal Finance," p. 99. 
emergence of financial capitalism is tied up with the history of 'risk', as early modern forms of mercantile and other insurance relied upon developments in probabilistic calculus, as well as later applications of statistical knowledge.

These developments in knowledge, as well as having contributed to the modern notion of 'risk', are deeply political. The employment of increasingly calculative practices as a legitimisation (and "professionalisation") of financial analysis has also helped contribute to the thin, but important, line of difference between gambling and finance. Derivatives are used not only as a form of insurance, but also as a form of speculation and extreme profit-making ventures. When an analysis of this type is explored it becomes clear how embedded many of these "technical" concepts are within the liberal ideological project of capitalistic principles.

Derivatives are a specific financial instruments that act as a form of insurance against the uncertainty of the market, and they offer opportunities to financially benefit from "getting it right when others get it wrong". For liberals, then, they exploit "inefficiencies" in the market, and help prices reach equilibrium - i.e. they help keep the market "freer and fairer". The Black-Scholes options-pricing model offers a framework of utilising financial derivatives in a more systematic and calculative way. Based on certain key assumptions ${ }^{114}$, the Black-Scholes model claims to eliminate the possibility of risk from an options-based derivative contract. Although modifications to it have been made since the original $1973^{115}$ version, it remains the foundation for most computer models used in derivatives

\footnotetext{
114 See Maurer and MacKenzie for clear and interesting discussions of these assumptions in a philosophical light. D. MacKenzie, "Physics and Finance: s-terms and Modern Finance as a Topic for Science Studies," Science, Technology, and Human V alues 26, no. 2 (2001).

${ }^{115}$ F. Black and M. Scholes, "The Pricing of Options and Corporate Liabilities," Journal of Political Economy 81 (1973).
} 
trading today. It exudes the epistemological confidence many academics and practitioners alike have in the ability to quantifiably bound uncertainty.

There are two key assumptions implicit in the Black-Scholes model. They relate to the analogy between stock prices and particles in Brownian motion (the theory of particle physics upon which the model is based). The first assumption is that of randomness, or stochastic process. The second assumption is that of equilibrium in the market. The world's market must operate according to the rules of neo-liberal economic theory, that is, including 'market efficiency', open information, and "free and fair" competition. These neo-liberal economic assumptions are not surprising. However, what is important to note is that the claim to scientific objectivity (and therefore greater expert legitimacy) that is implicit in the quantified Black-Scholes model is intricately reliant on these assumptions, and they are (essentially) normative views of human behaviour. These values are not made explicit.

De Goede notes that 'Black and Scholes reasoned that option prices could be calculated if one know the current stock price and the average volatility of a particular stock. ${ }^{116}$ This relies on the view that there are 'objectively true and fair' prices for stock options, and therefore relies on a deterministic view of financial behaviour. Underpinning this analysis is the view that humans are essentially rational and that markets can be understood according to the orthodox economics view of equilibrium. However, rather 'than as a contestable construction of the fair price of financial instruments, the Black-Scholes formula was heralded as the scientific discovery of financial truth. ${ }^{, 117}$

\footnotetext{
116 Goede, "Discourses of Scientific Finance and the Failure of Long-Term Capital Management," p. 157. 117 Ibid.
} 
Donald MacKenzie provides an interesting analysis of the Black-Scholes optionspricing formula. He argues that even if the assumptions that the model is based on are not true, so many financial firms use the model that many actors begin to act as if the assumptions were true. ${ }^{118}$ He explains that 's-terms are constituted by loops of self-reference ${ }^{119}$ and self-[validation]. ${ }^{120}$ These s-terms are viewed as similar to Hacking's analysis of "human kinds". Further, "[t]he self-validating inference loop that constitutes money has become so taken for granted as to be invisible. The patterns of belief that constitute money become evident only when those beliefs become precarious in times of social collapse or hyperinflation. ${ }^{121}$ If the trend-spotters create trends themselves (i.e. if there are enough of them) this is called positive feedback. If the opposite occurs, this is called negative feedback, proving the efficient market hypothesis. MacKenzie argues that it seems plausible that the predominant pattern is negative feedback - that the search for pricing anomalies to disappear, in other words, that the activities of those who believe the market not to be efficient help make it efficient. ${ }^{122}$ Importantly, then, 'finance theory has played an important role in its assumptions becoming more realistic. ${ }^{123}$

However, as Phillip Bougen's analysis of "catastrophe risk" in reinsurance markets suggests, there is not so much a recognition of the limits to understanding risk in the financial sector, as there is a view of risk as a malleable concept which utilises statistical knowledge and probabilistic calculus to make

\footnotetext{
118 MacKenzie, "Physics and Finance: s-terms and Modern Finance as a Topic for Science Studies."

119 These "s-terms" are viewed as similar to Hacking's analysis of "human kinds".

${ }^{120}$ MacKenzie, "Physics and Finance: s-terms and Modern Finance as a Topic for Science Studies."

121 Ibid.

122 Ibid.

123 Ibid.: p. 133.
} 
certain (neo-liberal) political rationalities dominant in the market. ${ }^{124}$ Insurance markets are only getting bigger, not smaller. The desire to insure against humanmade catastrophe is as great as it has ever been. Whether they will be successful is the question those who partake in risk debates want to see answered. Pat O'Malley points out the danger in the tempting view that: 'Modernity would have proven itself capable of governing these new risks, of taming yet another area of chance. [Or thinking that it] would demonstrate that modernization risks are governable by risk calculation and insurance. ${ }^{, 25}$ Rather, argues O'Malley, it is more instructive to argue that this line of inquiry into the "successes" of insurance markets in "catastrophe risk" "is to chart the variety of ways in which catastrophe risks are already being governed in this new environment., ${ }^{126}$ In this regard, O'Malley furthers claims to strengths in the governmentality school approach to questions of risk and government.

In relation to the culture of finance in general, and of derivatives trading in particular, Elton McGoun's analysis of hyperreal finance illustrates the extreme way in which finance has become decoupled from the 'real' economy, and has become a culture that privileges trading for the sake of trading. This analysis of the culture of derivatives trading does not, however, discount the self-interested individual (person or firm) that strives for more money and is therefore driven by greed. It does shift the focus away from this alone, however, placing the emphasis on a better understanding of what is being considered in the decisionmaking process by financial analysts and investors.

\footnotetext{
124 P. D. Bougen, "Catastrophe Risk," Economy and Society 32, no. 2 (2003).

125 P. O'Malley, "Governable Catastrophes: A Comment on Bougen," Ibid.: p. 276.

126 Ibid.
} 
The concept of the rational individual decision maker in financial analysis and trading is a prevalent one in orthodox economics. This notion not only gives credence to the legitimacy of the "expert", but also reinforces the assumptions that underpin the models used to analyse "risk". One has to ask, therefore, whether the actual practice of "risk management" matches the rational actor models used.

Assumptions regarding individual human behaviour are sought to be made true through the disciplinary normalising practices of economic, social and cultural change. This is where the question of governmentality comes in. Interesting in this regard, is the analysis of the "black box of mathematics" that Maurer assesses in relation to the way derivatives markets are analysed. To a large extent, it does not matter what the mathematical formulae and numerical calculations imply in mechanical terms, as the underlying construction of frameworks of knowing is "repressed, subjugated, forgotten, etc...." In other words, what these numbers actually mean is not considered important in their day-to-day usage by derivatives markets. In doing this, Maurer argues, there is a repression of epistemological process, and of the moral arguments that are part of historical construction of "fact". He argues that 'derivatives can take on the indexical power they do in critical and neo-liberal accounts only if their operational, mathematical technique is left in the black box, shut away, bracketed or repressed. ${ }^{127}$ He does not place the same emphasis on the influence of the model that de Goede does, however. He also disregards the focus of the claim that traders in derivatives actually use derivatives

They might not. Rather, I am claiming that, regardless of the mathematical technique's use of efficacy, its being "left aside" allows it to

127 B. Maurer, "Repressed Futures: Financial Derivatives' Theological Unconscious," Ibid.31, no. 1 (2002): p. 19. 
maintain a very privileged status in any account of contemporary derivatives trading. I am further arguing that its repression, exclusion, bracketing from analytical and neo-liberal scrutiny does a certain kind of work that allows derivatives to take on their putative stability as financial entities and also to take on the peculiar indexical power with which they have been invested, especially since the 1980s and 1990s as they have become more important to the world financial markets and more visible - the power to point towards big changes afoot, to the aspect, state or truth-value of other phenomena. ${ }^{128}$

Maurer's analysis of the Black-Scholes options-pricing model raises interesting issues concerning the power of the epistemological contestation over "fact" and "value". What is said to be known is therefore questionable. Even complexity theory $^{129}$, for all its attention to "details", does not ever stop to question the historical construction of statistical knowledge and probabilistic calculations. This is one of the "dangers" to many objectivist rationalist analyses of human practices, in that the meaning of such accounts is left ambiguous due to the abstract gap between the dichotomised "theory" and "practice".

All of the above analysis also raises issue as to the political nature of supposedly value-neutral technical pursuits, such as accounting, auditing, the practice of statistics, sampling, and credit rating. Understanding how these are political, and therefore prescriptive as well as descriptive, is important for a number of reasons. First, and foremost, from the perspective of the IPE scholar, is the recognition that technical pursuits such as those named above, make it possible to see how

\footnotetext{
128 Ibid.: pp. 19-20. (Emphasis in original).

129 P. Cilliers, Complexity and Postmodernism: Understanding Complex Systems (London and New York: Routledge, 1998).
} 
different forms of politico-economic structure might be replaced by ones deemed less desirable. From the perspective of Marxist, socialist, feminist, indigenous and other critical theories, this insight offers a powerful tool of critique to add to their agenda. Secondly, the issue of the reliability of tools for risk management, that depends so much on all of the above-mentioned technical pursuits for its "objectivity" is seriously undermined. Simply put, rationalist attempts to explain and predict financial (and other social) processes fail to factor in the social influence and affect on processes. In other words, the social world is not "out there" with objective laws that can be discovered. Rather, the theorist influences the outcome of their social analysis.

\section{How justified are financial "experts" in their claim to such a title?}

In a discussion of the "political" it is necessary to an understanding of the role of the "expert" in contemporary world affairs. IR theorist, Jenny Edkins, provides a useful outline of the role post-structuralist analysis can provide in understanding the construction of expert discourse. The key point to be taken from Edkins' analysis is that technologisation emerges as a result of the mental division of labour, combined with the cultural move to give a great deal of legitimacy to the "expert". ${ }^{130}$ Risk management becomes an issue for the expert of finance - it is a practice that is "depoliticized" (according to neo-liberal logic). This marginalizes the voices of critics who, it is claimed, do not understand the issues. Now, there are very good reasons for giving faith to the experts in a technocratic society, if one believes that technocratic structure to be necessary or desirable. However, there is a very real danger at the same time of instrumental reason driving the logic of policy options, and critical consideration of political, social and moral ends outside of that logic being excluded. The division of labour limits what is 
considered relevant to the expert's role, thereby rendering him or her deaf and blind to considerations important to in others in the same society.

For instance, Jenny Edkins analysis of poststructuralism and IR theory provides an interesting lead into how to understand derivatives trading. Derivatives can be see, in this regard, as an extension of politics as technologisation. No longer are questions of finance seen as political in nature, although political implications are not entirely ignored. But rather, the technologies of finance, such as derivatives trading, are a realm to be assessed by a collection of experts. Finance, financial capitalism, and the important assumptions that these processes rest upon, are not problematised as political. This is problematic, as the "scientific" basis for the "objective" accounts provided by financial experts rely on a particular ontological view of the world "out there". Deuchars outlines a crucial point, in this regard: the specific way in which the notion of "risk" is bracketed out from "uncertainty".

Economists talk about decision making under conditions of uncertainty, meaning incomplete information about the future. This makes the condition of uncertainty a neatly bounded problem, primarily concerned with expectations about the future, related to a possible range of decision choices. For example, even complete uncertainty can be rationally bounded. For economists, complete uncertainty is taken to mean a situation whereby 'all information about probabilities is absent'. This is a very specific definition underlying which are two main assumptions and a third cognate assumption. Firstly, the definition assumes that the condition of uncertainty is primarily if not wholly situated within the communicative frame for the purpose of making decisions. Secondly, it rests on the assumption that decision making is premised on rational calculation, specifically calculation that can be quantified as opposed to being simply a matter of qualitatively weighing up the pros and cons of particular situations prior to a decision-choice. Finally, the two main assumptions are 
linked by a third assumption, which is that we are dealing with a hypothetical individual as the primary unit of analysis. ${ }^{131}$

Interestingly, the aftermath of many financial crises such as LTCM and Enron has not been to critically assess the models relied upon, as the above analysis would suggest, but, rather there has been a call for greater complexity in the models. This is in line with 'the notion that radical uncertainty can be tamed by the increased use of advanced mathematics, non-linear modelling and so on. ${ }^{132}$ There is also an argument here that problems created by 'technological advance itself can solve problems created by technological advance. ${ }^{, 133}$ As noted in the previous section, complex mathematical models, such as the Black-Scholes options-pricing model, may provide greater predictability in the short term, however, the increasing complexity of OTC derivatives markets (largely spurred on by the development of these technological instruments) increases volatility and uncertainty. ${ }^{134}$ In this sense, and despite the complex formulae that proliferate more information about the market than ever before, increased complexity can reach the point where the system can not be said to be known. In other words the system's architecture no longer provides a complete picture.'135

Given this analysis of derivatives trading, there might be considered to be an "illusion of control" over OTC derivatives trading. As a system of self-regulation

\footnotetext{
131 Deuchars, The International Political Economy of Risk p. 109.

132 Ibid. p. 176.

$133 \mathrm{Ibid}$. This is a critique of instrumental rationality that goes back to the work of Horkheimer and Adorno and their analysis of the "dark side" of modernity. In particular, see M. Horheimer, Critique of Instrumental Reason: Lectures and Essays Since the End of World War II (New York: The Seabury Press, 1947), M. Horkheimer and T. Adorno, Dialectic of Enlightenment, trans. John Cumming (New York: Herder and Herder, 1972; reprint, 1972).

${ }^{134}$ Deuchars, The International Political Economy of Risk p. 176.

135 Ibid. p. 177.
} 
informed through expert discourse proliferates along with the phenomenal growth in OTC derivatives trading, control at the level of the international financial market is left questionable at best. Despite Toulmin's faith in rationalist ways of knowing, he provides an important consideration in light of the above discussion:

The general belief of the expert economists that the "data" to be considered in such decisions can be purely "factual," and so free from ethical and political assumptions, blinds them to the full range of factors they should take into account. The crucial questions do not turn on ensuring the formal correctness and consistency of our calculations; they depend rather on collecting all the relevant social, historical, cultural, and even personal information about the people involved, and their actual needs. In this respect, a traditional reliance on Euclidian and Newtonian models of theory continues to focus attention on "doing your sums right" and conceals the equally important task of making sure that you are "doing the right sums": in other words, doing calculation that are directly relevant to the practical situation in question. ${ }^{136}$

From my perspective, this requires not only a fundamental rethink of the assumptions made by liberal economists about human behaviour and time, but also a rethink of what factors actually matter in understanding market practices. Given that the global market is increasingly intertwined with a range of politicostrategic, politico-economic and politico-social factors, it appears impossible to separate out exactly what is important to analysis and what is not all of the time, especially at such a macro level incorporating a wide variety of products and incredible volumes. While increasingly complex mathematic models do provide a greater degree of accuracy, within a particular framework, they might not be able to account for multiple-contingencies that are very much a factor in such a globally integrated and complex financial market.

136 S. Toulmin, Return to Reason (Cambridge, Massachusetts: Harvard University Press, 2001) pp. 65-66. 


\section{Conclusion}

In summary, questioning the role of derivatives in these world affairs requires an understanding of both the scale and scope of their trade, as well as a critical account of how this scale and scope has been made possible. The above assessment has illustrated that derivatives are not only political in terms of who they affect, but also in the way technologies of risk management are ideologically loaded. Not only does this open up space for political critique, but it also illustrates severe limitations to neo-liberal accounts of how risk management is to be understood. 
Chapter 3

\section{THE CASE OF ENRON}

\section{Introduction}

Financial history is fraught with stories of boom and bust. ${ }^{137}$ Recent financial history is no different, and exhibits its own fair share of companies and institutions that have found their demise in the use of financial instruments such as derivatives. Notable examples include the spectacular collapse of the English bank Barings in 1994, the bankruptcy of the large German company Metallgesellshaft in 1993, the "mother of all municipal defaults" ${ }^{138}$ in Orange County in 1994, and the much-lamented failure of the hedge fund Long-Term Capital Management (LTCM) in 1998. All of these examples involved the use of derivative financial instruments, and each shares a similar common feature in the speculative way in which these instruments were used, contributing to their unpredictable collapses.

This chapter focuses on the example of the former American energy giant Enron, and how it used OTC derivatives to first "boom", and then "bust". Like the other examples cited above, the nature of Enron's demise is the subject of much debate, and many do not accept that derivatives trading can be seen as the key to why it became bankrupt. However, this thesis argues that the case of Enron demonstrates how OTC derivatives trading is mis-represented by the models upon which current theories of "risk management" are based, and how, without

\footnotetext{
${ }^{137}$ For an overview of aspects of historical financial crises, see Chancellor, Devil Take The Hindmost: A History of Financial Speculation, Galbraith, A Short History of Financial Euphoria, C. P. Kindleberger, Manias, Panics, and Crashes: A History of Financial Crises, Revised Edition ed. (New York: Basic Books, Inc., Publishers, 1989; reprint, 1989).

138 Gill, "Finance, Production and Panopticism: Inequality, Risk and Resistance in an Era of Disciplinary Neo-Liberalism," p. 69.
} 
the state intervention that followed, systemic risk was a very real possibility. First, this chapter outlines why Enron is an important case to consider, by documenting the scale and scope of Enron's empire and the "costs" of its demise. Second, this chapter documents how Enron came to trade so heavily in OTC derivatives, and gives a brief history of the company and of key developments in Enron, including its creation of new derivatives markets. Third, it assesses different ways to explain the collapse, arguing that derivatives were instrumental to the demise of Enron. Finally, it asks what this assessment means for an understanding of risk management analysis and practices with regard to OTC derivatives trading, as well as the regulatory responses discussed in the next chapter.

Why choose Enron as a case study?

Like all good stories, Enron provides a host of enticing themes. The world's largest corporate bankruptcy is a story of greed, deception, corporate incompetence and risk management failure on a massive scale. Of course, it's only a good story if the reader is not one of the many so adversely affected by this giant non-fiction work. It is the last of these themes that provides the basis for the analysis of this chapter, though, interestingly, it is the one given the least attention in the numerous articles and analyses attempting explanations for Enron's demise. The following account illustrates why the theme of financial risk management is indeed so important to understanding the fall of Enron.

Following the demise of the giant energy company Enron, Frank Partnoy, a law professor, submitted testimony to the US Senate Committee on Governmental Affairs in January 2002. He commented on the Enron collapse and the role the company's use of derivatives played in that collapse. To illustrate the importance 
of the Enron case, he provides a comparison with the much-noted hedge fund, Long-Term-Capital-Management.

According to Enron's most recent annual report, the firm made more money trading derivatives in the year 2000 alone than Long-Term Capital Management made in its entire history. Long-Term Capital Management generated losses of a few billion dollars; by contrast, Enron not only wiped out $\$ 70$ billion of shareholder value, but also defaulted on tens of billions of dollars of debts. Long-Term Capital Management employed only 200 people worldwide, many of whom simply started a huge hedge fund after the bailout, while Enron employed 20,000 people, more than 4,000 of whom have been fired, and many more of whom have lost their life savings as Enron's stock plummeted [in 2001]. ... In short, Enron makes Long-Term Capital Management look like a lemonade stand. ${ }^{139}$

The implications of the collapse of Enron are obvious for those who have been directly affected, as Partnoy notes above. And the comparison with LTCM is a salutary one for those interested in the role of derivatives in the international political economy, as much focus has been given to LTCM and its group of "financial superstars". LTCM has also been described as the "epitome of scientific finance ${ }^{, 140}$, illustrating just how much faith is put in the ability of highly sophisticated financial risk management systems to predict and/or prevent financial collapse. Though Enron did not profess the same expertise as LTCM, it did develop and use complex derivatives in innovative ways to create markets and speculate on weather and energy uncertainties.

\footnotetext{
${ }^{139}$ F. Partnoy, Enron and Derivatives (Obtained from Social Science Research Network Electronic Library, 24 January 2002 [cited 5 June 2004]); available from http://ssrn.com/abstract=302332.

140 Goede, "Discourses of Scientific Finance and the Failure of Long-Term Capital Management," p. 156.
} 
A preliminary note about these aspects of the Enron case is perhaps apt. Media coverage of Enron's bankruptcy focused around a few key figures, such as CEO Kenneth Lay, and the accounting firm Andersen's. This is understandable for a couple of reasons. First, fraudulent accounting was carried out at Enron, and there has since been a great deal of enquiry into this issue. This raises interesting issues of classification in accounting systems, though this is not central to the argument of this thesis. But secondly, and I think more importantly, derivatives were rejected as the real issue too quickly to allow US policy makers to assess situations such as Enron in more critical terms.

As Partnoy notes, 'Enron is largely a story about derivatives'. ${ }^{141}$ He argues that a 'close analysis of the facts shows that the most prominent SPE [Special Purpose Entities] transactions were largely irrelevant to Enron's collapse, and that most of Enron's deals with SPEs were arguably legal, even though disclosure of those deals did not comport with economic reality. To the extent SPEs are relevant to understanding Enron, it is the derivatives transactions between Enron and the SPEs - not the SPEs themselves - that matter. ${ }^{, 142}$

Noting the various and widespread impact of the Enron collapse, 'American taxpayers are potentially on the hook for $\$ 1.059$ billion in OPIC [Overseas Private Investment Corp.] loans and insurance policies for 12 active projects in which Enron is one of the sponsors ${ }^{\text {143 }}$. The international impact was felt immediately. 'Fallout from the collapse of the US energy trading company Enron

\footnotetext{
${ }^{141}$ F. Partnoy, A Revisionist View of Enron and the Sudden Death of 'May' (Villanova University School of Law's Law Review Symposium Issue, 2003 [cited 1 June 2004]); available from http://ssrn.com/abstract $=417261$.

142 Ibid.([cited).

143 P. Sperry, Power For Sale: Huge Enron Loans Expose Taxpayers (WorldNetDaily, 22 January 2002 [cited 5 July 2004]); available from http://worldnetdaily.com/news/article.asp?ARTICLE_ID=26159.
} 
resulted in the loss of more than 1,000 jobs within the group's UK operations ${ }^{1144}$. Importantly, 'Enron had nearly 20\% of the British energy trading market ${ }^{145}$ and many UK companies faced losses because of contracts with the US group. One notable example it that 'Centrica, the British gas group, said its exposure to Enron totalled around $f 30 \mathrm{~m} .{ }^{, 146}$

Normally commercial banks and insurers avoid backing long-term projects in emerging markets (many of them in the developing world), ${ }^{147}$ however, Enron pursued these markets vigorously, thereby increasing both the riskiness of its derivatives contracts, as well as spreading the impact of its demise to the third world as well. The spread of Enron's empire is impressive:

OPIC's [Overseas Private Investment Corp.] portfolio of active Enron projects includes deals in Guatemala (fiscal 1992); the Philippines and Argentina (1993); Dabhol, India (1994); Colombia and Turkey (1994); Turkey (1995); Venezuela, Brazil and the Philippines (1998); Brazil and Bolivia (1999); Phase 2 of Dabhol (1999); and Guatemala (2000). OPIC provided additional funding or insurance for existing projects in countries like Turkey, while financing or underwriting more than one project in other countries. ${ }^{148}$

The overall impact of Enron's collapse cannot be understated. Enron left behind approximately $\$ 25 \mathrm{US}$ billion in debts, and approximately 20,000 workers around the world lost their jobs. Its shares became worthless. ${ }^{149}$ 'Many banks were exposed to the firm, from lending money and trading with it. JP Morgan

\footnotetext{
144 G. Gibbs, J. Treanor, and R. Wray, "1,100 UK Jobs Go In Enron Collapse," Guardian, 1 December 2001.

145 G. Gibbs, "Costs Begin to Mount on This Side of the Pond," Guardian Unlimited, 30 November 2001.

146 Ibid.

147 Sperry, Power For Sale: Huge Enron Loans Expose Taxpayers ([cited).

148 Ibid.([cited).

149 BBC, The Enron Collapse (BBC, 8 July 2004 [cited 10 August 2004]); available from http://news.bbc.co.uk/1/hi/business/3398913.stm.
} 
admitted to $\$ 900 \mathrm{~m}$ of exposure, and Citigroup to nearly $\$ 800 \mathrm{~m} .^{, 150}$ As Dodd puts it, 'Enron is the largest bankruptcy in U.S. history, and it will inflict substantial damages on U.S. banks, broker-dealers (who are already being sued for under-writing currently worthless Enron securities), insurance companies and pension funds that invested directly in Enron, energy companies, many small and large investors, and Enron's own employees.' ${ }^{151}$

The interest of the Enron case to this thesis lies in the way Enron developed trade in OTC derivatives and shifted from the relatively concrete role of being an energy trader to the far more abstract role of a trader in energy-based derivatives. A brief history of Enron will help illustrate the extent of these developments, as well as their link to deregulation in the US energy sector, and the sheer scope of Enron's “empire".

\section{How did Enron come to trade in derivatives? A brief history of Enron}

Enron came into existence in 1985 with the merger of Houston Natural Gas and Omaha-based InterNorth. ${ }^{152}$ Originally involved in power and natural gas liquids in North America alone, Enron executives and energy lobbyists pushed for deregulation of the energy sector, advocating that more open competition would be better for companies and consumers in general. Deregulation of the energy sector brought about two things: first, deregulation brought a lot of new suppliers of energy sources into the market; and second, the price of energy became more volatile.

\footnotetext{
150 Ibid.([cited).

151 R. Dodd, "Untangling Enron: The Reforms We Need," Challenge, March-April 2002, p. 75.

152 A general overview of Enron's trading history can be obtained via http://news.bbc.co.uk/hi/english/static/in depth/business/2002/enron/timeline/default.stm or http://specials.ft.com/enron/FT38O0NQUWC.html.
} 
As a result of deregulation of energy markets, Enron, among other companies, was able to create new markets, including futures and other derivatives markets, both for the purposes of hedging its own bets against changes in the uncertain new deregulated energy markets, and as a trader in the energy derivatives market more generally. This began in the 1980s primarily with the use of futures markets to insure against price fluctuations in gas-generated energy. Due to the deregulated market the use of such futures appeared a prudent, as well as profitable, approach for both Enron and the rest of the financial market.

At its height, Enron controlled a quarter of all gas business in the US. ${ }^{153}$ Following the logic that so many companies apply in a situation of newfound success, Enron sought new ways of creating energy-related products, expanding their derivatives market to include steel and coal. By the end of the 1990s Enron was even providing derivatives to hedge against external factors such as "weather risk". This may have been a smart business move for the energy giant, as Enron had

situated itself as one of the most important market makers in weather derivatives, which allow weather-sensitive industries (the ice-cream company being a quintessential example) to hedge against adverse weather. It has recently been asserted that the market in weather risk is experiencing exponential growth, and one provider of these products writes that "an estimated $70 \%$ of all businesses face weather risk and, as one might expect, weather risk extends across geographic market divides." 154

That Enron was involved in derivatives trading in energy-related products is perhaps not so surprising, but what is worthy of note is that Enron was moving further and further away from its role as an energy company towards one of a

153 BBC, The Enron Collapse ([cited). 
trading company. Jeff Skilling, former chief executive and financial innovator for Enron, is said to have wanted to rid Enron of its physical assets. This would have left Enron in the business of trading financial contracts in the energy market alone. However, Enron was also using its newfound financial significance to move into water markets in the UK, and into power generation in India. ${ }^{155}$ Importantly, though, Enron did not enter these market based on surplus profits it had made from its expansion, but instead 'used debt to purchase a large amount of plant, equipment, and inventory ${ }^{156}$ in a relatively short space of time. Expansion into both the UK and India was made possible by bank loans and debt issuance, producing a high debt-to-equity ratio 'that was partially hidden from investors through the partnerships known as "special purpose entities". ${ }^{157}$

The relationship between accounting and derivatives is also made particular interesting in light of the Enron case. Piga discusses how derivatives are used to 'window dress' their public accounts for the purpose of disguising budget deficits, ${ }^{158}$ and Hosking discusses how 'Enron used energy derivative to flatter its profit-and-loss account. ${ }^{159}$ Enron 'used derivatives [...] to hide losses suffered on technology stocks.' Enron also 'used derivatives [...] to hide debt incurred to finance new businesses. ${ }^{, 160}$

\footnotetext{
154 M. d. Goede, "Repoliticizing Financial Risk," Economy and Society 33, no. 2 (2004): p. 198.

155 It is important to note that deregulation of energy markets was not a theme limited to the US. Both India and the UK have had their energy markets deregulated and privatised over the past 20 years to a considerable extent.

156 Dodd, "Untangling Enron: The Reforms We Need," p. 68.

157 Ibid., pp. 68-69.

158 G. Piga, "Do Governments Use Financial Derivatives Appropriately? Evidence from Sovereign Borrowers in Developed Economies," International Finance 4, no. 2 (2001).

${ }^{159}$ Hosking, "The Business."

160 Partnoy, A Revisionist View of Enron and the Sudden Death of 'May' ([cited).
} 
A key liberal economic principle is that there needs to be open information for a "free" and "fair" market to operate. This applies to financial securities as well, meaning that a company or individual cannot trade based on information it has that is not available to the rest of the market. But 'Enron's dual role as energy supplier and dealer enabled it to have an advantageous "view". It had more information on the market that enhanced its ability to earn speculative profits trading against other sophisticated and unsophisticated counterparties in the markets. ${ }^{161}$

In November 1999 EnronOnline was launched as a global commodity trading site and Enron positioned itself as, what is creatively called, a "new economy" company. ${ }^{162}$ Including its general expansion of financial markets Enron was able to use financial innovation to improve its position with regard to reported taxable income and avoided specific rules in the natural gas and electricity markets. Complete bankruptcy examiners report of how Enron used derivatives runs to several thousand pages. ${ }^{163}$ This is tantamount to the intricate accounting details that are central to the liberal regulatory understanding of this bankruptcy, with the issues of transparency and accountability at the top of their checklist.

Enron's share price was also completely out of synch with what its "real" value should have been. In liberal terms, this would have been corrected eventually (and in an extreme sense, it was when Enron was declared bankrupt), however, neither the market nor Enron's directors viewed it as overvalued. The issue of

\footnotetext{
${ }^{161}$ Dodd, "Untangling Enron: The Reforms We Need," p. 69.

162 R. Jameson, Enron's Off-Balance Machine (ERisk, December 2001 [cited 5 July 2004]); available from http://www.erisk.com/ResourceCenter/Features/news_feature2001-12-12.pdf.

163 N. Batson, Second Interim Report, Court-Appointed Examiner, In Enron, Doc. No. 9551 (5 March 2003 [cited 11 November 2003]); available from http://www.elaw4enron.com.
} 
transparency is certainly relevant in liberal eyes. But a more critical question relates to whether this type of market structure, so open to the speculative whims of people who may not operate according to strictly "rational" logic, is capable of providing the checks to stop the sort of "detached" valuation that leads to such unstable prices.

Another key point, that relates to OTC derivatives in general, is that Enron created new markets through its creation of derivatives markets through its EnronOnline trading operations. Not only was Enron responding to the "risks" in the current market, but it was also creating new markets, with new risks. In this regard, some argue that Enron is significantly different to LTCM, for example, which 'did not create markets but merely sought to gain by trying to exploit pricing irregularities in markets that already existed. ${ }^{, 164}$ However, it should be noted that LTCM was also in the business of actively creating financial markets, as all trade in derivatives is.

Simply put, Enron went from being involved primarily in the fundamentals of the energy business to primarily trading in derivatives. 'Enron's reported earnings from derivatives appear to be more imagined than real. ${ }^{165}$ In actuality, Enron's position was extremely volatile, and its staff began to lie about the profitability of its derivatives trading. Attempts were made to hide this volatility.

Enron derivatives traders faced intense pressure to meet quarterly earnings targets imposed directly by management and indirectly by securities analysts who covered Enron. To ensure that Enron met these estimates, some traders apparently hid losses and understated profits. Traders apparently manipulated

\footnotetext{
${ }^{164}$ Dodd, "Untangling Enron: The Reforms We Need," p. 70.

165 Partnoy, Enron and Derivatives ([cited).
} 
the reporting of their "real" economic profits and losses in an attempt to fit the "imagined" accounting profits and losses that drove Enron down. ${ }^{166}$

Interestingly, the accounting practices related to derivatives trading for Enron were not as "factually" certain as one might expect. "Instead of recording the entire profit for a trade in one column, some traders reportedly split the profit from a trade in two columns. The first column reflected the portion of the actual profits the trader intended to add to Enron's current financial statements. The second column, ironically labelled the "prudency" reserve, included the remainder.' ${ }^{167}$ 'In essence, traders were saving for a rainy day. "Prudency" reserves would have been especially effective for long-maturity derivatives contracts, because it was more difficult to determine a precise valuation as of a particular date for those contracts, and any "prudency" cushion would have protected the traders from future losses for several years going forward. ${ }^{168}$

Other examples of "creative accounting" practices in relation to Enron's derivatives trading include its mismarking of "forward curves". Enron's investors essentially valued the same market twice - 'once in the company's calculation of profits and once in the multiple the stock market applied to them.' 169 This discussion of the creative ways in which accounting can be used to back up derivative trading that is not necessarily viable, highlight the complexity of any regulatory mechanism. If OTC derivatives are traded liberally, and without the many regulations that are applied to exchanges, then "controlling" the effects these instruments have on the entire financial market is highly problematic.

\footnotetext{
166 Ibid.([cited).

167 Ibid.([cited).

168 Ibid.([cited).

169 P. Martin, How to Expect the Unexpected (Financial Times, 13 March 2002 [cited 6 December 2004]); available from http://specials.ft.com/enron/FT3SQT8M0XC.html.
} 
One of the more honest accounts of the Enron case, points out a fundamental point with regard to the nature of business in a liberalised and deregulated market economy. 'The solution is not to invent ever more sophisticated measures of risk or ever more elaborate means of parcelling it out to others. It is to face up to the inherent riskiness of business activity and to understand where the vulnerabilities lie. ${ }^{170}$

\section{A critical evaluation of Enron}

Explaining the cause for Enron's collapse is in one way relatively simple: like all financial crises before it, Enron's demise came about as a result of too many people cashing in on their debt speculations at the same time. Because Enron did not have enough underlying assets or securities to offset these "calls" on Enron's bluff, the value of Enron's weather derivatives essentially became nothing. ${ }^{171}$

The value of Enron, like all the derivatives trading it was involved in, depended on the market assessment of Enron's worth - in other words, an aggregate of individual investors demonstrating their faith that Enron is a good company that is profitable and likely to continue being so. However, as Enron became less involved in the "productive" side of the energy markets, and more involved in derivatives markets, the value of which were far more abstract than the energy products Enron traditionally traded in, Enron's financial position became increasingly left to the whims of the financial market. This might have been fine, as long as Enron could rely on its risk management models to adequately predict significant risks to their OTC derivatives trading.

\footnotetext{
${ }^{170} \mathrm{Ibid}$.([cited).

${ }^{171}$ For instance, see Galbraith, A Short History of Financial Euphoria.
} 
The question then is: why was the collapse so unpredicted, in spite of the powerful risk management tools employed by Enron?

Energy policy affects derivatives mainly through its impacts on the underlying commodity and transportation (transmission) markets. Commodity markets with large numbers of informed buyers and sellers, each with multiple means of moving the commodity to where it is needed, support competitive prices. Derivatives for managing local price risks can then be based on the overall market price with relatively small, predictable adjustments for moving the commodity to local users. Federal energy policy has a significant impact on competitors' access to transportation (transmission), on the volatility of transmission charges, and therefore on derivative markets. ${ }^{172}$

The second point argued by Partnoy is 'that the regulatory response to Enron was in large part misguided because it focused too much on the conventional story. If the conventional story about Enron is correct - then the prescriptions that follow from Enron's collapse, if any, should relate to the regulation and disclosure of derivatives. ${ }^{173}$

He argues that this second point is important as it raises the issue of how 'interested private actors quickly capture the agency rule-making process', and are able to persuade US Congress to make more stringent recommendations for derivatives regulation than those already suggested by the SEC. ${ }^{174}$ The question of vested interests appears valid, as 'even after intense media scrutiny,

\footnotetext{
172 This is from a report by the Energy Information Administration / Derivatives and Risk Management in Energy Industries.

173 Partnoy, A Revisionist View of Enron and the Sudden Death of 'May' ([cited).

${ }^{174}$ Ibid.([cited).
} 
congressional hearings and other governmental investigations, most of the firm's derivatives dealings remain unpenetrated. ${ }^{, 175}$

In discussion how derivatives trading was documented by Enron, Partnoy says that 'Enron's risk exposure to derivatives was disclosed in limited ways, but arguably was consistent with prevailing standards of practice, which required disclosure of only "reasonably likely" contingencies. Overall, Enron's disclosure practices were driven by accounting rules and did not necessarily comport with economic reality. ${ }^{176}$

Partnoy argues that the derivatives problem at Enron goes much deeper, though. 'If Enron had been making money in what it represented as its core business, and had used derivatives simply to "dress up" its financial statements, this Committee would not be meeting here today. Even after Enron restated its financial statement on November 8, 2001, it could have clarified its accounting treatment, consolidated its debts, and assured the various analysts that it was a viable entity.' ${ }^{177}$ Partnoy asks why it could not. Simply put, because 'most of what Enron represented as its core businesses were not making money. ${ }^{, 178}$ Dodd argues that 'Enron illustrates the problem with the laissez-faire approach to financial markets. Safeguards must be put in pace first so that they precede market activity. Once a crises emerges there is little that can be done. ${ }^{179}$

\footnotetext{
175 Ibid.([cited).

176 Ibid.([cited).

177 Partnoy, Enron and Derivatives ([cited).

178 Ibid.([cited).

${ }^{179}$ Dodd, "Untangling Enron: The Reforms We Need," p. 73.
} 
Partnoy also makes clear the point that 'Enron's trading operations were not regulated, or even recently audited, by U.S. securities regulators, and the OTC derivatives it traded are not deemed securities. OTC derivative trading is beyond the purview of organized, regulated exchanges. This Enron - like many firms that trade OTC derivatives - fell into a regulatory black hole. ${ }^{180}$

Enron was a financial institution, and by all appearances a large one. However, it was subject to no federal regulation as a financial institution. The quarterly reports it filed under the securities laws pertained to Enron only as a corporation in general.' 181 Therefore, because of the way OTC derivatives markets are framed in the US regulatory system, Enron was able to continue trading in derivatives, and essentially avoid the many checks on "recognised" financial institutions, such as 'basic safety, soundness, and transparency requirements that Enron and similar [OTC] derivatives dealers are not. ${ }^{182}$

The Commodity Futures Modernization Act (CFMA) of 2000 also played an important role in the reduced level of prudential regulation in the OTC derivatives markets that Enron was trading in. 'It reduced transparency and the government's surveillance abilities over exchange-traded derivatives, and it completely eliminated or "excluded" federal derivatives regulation of the [OTC] market. Enron operated in that completely deregulated environment. ${ }^{183}$

However, neither Dodd nor Partnoy are willing to view the risk management models themselves as problematic. Their contribution lies in recognising an element of ideological commitment to financial liberalisation and deregulation that has pervaded policy in countries such as the US for the previous thirty years.

\footnotetext{
180 Partnoy, Enron and Derivatives ([cited).

181 Dodd, "Untangling Enron: The Reforms We Need," p. 71.

182 Ibid., p. 72.

183 Ibid., p. 73.
} 
This is still essentially a discussion for experts to take part in though, and they are also essentially "problem solving" accounts in that they do not address the nature of the risk management practices that they themselves are questioning.

This self-regulation of OTC derivatives markets has been encouraged where neoliberal attempts to keep government out of financial markets have prevailed. This is a movement both within states that have pushed a neo-liberal political agenda for some time (such as the US and the UK), as well at more international levels. At the international level, the most prominent and influential institution is the Basel Committee on Banking Supervision (BCBS). This organisation

has accepted as unavoidable the role of these internal risk assessment models in setting reserve requirements. In proposals for a new Basel Capital Accord, which were drafted in 2001 and which are currently under review with a view to implementation in 2006, banks have a choice whether to use a standardized approach (devised by the committee) or their own internal risk estimates for the calculation of the three risk categories which determine the level of capital reserves to be held by financial institutions (credit risk, market risk, and operational risk). ${ }^{184}$

'More generally, the BCBS increasingly negates the need for a broader discussion on the possibilities, merits, and politics of current developments in mathematical risk modelling. ${ }^{185}$ The following discussion of risk models used by Enron may make this stance appear "imprudent", at best.

As noted in the previous chapter, key modes of governing practice in finance are through the way risk is neatly bounded, and is attached to certain things. Enron used the Black-Scholes model and Value-at-Risk models to help it predict market

\footnotetext{
184 Goede, "Repoliticizing Financial Risk," p. 209.

185 Ibid.: p. 211.
} 
trends. By analysing probabilities to future events, the VaR can provide numerical basis for decision-making. Because the $\mathrm{VaR}$ is ultimately reliant on the normal distribution (i.e. a belief that there is a general law to be followed), main criticisms of $\mathrm{VaR}$ are for its underestimation of the chances of extreme and unexpected events. As de Goede notes, '[l] eaving aside the question of the accuracy and availability of all the historical data required, it does not take a mathematical genius to realize that this strategy allows for little consideration of the occurrence of unprecedented events ${ }^{186}$. This has important implications for situations where multiple-event hazards occur simultaneously. For example, Barings certainly had a rogue trader to deal with, but it is not clear how successful he would have been had the Kobe earthquake not struck at such as "inopportune" moment.

It is important to consider in the case of Enron what risks - or uncertain events its risk models could not account for. Quantifiable risk have become essential to modern financial markets, however, as the relationship between seller and buyer relies so heavily on these standardised, abstract, and objectified numbers, the models have created increasing importance for themselves. That these mathematical models might be largely contestable (as discussed in the previous chapter) does not stop them from becoming central to financial decision making if enough of the "right" people believe them to be of use. In the case of Enron, financial derivatives were developed by EnronOnline and, because of their central (almost monopolistic) role in this part of the global financial economy, the rest of the financial market relies on these numerical models as well. That these are taken for granted by many financial experts speaks volumes about the way "scientific" risk management practices are carried out.

186 Ibid.: p. 210. 
Also, '[b]y accepting and formalizing banks' internal risk management models, the BCBS's proposals for the new Capital Adequacy Accord legitimate these financial practices.' Adding a feminist analysis, she notes that 'The identity of the masculine financial risk manager - the late-modern master of the future and imperial adventurer - is now underpinned by scientific authority and mathematical models, which appear as profoundly a-political. ${ }^{187}$

De Goede notes that 'financial risk management does not just react to but creates particular definitions of insecurity. There is a circular argument propping up the financial sphere: while pretending to eradicate uncertainty from business ventures, finance identifies and invents more and more possible uncertainties to be hedged. ${ }^{, 188}$ This might also be understood according to the logic of capital expansion that Marxists find convincing.

'The politics of risk', argues de Goede, 'figure in the Enron scandal in two, interrelated, ways. First, Enron's ambitions to be an important player in the financial markets led the company to diversify into offering complicated risk management products. ${ }^{189}$ This might be likened to Beck's notion that risks are a 'bottomless barrel of demands' - i.e. that they can create risks ad infinitum - and that this is possibly infinitely profitable.

Disagreeing with the direct link between the creation of new weather markets and Enron's demise,' de Goede argues that, 'while potentially profitable, the increasing commercialisation of uncertain futures carries risks of its own. In particular, the successful marketing of risk management products requires cultural

\footnotetext{
187 Ibid.: p. 213.

188 Ibid.

189 Ibid.: p. 198.
} 
parameters that see it as morally and economically compulsory to be insured against that risk in question. ${ }^{190}$ She goes on to note that 'The second way in which the Enron scandal illustrates the problematic of politics of modern risk management is that it has become increasingly difficult to know the overall risk exposure of large financial institutions at any point in time. ${ }^{191}$

'Rationality and risk calculation, while unable to reveal the future, provide the "guarantee that even if things go wrong, one can have acted correctly. They immunise decision-making against failure"” 192 Therefore, while increasing financial volatility and systemic risk, the legitimacy given to financial experts remains intact. That there have been a number financial crises, and that each large collapse requires some form of market intervention from the state (be it to ensure market failure does not occur, or, less likely, to ensure that pensions tied up with the financial market are not lost), raises important political questions over the regulatory role of the state.

It is important to recognise the social and moral role of risk management in a case such as Enron. As de Goede notes, '[t]he identification and classification of, and attempts to insure against, dangers which lie at the heart of risk management entail a normative judgement on what kind of life is worth preserving or protecting, and which dangers are most urgently studied and expelled. ${ }^{193}$ This point is crucial. There are competing conceptions of humans beings at stake here, and the question of which we prefer has important implications for politicoeconomic processes and beyond.

\footnotetext{
190 Ibid.: p. 199.

191 Ibid.

192 Ibid.: p. 213.

193 Ibid.: p. 205.
} 
The issue of classification in accounting systems is also important to consider.

Specifically, Enron used derivatives and special purpose vehicles to manipulate its financial statements in three ways. First, it hid speculator losses it suffered on technology stocks. Second, it hid huge debts incurred to finance unprofitable new businesses, including retail energy services for new customers. Third, it inflated the value of other troubled businesses, including its new ventures in fibre-optic bandwidth. Although Enron was founded as an energy company, many of these derivatives transactions did not involve energy at all. ${ }^{194}$

There is also a more difficult element to this issue of accounting classification that makes legal and economic accountability a tenuous line to follow. As MacKenzie, following Wittgenstein, points out in his interpretation of the "ethno-accountancy" of OTC derivatives in Enron, following a rule in accounting is an ambiguous and problematic area, especially when it plays such a central role in a self-regulated market. ${ }^{195}$

The way in which Enron created new derivatives markets also raises issue over the normalising disciplinary structures in international finance. This is a question of analysing human behaviour. Is there an objective basis for an analysis of financial crises, or does human behaviour alter depending on the ideational and material context? If it is the latter, then one issue for the prevention of financial crises is to educate the people involved in derivatives trading and to provide information and signals to avoid the "emergence" of such euphoric episodes that appear again and again throughout financial history.

\footnotetext{
194 Partnoy, Enron and Derivatives ([cited).

195 D. MacKenzie, "A Philosophical Investigation into Enron," Guardian, 22 May 2003.
} 
Objective and reliable financial risk analysis of the kind that can predict financial crises as a result of OTC derivatives trading is not possible unless there are clear laws of human behaviour that can be modelled. If a social constructivist line is to be taken, it is more likely that advances in more sophisticated mathematical models and derivatives instruments will increase volatility as much as they provide greater levels of accuracy within their own epistemological framework.

Enron is a good case in point. The development of complex forms of weather derivative, for example, not only made it possible to give the impression of insuring against an uncertain future, but the development of sophisticated derivatives and financial models provided the basis for the kind of security required for the majority of market-actors wanting to know that their business would not be adversely affected by extreme weather changes. The cultural faith in these sophisticated tools was enough to encourage a wide range of global actors to engage in OTC derivatives contracts. Importantly though, and paradoxically, the security provided by the development of these new tools of risk analysis provided those with speculatory capital a new market in which to profit. Key in this case is that Enron was one of the largest speculators. As one commentator put it, 'derivative contracts formed a Gordian knot at the financial heart of a company that was once America's seventh largest and is now its biggest bust. Those who have chuckled at the regulators' apparent obsession with threat posed by the phenomenal growth in the use of derivatives should recollect the jibes and blush. Not that regulation comes out of this affair with any credit., ${ }^{, 96}$

Moreover, the role of the state in preventing market failure is evident with Enron, as it was with the case of LTCM. 'Federal overseas economic-development agencies have financed or underwritten 18 Enron Corp. projects, exposing U.S.

${ }^{196}$ E. Warner, "As Derivatives Unravel, It's Your Lookout," Ibid., 1 December 2001. 
taxpayers to a total of more than $\$ 1.73$ billion in potential liability, according to agency officials. ${ }^{197}$ Importantly, though, the state did not step in to bailout Enron and protect the many pension schemes, workers investments and what used to be state infrastructure of the energy market in the US. The politics of privatisation and deregulation are stark in this regard. ${ }^{198}$

Despite the demise of Enron itself, this is unlikely to be the end of innovation in the derivatives energy market. As chairman and chief executive of Environmental Financial Products noted in 2002, less than a year after Enron's collapse, '[w]hile the halcyon days of Enron captured huge amounts of attention, the second type of market architecture quietly proceeded to grow, transform and mature into a deep market that is effectively filling the gap left by Enron's collapse. ${ }^{199}$ Making reference to the traditionally multilateral, "voice-brokered" type markets, the New York Mercantile Exchange and the International Petroleum Exchange (IPE), Sandor notes that 'OTC markets continue to thrive and are being transformed by the introduction of new approaches to trading. ${ }^{200}$ Further, he sees indications "towards a "fusion" of these two types of OTC/multilateral markets. ${ }^{201}$

Interestingly, though, rather than offer scepticism of OTC derivatives markets and a call for regulatory change, Sandor sticks with the extreme liberal line that the market is likely to learn from its own history, and that the 'self-regulating

\footnotetext{
${ }^{197}$ Sperry, Power For Sale: Huge Enron Loans Expose Taxpayers ([cited).

198 See R. Blackburn, "Enron and the Pension Crisis," New Left Review 14 (2002). For a critical overview of the role of Enron and its close links with government, see V. Prashad, Fat Cats and Running Dogs: The Enron Stage of Capitalism (London: Zed Books, 2002). 
markets may again enjoy expanded benefits from the market confidence provided by their systems of rules, checks and balances and exposure to external inspection. The results are greater profitability for the survivors and more efficient markets. This ultimately leads to lower transaction costs. Improved efficiency in these markets will help ensure economically rational allocation of energy resources. ${ }^{202}$ The faith in human beings as calculating is obviously a difficult assumption to shake off for those with such a vested interest in this particular type of market system.

Consider, by contrast, Galbraith's notes on the nature of what he calls financial euphoria:

the extreme brevity of financial memory. In consequence, financial disaster is quickly forgotten. In further consequences, when the same or closely similar circumstances occur again, sometimes only in a few years, they are hailed by a new, often youthful, and always supremely self-confident generation as a brilliantly innovative discovery in the financial and larger economic world. There can be few fields of human endeavour in which history counts for so little as in the world of finance. ${ }^{203}$

That historical knowledge should count for so little, is compounded by what Galbraith calls 'the specious association of money and intelligence.'204 The rationalist notion of the division of labour, which provides the basis for cultural faith in the risk analyst as expert, as well as the cultural institution of the corporation, informed by neo-liberal ideology, provide further reasons for financial caution. Galbraith's third point is that 'we compulsively associate unusual intelligence with the leadership of the great financial institutions - the

\footnotetext{
202 Ibid.

${ }^{203}$ Galbraith, A Short History of Financial Euphoria p. 13.

204 Ibid.
} 
large banking, investment-banking, insurance, and brokerage houses. The larger the capital assets and income flow controlled, the deeper and presumed financial, economic, and social perception. ${ }^{205}$

These themes are not restricted to the case of Enron. In fact, very recently the state-controlled Chinese Aviation Oil (CAO) had a US\$550m derivatives trading loss. The Chinese government blamed the company for "irregular speculation". ${ }^{206}$ It is too early to comment on the particulars of this case or exactly what the implications might be, however, it is clear that large financial losses from derivatives trading is not a thing of the past.

\section{Conclusion}

The case of Enron demonstrates how OTC derivatives can be used in a deregulated market economy. It is clear that these tools of risk management can very easily become tools for creating risk in a deregulated market economy, as critics of speculative capital have argued for some time. The chapter has also illustrated that the policy responses within the US has not focused on the role of derivatives, but has instead framed the collapse as an issue of accounting standards and white-collar crime. More fundamentally, however, the faith in "experts" of risk management appears to have remained un-dented, in spite of the fact that the complex mathematical models for risk analysis do not adequately predict the financial behaviour of OTC derivatives traders where increasing volumes of trade and a multitude of different energy markets and "invented" products increase the complexity at a more systemic level. The question of how best to regulation OTC derivatives is therefore left largely in the hands of the "experts" of financial risk management, in spite of a poor track record where

\footnotetext{
205 Ibid. p. 15.

206 M. Dickie and J. Leahy, "China Blames Speculation for CAO Scandal," Financial Times, 10 December 2004.
} 
macro-financial risk is concerned. From this critique of scientific risk management comes an interesting query for the question of regulation: what is the relationship between the epistemological faith in objectivist rationalism to understand and explain financial processes such as OTC derivatives trading, and the vested interests of state and expert actors in policy circles. 


\section{Chapter 4}

\section{HOW IS THE QUESTION OF REGULATION TO BE FRAMED?}

\section{Introduction}

Given the salutary lessons learned from the case of Enron discussed in the previous chapter, the question of how much "control" there is over global finance in general and OTC derivatives in particular is clearly a valid one. A key question is now: how can some form of effective regulation be developed and for whom? This chapter begins by assessing what the question of regulation means in the context of global finance. This leads to a discussion of the various analytic languages IPE offers to demonstrate how various rationales inform the logic of regulatory response. In outlining these analytic languages the discursive relationship between power and knowledge highlights the way risk management practices, such as derivatives trading, are set up. By arguing for and against regulating OTC derivatives trading, this chapter puts forward an argument that the dominance of problem solving theory in risk management practices makes some form of state or inter-state regulation highly desirable, but any such regulation will also require a serious re-evaluation of the role of the "expert", and the technical knowledge they rely on, in the international financial system. Finally, after assesses the question of regulation with regard to broader politicoeconomic, politico-strategic, politico-social and environmental criteria, the chapter puts forward options for different types of regulation.

\section{What does regulation mean in global finance?}

The question of regulation is essentially a question of power and control. According to the Oxford English Dictionary, to regulate is 'to control, govern, or

direct by rule or regulations; to subject to guidance or restrictions; to adapt to 
circumstances or surroundings. ${ }^{207}$ Regulation is generally understood in IPE as a question of state regulation, of imposing laws on a set of practices to ensure that a rule is followed, or at least not broken. The reason for regulation is usually not arbitrary, as reason dictates that there must be logic to any rule, informed by moral, ideological, or technical knowledge. Therefore, any consideration of regulation in international financial markets needs consider the role of the State, of institutions (both national and international), and of knowledge that informs both regulatory policy and financial practices.

As was explored in the introduction, each of the different theories of IPE sees differing conceptions of human nature, or human nurture depending on a range of material and/or ideational factors, as more important that the others. Each analytic language, therefore, puts forward a different ontological understanding of the social world to be understood. This is an important point to make clear, as each analytic account, while often purporting an objective analysis, uses these assumptions of human nature/nurture to make normative claims over how politics and policy should proceed. Therefore, Outlining the various analytical takes on this question clarifies the differing emphasis each approach places on states, markets, information, class, expert discourse, etc.

We have established that neo-liberal cases for self-regulation, which are particularly dominant in informing national and international policy prescriptions, base their economic analysis on what they term "technical" knowledge, devised and purported by specialist "experts". Theirs is a type of analysis that is based on supposedly "objective", "unbiased", and "scientific" explanations of financial behaviour. They might agree with critics that economists and financial analysts track records are not perfect, but they would argue that theirs is as good analysis

207 OED, ([cited). 
as there is likely to be, and better than the alternative of giving up to the unpredictability and uncertainty of the market. Following from this position of faith in "expert" discourse, neo-liberals are particularly concerned with the "inefficiency" any excessive regulation of OTC derivatives would result in. This inefficiency, neo-liberals argue, would be seen in increased bureaucratic "red tape" and would not make the global financial market any safer. Moreover, it is argued that derivatives are needed in the global financial market, as they offer insurance against all sorts of market risks that go with it. How else are we to deal with the uncertainty of economic globalisation?

Furthermore, neo-liberals argue that new forms of financial regulation are neither desirable nor feasible as ways to cope with financial disorder. ${ }^{208}$ 'Any attempt to regulate the international financial markets in a way which would replicate the regulation of national financial markets would be doomed to failure, because it would require the creation of a world government. ${ }^{209}$ This follows from the liberal logic, that views cooperation (from individuals, firms and states) as only following from mutual benefit. Therefore, the authority of any such global regulatory body would be difficult to enforce, not to mention the numerous "inefficiencies" from bureaucracy that such an arrangement would result in.

There are alternatives to this neo-liberal approach of self-regulation, however, and a substantial debate has now developed within IPE to address the question of regulation of the international financial system. 'The debate is concerned with the question of the desirability of the scope and the purposes of regulation in the new global economy, but underlying it is a much deeper and older question -

\footnotetext{
208 A. Gamble, "Debate: The Regulation of Global Finance," New Political Economy 4, no. 3 (1999): p. 410. ${ }^{209}$ Ibid.
} 
whether regulation of a capitalist economy is feasible at all. ${ }^{210}$ Furthermore, Gamble argues that the difference in this debate is not over whether or not there should be a regulatory regime, but where it should be located.

The supporters of new forms of regulation believe that the neoliberal view of regulation and state action, which has been dominant in the past three decades, is far too pessimistic about the possibilities of building on cooperation between states to create international regimes which can effectively regulate. ${ }^{211}$ For instance, John Eatwell argues that a lack of regulation of the international financial market will lead to increased pressures on those states that benefit least from international capital mobility leading to a revival of protectionist and isolationist policies. ${ }^{212}$ In other words, the future of a liberal world order will be put at risk if the continued self-regulation approach to financial trade, such as that in OTC derivatives, is left to carry on. Here, Eatwell, like many other moderate liberals, argues for the incremental development institutions to move to more effective monitoring and control of global capital flows. For instance, the role of institutions such as the Bank of International Settlements (BIS) is viewed as a good example of an institution that operates outside of state control, but is able to offer respected opinion on financial stability that is taken seriously by both states and firms.

Girvan and Griffith-Jones agree about the need to regulate the financial markets, but they argue for more inclusive political forms to manage the regulation, and for regulation to be significantly tighter. They argue for an International Monetary Authority, which would supersede the national monetary authority of

\footnotetext{
210 Ibid.: p. 409.

211 Ibid.

${ }^{212}$ J. Eatwell and L. Taylor, eds., Global Finance at Risk: The Case For International Regulation (New York: The New Press, 2000).
} 
existing states by issuing a global single-currency, imposing taxation on shortterm financial flows and controlling international financial flows. ${ }^{213}$

By contrast, the mercantilist is concerned with the economic welfare of their state as it affects state sovereignty in terms of economic decision-making and military expenditure and power politics in general. Believing that humans are essentially bad and that the nation-state is the natural and legitimate actor in the international political economy, mercantilists push for greater state control of the way financial markets operate. Accordingly, OTC derivatives may not be desirable at all, or there may be some kind of state tax imposed on every trade to dissuade speculatory trading. This would almost certainly have the effect of limiting the development of new types of derivative financial contracts, ensuring their purpose was more closely aligned to that of insurance against market uncertainty. However, a state is only likely to move for this kind of regulatory protection if they perceive a risk to their economic power to exist. In the case of most Western states, including the US, this has not been the case. Rather, the type of reactive response to financial crises, that was discussed in chapter one, appears to be the norm rather than the exception in the history of financial capitalist expansion.

Furthermore, for state actors to have that kind of autonomy of financial capital would require a significant shift in power relations towards state-control of economic processes in general. The issue here is that if the state is to regulate in isolation from moves to international regulatory institutions and the will of large financial institutions, whether this would really protect the single state that had made that move. The complex web of finance that was discussed in chapter one means that any move to reverse this liberalised and integrated financial market

213 See Gamble, "Debate: The Regulation of Global Finance." 
would require a forceful and revolutionary movement of more than state-led scope. As Coleman notes,

If [the] state is capable only of supervising and regulating the activities of the given global firm within its own territory, it will have a very partial, and arguably, inadequate view of the financial health of that firm. What is more, the nationstate might worry it its supervision and regulation were to appear too demanding to a given number of global firms, they might simply transfer aspects of their business to another financial centre where the regulatory touch was more to their liking. The signing and execution of over-the-counter derivatives contracts can be physically located in a number of places.'214

The issue here is one of "competitive laxity" among national regulatory authorities, as the era of economic globalisation means that state policy follows the market rules of competitive advantage and disadvantage. However, the state is certainly not "powerless" in this situation, as Weiss has explained using the notion of 'transformative capacity' to 'help explain why some states are more successful than others in steering economic adjustment. ${ }^{, 215}$ For Weiss, the focus ought to be on how state actors and industry representatives coordinate and agree to cooperate towards broader goals. 'Of central importance is the state's ability to use its autonomy to consult and to elicit consensus and cooperation from the private sector. Through its linkages with key economic groupings, the state can extract and exchange vital information with producers, stimulate private-sector participation in key policy areas, and mobilise a greater level of industry collaboration in advancing national strategy. ${ }^{216}$

\footnotetext{
214 W. D. Coleman, "Governing Global Finance: Financial Derivatives, Liberal States, and Transformative Capacity," in States in the Global Economy: Bringing Domestic Institutions Back In, ed. Linda Weiss, Cambridge Studies in International Relations (Cambridge: Cambridge University Press, 2003), p. 271.

215 Ibid., p. 272.

216 L. Weiss, Myth of the Powerless State (Ithaca: Cornell University Press, 1998) p. 39.
} 
However, as Coleman notes in his analysis of global governance initiatives, 'governments have difficulty cooperating in the international realm and many of them are unwilling to extend their rule-making capacity beyond the nation-state. Both of these factors are relevant to the governance of OTC derivatives. ${ }^{217}$ Cooperation between states is made further problematic due to the complex nature of the OTC derivatives market and the technical nature of issues such as disclosure, transparency, and the actual derivatives products themselves. With general state support for market forces, states are not so concerned with a bit of "market discipline", however, the issue of systemic risk is one that states are anxious about. For that matter, so are private actors, ${ }^{218}$ which makes the moderate liberal argument for increased cooperation between states and markets on regulatory issues valid, provided they agree on the nature of the problem.

By contrast, Marxists are keen to emphasise how tied up with the interests of capital (including finance capital) state structures are. In this regard, and because Marxists believe that the structures of capitalism determine the way humans behave, any real reform of financial capital flows is more likely to be temporary, and will fail to restrain the development and trade in financial contracts such as derivatives. Moreover, classical Marxists are likely to welcome derivatives as they are seen to speed up the collapse of wider capitalist processes - an inevitable, but not necessary predictable outcome of these unsustainable politico-economic practices. $^{219}$

\footnotetext{
${ }^{217}$ Coleman, "Governing Global Finance: Financial Derivatives, Liberal States, and Transformative Capacity," p. 274.

218 Note, for instance, the establishment of "private regimes" such as the International Securities and Derivatives Association (ISDA.

${ }^{219}$ From a classical Marxist account of international finance, capitalism has not altered significantly so much as expanded, and OTC derivatives might be seen as a logical extension of capital as it searches for more markets and continued growth. In this regard, one need look no further than Hilferding for an understanding of the power of capital. R. Hilferding and T. B. (ed), Finance Capital: A Study of the Latest Phase
} 
These issues certainly make clear the plight of state agency in a globalising financial economy. To frame this as a reified dichotomy between state and market forces is not only over-simplistic, however, it is also dangerously inaccurate. For instance, according to the more critical approach offered by postmodernists and post-structuralists, the relationship between knowledge and power is so intertwined that "risk" is already a form of regulation. This is a crucial point to note as a critique of neo-liberal economic theory, as the case for regulation is essentially set up on the basis of "what the risks are" from derivatives trading. In this respect, we are left with the experts telling us the credit risks, legal risks, counterparty risks, etc., that exist in the derivatives market. In other words, the type of social and economic practices, accounting classifications, and tools of risk management have in-built regulatory mechanisms in that they develop certain logics in practice. Key here are the normalisingdisciplinary practices that Foucauldians ${ }^{220}$ talk about, and Gill highlights in his discussion of market civilisation. ${ }^{221}$

In this regard, the role of OTC derivatives fits within wider questions of governance and control in the international financial system, as Deuchars notes. '[T] he drive to standardise and rationalise financial systems immediately raises questions to do with power. Whose standards are to be implemented? Whose

\footnotetext{
of Capitalist Development, trans. Morris Watnick and Sam Gordon (London, Boston and Henley: Routledge \& Kegan Paul, 1981; reprint, 1981).

${ }^{220}$ I refer here to authors such as Deuchars and de Goede, as well as the wider governmentality literature outside the discipline of IPE. For instance, see M. Douglas, "Governability: A Question of Culture," Millennium: Journal of International Studies 22, no. 3 (1993), W. Larner, "Neo-liberalism: Policy, Ideology, Governmentality," Studies in Political Economy, no. 63 (2000), P. Miller and N. Rose, "Governing Economic Life," Economy and Society 19, no. 1 (1990), N. Rose, "Governing by Numbers: Figuring out Democracy," Accounting, Organizations and Society 16 (1991).

221 S. Gill, "Globalisation, Market Civilisation, and Disciplinary Neoliberalism," Millennium: Journal of International Studies 24, no. 3 (1995).
} 
best practices should be adopted? How were these best practices derived, and are they universally appropriate at all places at all times? ${ }^{222}$ Therefore, the power/knowledge relationships that constitute the practices of risk management do regulate the behaviour of financial players at a more subtle level. Thus, "control" of financial processes needs to take into consideration the ways in which government and international institution policies, social processes, market structures, as well as the construction of new financial instruments and financial risk management technologies affect behaviour in global derivatives markets.

This understanding of governance as operating at multiple levels and through diffuse means contributes to other critical understandings of governance provided by authors such as Hewson and Sinclair. ${ }^{223}$ Langley's analysis of the 'everyday life of finance' outlines the importance of understanding the governance of large groups of people more in terms of the complex social relations that are played out here. In this regard, 'what IPE scholars tend to label global financial governance (i.e. the institutions of the "new international financial architecture") already and at once assumes and constructs the identity of the community that is to be governed. The construction of the identity of the investor' and the rational 'good financial citizen' discussed above - prioritised and naturalised in a disciplinary discourse - is, then, central to global financial governance. 224

\section{The question of control: structure or agency?}

The central importance of the stability of the international financial system is noted by Tickell and Clark. 'To a greater extent than, at least, any other over the

\footnotetext{
222 Deuchars, The International Political Economy of Risk p. 222.

${ }_{223}$ M. Hewson and T. J. Sinclair, eds., Approaches to Global Governance Theory, SUNY series in Global Politics (Albany: State University of New York Press, 1999).

${ }^{224}$ Langley, "The Everyday Life of Global Finance," p. 21.
} 
past 60 years, a complex series of interlinked policy decisions and economic circumstances means that the health of the global economy relies upon the systemic stability of the financial sector. ${ }^{225}$ The key question this thesis has posed is: is control at a structural level possible in global OTC derivatives markets?

The question of control is also a question of human agency, be it that of the individual, of the firm, or of the state. Is it possible, for instance, for the actions of a few to alter the overall outcome of a process in a way that is understood in clearly causal terms? In other words, can the financial world control it's own collective destiny? Or, more specifically, can individuals and firms control their own destiny in the global OTC derivatives market. The analysis provided in this thesis so far suggests that the answer is no. This is in clear antithesis to the argument put forward by neo-liberals that financial liberalisation (including the liberalising of global OTC derivatives trading) is necessary, and that risk management "experts" are those best equipped to deal with the task of regulating their exchange. They may well be the best equipped, however, the evidence of their "control" over such processes at a systemic level is undermined by the collective actions of many financial players, and that at a macro level "risk" is very difficult to document in calculable terms. In other words, systemic risk is very difficult to predict.

More of the global economy is becoming embroiled in this global financial "casino". Controlling this globalised system relies on constructing value and disciplining behaviour at a number of levels, from the "high levels" of financial policy and regulation, to the regulation of accounting practices, to the

\footnotetext{
225 A. Tickell and G. Clark, "New Architechtures or Liberal Logics? Interpretating Global Financial Reform," Future Governance Paper, no. No. 3 (2001): p. 1.
} 
construction of classificatory systems and risk management techniques. It also relies on disciplining the behaviour of an increasing number of people throughout the world, so as to make sure they comply by the rules of the financial market place that is replacing more traditional mediums of exchange.

Risk managers have highly complex formula upon which to base their decisions for trade in large volumes of derivatives contracts. Very few people actually understand the complex formula at the heart of these derivatives contracts, instead relying on the assumption that everyone else believes these to be accurate representations of the "risks" involved in trading in derivatives. "Risk" is understood to be something that exists exterior to and independent from the analysts gaze. It is certainly not accepted that "risk" is influenced by the theory of "risk" itself. Moreover, very few people involved in risk management practices understand the construction of value and classificatory systems at the heart of central models such as the Black-Scholes model. Instead, what Maurer calls the "black-box" of finance is left unquestioned. Inside this black-box resides a formula that encompasses the historical construction of statistical knowledge and the classification of human behaviour based on the assumption of human behaviour as driven by rational, self-interest, narrowly understood. It hides the bell-curve, the assumption of the l'homme moyen that is implicit in liberal analysis, and the notion that these are factual accounts of financial behaviour, objectively understood and independent of value-laden bias.

We've also noted serious limits to the way risk (understood in the objectivist rationalist terms that are prevalent in expert and policy circles) is able to provide a framework for prediction and control at complex, global, and systemic levels. Therefore, we are left with a few different options. First, can the risk models be adapted to deal with the increasing complexities of the global financial market? If 
so, then we need to give even more control to the financial experts, and possibly provide regulatory oversight to make sure transparency and accountability remain key parts of the financial service. This option stays within the liberal framework of allowing financial markets to operate freely, without hindrance from the state. Second, if the risks cannot be known at this complex and systemic level, then we have to ask ourselves what role we are to give these financial experts in society. Do we, a) provide them with the lessons of the limits there are to objectivist rationalism in understanding uncertainty, allowing for financial players to recognise more clearly the limits to the "safe trading" they can carry out. Perhaps this will lead to more diversified investments and self-imposed restrictions on financial speculation? However, if financial history is to have any credence, it would appear that expect restraint where the potential for quickly-gained profit is concerned is optimistic at best, or, perhaps more accurately, just downright ignorant to the driving motivators of greed and crowd behaviour.

There is a key political question here of power, and who has it. We have already established that the "experts" of financial risk management may not have the kind of control neo-liberal analysts believe them to. We might even go so far as to call this the neo-liberal "illusion of control". However, when was the last time you saw a financial analyst or economist lose their job as a result of incorrect predictions? Moreover, due to the concentration of wealth in the hands of a relatively small number of large financial institutions, most states will not allow them to go bankrupt in the way they allow small businesses to go bankrupt. Rather, as was the case in LTCM, the state will often step in to ensure that damage to "fundamental" international financial institutions is limited.

What other options do we have that might offer better control and a greater level of "certainty" at the macro level of the international financial system? What 
about through further calls for self-regulation? In other words, through agency rather than structure? In this liberal vein, what is required is better transparency and accountability of derivatives practices. Therefore, greater disclosure and capital requirements might become part of regulatory policy. This may well prevent instances such as Enron, Barings and Orange County becoming exacerbated, but this approach ignores the nature of "financial euphoria" that surrounds new financial products such as derivatives. In this regard, a belief that trade in OTC derivatives can follow a path of continued growth with relatively small systemic risk ignores historical and contemporary evidence of trade in derivatives and financial instruments and the crowd mentality that has been evident in all of these episodes. This is an essential element of human nature that "scientific" risk models leave out of their equations. Rather, in a liberalised global economy that allows for betting on almost any kind of asset or security price imaginable, and for such massive gains, the general trend of increased derivatives trading and its tenuous construction of value is likely to continue.

What about through international institutions? There are significant multi-lateral moves to increase cooperation on international financial regulation, such as the Basel II Accord. And that there has been a dramatic growth in international organisations and NGOs, makes for strong argument here. ${ }^{226}$ The role of the G20 in particular has been touted as a key institution for focusing on aspects of financial stability, economic growth and development. However, any significant multilateral accords need to get the full backing of the US, as this is the key state to consider. The US, under the Bush administration in particular, has made clear its preference for free market policies, and a push for deregulation of financial markets, as evidenced by the CFMA of 2000. Secondly, most international

\footnotetext{
${ }^{226}$ N. Woods, "Globalization and International Institutions," in The Political Economy of Globalization, ed. Ngaire Woods (New York: St Martins Press, 2000), p. 204.
} 
institutions look to carry on the current trend of liberalising global derivatives trading, and therefore ignore the fundamental problem that lies behind the problem of system risk - that of the sheer volume and speed of OTC derivatives trading, and the increased volatility resulting from this.

Another option purported by moderate liberals some kind of Tobin tax on each derivatives contract. ${ }^{227}$ The idea of the Tobin tax is to give a disincentive to "speculative" trade in OTC derivatives, by making a small percentage charge on each contract. There are two benefits to such an approach. First, the money gained from this tax can be channelled to any number of "good causes", or even channel this money into state funds to prepare for large-scale bankruptcies that threaten various public savings and pensions schemes. Second, it is believed that the disincentive of Tobin tax would be enough to curb a great deal of speculative trade, and that this would limit the volatility that currently prevalent in global OTC derivatives trading. This is not a measure on its own, and again it is a policy that has to fit within moves for greater multilateral cooperation, however, it does avoid the problem of having to comprehend global trade in systems terms.

Of course, the most extreme option would be to ban trade in OTC derivatives altogether. This would eradicate the problem of systemic risk created by trade in derivatives. There is the liberal argument, however, that derivatives in their role as a form of risk management, do offer insurance against the uncertain market forces of a deregulated global financial market. For instance, currency volatility offers as much of a risk to many banks and firms. ${ }^{228}$ Therefore, any move to ban OTC derivatives would best be part of a general move to regulate the global economy.

227 See H. Patomaki, Democratising Globalisation: The Leverage of the Tobin Tax (London: Zed, 2001).

${ }^{228}$ For instance, see J. Stiglitz, Globalization and its Discontents (London: Allen Lane, 2002). 


\section{What other criteria for regulation?}

There are many measures by which to assess the purpose of regulation. Scholte sees global finance as needing to meeting goals of 'efficiency, stability, social justice, ecological integrity and democracy. ${ }^{229}$ This next section briefly assesses each of these criteria with relation to trade in OTC derivatives.

This thesis has so far focused on the stability issue, as this is key not only to neoliberal accounts but also to the more critical approaches. Therefore, let us first assess this question of regulation with relation to systemic risk. According to the analysis of this thesis, volatility of the OTC derivatives market is impossible to escape at the macro level. This means that we have to live with uncertainty all the time. There is a very interesting question to be asked here regarding how much (economic) uncertainty a society can bear, and at what consequence? ${ }^{230}$ While the global trade in OTC derivatives appears very abstract from the lives of most people, the increasing presence of global finance in everyday lives and the liberal push for "market freedoms" means that the question of the stability of OTC derivatives markets is a politico-social one as well as a politico-economic one.

The measure of efficiency is a key one to liberal accounts of money and finance. OTC derivatives, in this regard, offer private market actors a form of insurance that is more flexible and "responsive" that anything offered under a more socialist or regulated economic environment. However, "efficiency" will depend on the measures one has for it. In the case of Enron, energy and OTC derivatives markets were deregulated partly in order to increase the overall

\footnotetext{
229 J. A. Scholte, "Governing Global Finance," in Governing Globalization: Power, Authority and Global Governance, ed. David Held and Anthony McGrew (Cambridge: Polity, 2002), p. 197.

230 See S. Dunant and R. Porter, eds., The Age of Anxiety (London: Viagro Press, 1996).
} 
efficiency of the system creating growth and innovation, to use liberal parlance. This logic extended to India and the UK among others, where water and energy plants were subjected to the benefits of such free market flexibility and expertise. However, the spectacular demise of Enron and the gross social and economic effects it has had on these markets certainly calls for a critical framing of the notion of "efficiency".

In this regard, the economic human rights of citizens to "free and fair" markets might well be seen to undermine other rights to control over local water supplies, energy technologies and any other areas of social (as well as economic) concern that trade in OTC derivatives can become embroiled in. As with many of these criteria, these are questions that are intricately tied up with broader processes of economic globalisation. The power that is given to large Western banks and firms in this structure, and through OTC derivatives markets, disproportionately advantages the. This is of particular concern to a growing number of people, as the ties between every day life and global finance renders the question of democratic control seemingly problematic. Furthermore, and for similar reasons, the ecological integrity of speculative trade in OTC derivatives is questionable. For instance, the recently approved Kyoto protocol creates an opportune moment for options trading in carbon emission credits. Here, as with other social and political concerns, the ecological impact of such trading is far from a priority of OTC derivatives markets.

Therefore, given that there is no "natural" logic to the evolution and role of derivatives in capitalism; given that there is little evidence to suggest that derivatives can be "controlled" by some form of "expert" self-regulation due to the speculative way in which these instruments are used; and coming from a critical perspective that views the speculative use of OTC derivatives trading in 
more parasitic than productive terms; the option of significant state and interstate regulatory intervention appears apt.

\section{Conclusion}

This chapter has outlined the predominance of liberal modes of self-regulation in OTC derivatives markets around the world. This is particularly the case in countries such as the US, the UK and Singapore, which are key financial centres and the focal point for most trade in OTC derivatives. This chapter has argued that, rather than "expert" knowledge of financial risk management providing a solid and legitimate basis for self-regulation of OTC derivatives trading, the control that can be achieved via human agency appears severely undermined by the scale and scope of global finance. Therefore, the call for greater regulation of OTC derivatives trading at an inter-state level appears legitimate, based on a range of criteria, including financial stability, social justice, ecological integrity and democracy. 
Conclusion

\section{WHAT NOW FOR OTC DERIVATIVES TRADING?}

This thesis has addressed the question of whether over-the-counter (OTC) derivatives should be regulated, and how best to do so. The question of regulation is ultimately a political one, though, given the dominant politicoeconomic structures that drive financial policy, arguments tend to be based on the advice of "experts" in the technocratic structure of the neo-liberal market. In this regard, most discussion of financial regulation in past decade has been in response to concerns over control at the systemic level of the international financial system. At base, therefore, the question of regulating OTC derivatives is one of structure versus agency, in that it is a question of how control can be maintained over politico-economic processes at the international, or even global, level. How these politico-economic processes are understood depends on how we understand the global financial market. This thesis has employed a variety of analytic languages to illustrate the limits to a liberal account, informed by objectivist rationalist analyses, of the politico-economic dimension of world affairs.

Chapter one showed how the question of regulation is contextualised within a specific market structure, that not only measures the need to regulate based on what is perceived to be a "risk" to market structure, but that this market structure also serves specific interests and ignores many others that well might be considered more important by large proportions of the world's population. Importantly, the way the notion of "risk" is framed here provides a key basis for expert discourse, and is central to an understanding of the way in which the 
market is understood by them, and, just as illuminating, the ways in which the market is not understood.

The purpose of chapter two was to outline the logic of derivatives trading, and to critically assess how derivatives are understood. By drawing on post-structuralist interpretations of "risk" and finance, the chapter illustrated how scientific risk management relies on social constructions, and that while they tend to be very effective at smaller and more immediate levels of analysis, such as those provided in basic credit risk analysis, claims to objectivity, calculability and predictability at the macro level appear undermined, as is evident in attempts to quantify systemic risk in OTC derivatives trading.

Chapter three illustrated, by way of case study, some of the limits to objectivist rationalism in the analysis of trade in OTC derivatives. By outlining the way Enron developed and used derivatives contracts, and how it relied on specific financial risk models, and also taking into account the regulatory context of the US and other international financial markets, the chapter showed some of the following key problems: trade in products that are beyond its expertise; growth in trade of OTC derivatives contracts at a rate too great to be monitored by either the Enron corporation or state and inter-state regulators; problems of accounting classification; potential for systemic risk, and the role of the state post-collapse of the Enron empire. It also raised issue with responses offered by economic and state experts.

Chapter four critically assessed the question of regulating OTC derivatives trading in light of the analysis presented in this thesis. By asking what regulation means, we can move beyond basic state versus market dichotomies that tend to oversimplify the complex human interactions that are going on here. The post- 
structuralist critique offers us a way of understanding the power/knowledge contests that constitute an important part of the contextualisation of present-day derivatives trading. The notion of "risk", in this regard, already forms an important way of regulating financial practices, both through the creation of expert discourse that informs the behaviour of financial actors through the faith provided in complex mathematical models that frame their possible actions within a rationalist framework, and through the normalising disciplinary effects of the wider politico-economic structures that provide rules to be followed by the wider operations of society.

The dominant accounts of international political economy, in particular neoliberal accounts, offer what Cox calls problem-solving theories. They are problem-solving because they focus on the behaviour of agents within a particular ontological framework. Derivatives trading, which is a logical extension of the liberal market structure, is understood by most theorists and analysts in primarily rationalist terms. Because humans are assumed by liberals to be primarily calculating, liberal models analyse and predict human behaviour according to models that make use of historical information and derive likely events from it. They are used to predict what prices for assets and securities might be at a particular date in the future, laying the foundation for the derivative financial instruments that are traded between those wishing to insure themselves against the uncertainty of the market.

The way in which these financial contracts are traded (while remembering that the underlying assets or securities are often not traded) raises question as to whether "risk management" or speculation is the driving force behind the phenomenal growth in the volume of OTC derivatives over the last thirty-odd years. Not only is the value of derivatives increasingly abstracted from the value 
of the underlying assets, but the trade in these instruments is in such great volume and velocity that one has to ask how best to understand and explain the behaviour of the financial actors involved. However, understanding the "nature" of derivatives trading requires moving beyond a simple dichotomy of "insurance" versus "speculation". The construction of risk management techniques within the processes of financial capitalism has been the subject of analysis from poststructuralist perspectives that seek to understand the role of a particular expert discourse in the creation of an "illusion of control" over global financial processes.

If a technocratic society is desired, then experts are required. This thesis demonstrates that "experts" need to be more critically, and socially aware, of the relevance of their models for risk management. However, "experts" may not be capable of providing the kind of knowledge necessary for control in a deregulated financial market, due to the unpredictable nature of human behaviour.

While other analytical approaches might not offer an alternative to the neo-liberal models of risk management employed in the many financial houses across the world, a "critical theory" approach, including the analyses of post-structuralist as well as other social constructivist, feminist, neo-Marxist, ecologist and indigenous perspectives, illustrates some key limits to the problem solving theories that focus only on individual behaviour. By drawing from critical histories, for instance, theorists of IPE are able to show that the basis for the many analytic models used by risk analysts, do not account for the way their "facts" are historically and socially constructed.

The conclusion of this thesis is that control over OTC derivatives trading is not possible in a self-regulatory system that relies on experts, as neo-liberals think. 
History tells us that prudential restraint is not a strong feature of human behaviour where there is perceived to be an easy way of making money. Trade in OTC derivatives provide exactly this kind of opportunity, and the cultural framework that both legitimises and encourages this activity is unprecedented.

But what kind of regulation should be employed depends then on what is possible and what is desirable? It is possible to have state, inter-state or even global regulation of derivatives trading, if the right political institutions are set in place. The likelihood that they will be will depends on what one believes of human nature and nurture. What is desirable depends on the end one seeks. I would argue that OTC derivatives trading in such large volumes and at such great velocity do not offer any significant benefit to the wider market. This conclusion might be likened to that of Marx, who believed that financial speculators were parasites on society, offering little and gaining much in terms of financial reward. ${ }^{231}$ My analysis parts company with Marx's in terms of its analytic interpretation of the nature of market practices, however, I do believe it is necessary to restrict the role of such unproductive and uncreative pursuits and to meet more fundamental needs and wants than those of desire and greed.

${ }^{231}$ K. Marx, Capital, trans. David Fernbach, vol. 3 (New York: Vintage, 1981) Ch. 33. 


\section{BIBLIOGRAPHY}

Amin, A., and R. Palan. "Towards a Non-Rationalist International Political Economy." Review of International Political Economy 8, no. 4 (2001): 559-577.

Balaam, D. N. Introduction to International Political Economy. New Jersey: Prentice Hall, 1996.

Batson, N. Second Interim Report, Court-Appointed Examiner, In Enron, Doc. No. 9551 5 March 2003 [cited 11 November 2003]. Available from http://www.elaw4enron.com.

Baudrillard, J. The Mirror of Production. Translated by Mark Poster. St. Loius: Telos Press, 1975.

- For a Critique of the Political Economy of the Sign. Translated by Charles Levin. St Louis: Telos Press, 1981.

BBC. The Enron Collapse BBC, 8 July 2004 [cited 10 August 2004]. Available from http://news.bbc.co.uk/1/hi/business/3398913.stm.

Beynon, R., ed. The Icon Critical Dictionary of Global Economics. London: Icon Books, 1999.

BIS. "BIS Quarterly Review." Geneva: Bank of International Settlements,2004.

Black, F., and M. Scholes. "The Pricing of Options and Corporate Liabilities." Journal of Political Economy 81 (1973): 673-654.

Blackburn, R. "Enron and the Pension Crisis." New Left Review 14 (2002).

Blyth, M. "Same as it Never Was: Temporality and Typology in Varieties of Capitalism." Comparative European Politics, no. 1 (2003): 215-225.

Bougen, P. D. "Catastrophe Risk." Economy and Society 32, no. 2 (2003): 253-274. 
Buchan, J. Frozen Desire: The Meaning of Money. New York: Farrar Straus Giroux, 1997.

Chancellor, E. Devil Take The Hindmost: A History of Financial Speculation. New York: Farrar, Straus, Giroux, 1999.

Cilliers, P. Complexity and Postmodernism: Understanding Complex Systems. London and New York: Routledge, 1998.

Cohen, B. "Money in a Globalized World." In The Political Economy of Globalization, edited by Ngaire Woods. New York: St Martins Press, 2000.

Coleman, W. D. "Governing Global Finance: Financial Derivatives, Liberal States, and Transformative Capacity." In States in the Global Economy: Bringing Domestic Institutions Back In, edited by Linda Weiss. Cambridge: Cambridge University Press, 2003.

Cox, R. W. "Critical Political Economy." In International Political Economy, edited by Bjorn Hettne, 31-45. Halifax: Fernwood Books Ltd, 1995.

d'Alambert, J. L. R. Preliminary Discourse to the Encyclopedia of Diderot. Translated by Richard N. Scwab. Chicago: University of Chicago Press, 1995.

Day, J. Money and Finance in the Age of Merchant Capitalism. Oxford: Blackwell Publishers, 1999.

Dean, M. "Risk, Calculable and Incalculable." In Risk and Sociocultural Theory: New Directions and Perspectives, edited by Deborah Lupton. Cambridge: Cambridge University Press, 1999.

Descartes, R. Discourse on Method. Translated by John Veitch. London and New York: J. M. Dent, Dutton, 1975.

Deuchars, R. The International Political Economy of Risk: Rationalism, Calculation and Power: Ashgate, 2004.

Dickie, M., and J. Leahy. "China Blames Speculation for CAO Scandal." Financial Times, 10 December 2004. 
Dodd, R. "Untangling Enron: The Reforms We Need." Challenge, March-April 2002, 67-76.

Douglas, M. "Governability: A Question of Culture." Millennium: Journal of International Studies 22, no. 3 (1993): 463-482.

Dunant, S., and R. Porter, eds. The Age of Anxiety. London: Viagro Press, 1996.

Eatwell, J., and L. Taylor, eds. Global Finance at Risk: The Case For International Regulation. New York: The New Press, 2000.

Ehrenberg, R. Capital and Finance in the Age of the Renaissance: A Study of the Fuggers and Their Connections. Translated by H. M. Lucas. New York: Augustus M. Kelley, Bookseller, 1963.

Enloe, C. Bananas, Beaches and Bases: Making Feminist Sense of International Politics. Berkeley: University of California Press, 1989.

Foucault, M. Power/Knowledge: Selected Interviews and Other Writings 1972-1977. Translated by Colin Gordon, Leo Marshall, John Mepham and Kate Soper. Brighton: Harvester Press, 1980.

—. "Nietzsche, Genealogy, History." In The Foucault Reader: A Critical Introduction to Foucault's Thought, edited by Paul Rabinow. London: Penguin, 1991.

Friedman, M. "The Methodology of Positive Economics." In Essays in Positive Economics. Chicago: University of Chicago Press, 1953.

Galbraith, J. K. A Short History of Financial Euphoria. New York: Whittle Books, 1990. Reprint, 1993.

Gamble, A. "Debate: The Regulation of Global Finance." New Political Economy 4, no. 3 (1999): 409-410.

Gibbs, G. "Costs Begin to Mount on This Side of the Pond." Guardian Unlimited, 30 November 2001. 
Gibbs, G., J. Treanor, and R. Wray. "1,100 UK Jobs Go In Enron Collapse." Guardian, 1 December 2001.

Gill, S. "Epistemology, Ontology, and the 'Italian school'." In Gramsci, Historical Materialism and International Relations, edited by Stephen Gill, 21-48.

Cambridge: Cambridge University Press, 1993.

. "Globalisation, Market Civilisation, and Disciplinary Neoliberalism." Millennium: Journal of International Studies 24, no. 3 (1995).

—. "Finance, Production and Panopticism: Inequality, Risk and Resistance in an Era of Disciplinary Neo-Liberalism." In Globalization, Democratization and Multilateralism, edited by Stephen Gill. Basingstoke: Macmillan, 1997.

Gill, S., and D. Law. The Global Political Economy: Perspectives, Problems, and Policies. Baltimore: The John Hopkins University Press, 1988.

Gill, S., and J. H. Mittelman, eds. Innovation and Transformation in International Studies. Cambridge: Cambridge University Press, 1997.

Gilpin, R. Global Political Economy: Understanding the International Economic Order. Princeton and Oxford: Princeton University Press, 2001.

Goede, M. d. "Discourses of Scientific Finance and the Failure of Long-Term Capital Management." New Political Economy 6, no. 2 (2001): 149-170.

Goede, M. D. "Beyond Economism in International Political Economy." Review of International Political Economy 29 (2003): 79-97.

Goede, M. d. "Repoliticizing Financial Risk." Economy and Society 33, no. 2 (2004): 197-217.

Goldsmith, R. W. Premodern Financial Systems: A Historical Comparative Study. Cambridge: Cambridge University Press, 1987.

Green, S. "Negotiating with the Future: The Culture of Modern Risk in Global Financial Markets." Environment and Planning D: Society and Space 18 (2000): 77-89. 
Hacking, I. The Emergence of Probability. London: Cambridge University Press, 1975.

Hall, P. A., and D. Soskice. Varieties of Capitalism: The Institutional Foundations of Comparative Advantage. Cambridge: Cambridge University Press, 2001.

Hayek, F. A. Road to Serfdom. London: Routledge and Keegan, 1944.

Heilbroner, R. The Worldly Philosophers: The Lives, Times and Ideas of the Great Economic Thinkers. Revised 7th Edition ed. London: Penguin Books, 2000. Reprint, 1999.

Helleiner, E. States and the Re-emergence of Global Finance. Ithaca, New York: Cornell University Press, 1994.

Henwood, D. Wall Street: How it Works and for Whom. New York: Verso, 1997. Reprint, 1998.

Hewson, M., and T. J. Sinclair, eds. Approaches to Global Governance Theory. Edited by James N. Rosenau, SUNY series in Global Politics. Albany: State University of New York Press, 1999.

Hilferding, R., and T. B. (ed). Finance Capital: A Study of the Latest Phase of Capitalist Development. Translated by Morris Watnick and Sam Gordon. London, Boston and Henley: Routledge \& Kegan Paul, 1981. Reprint, 1981.

Hollingsworth, J. R., and R. Boyer, eds. Contemporary Capitalism: The Embededdness of Institutions. New York: Cambridge University Press, 1997.

Hollis, M., and S. Smith. Explaining and Understanding International Relations. Oxford: Clarendon Press, 1990.

Horheimer, M. Critique of Instrumental Reason: Lectures and Essays Since the End of World War II. New York: The Seabury Press, 1947.

Horkheimer, M., and T. Adorno. Dialectic of Enlightenment. Translated by John Cumming. New York: Herder and Herder, 1972. Reprint, 1972.

Hosking, P. "The Business." New Statesman, 24 March 2003. 
Jacobsen, J. K. "Much Ado About Ideas: The Cognitive Factor in Economic Policy." World Politics 47, no. 2 (1995).

Jameson, R. Enron's Off-Balance Machine ERisk, December 2001 [cited 5 July 2004]. Available from http://www.erisk.com/ResourceCenter/Features/news feature2001-1212.pdf.

Kindleberger, C. P. Manias, Panics, and Crashes: A History of Financial Crises. Revised Edition ed. New York: Basic Books, Inc., Publishers, 1989. Reprint, 1989.

Kirshner, J. "Money is Politics." Review of International Political Economy 10, no. 4 (2003): 645-660.

Kitschell, P. L., G. Marks, and J. D. Stephens, eds. Continuity and Change in Contemporary Capitalism. Cambridge: Cambridge University Press, 2000.

Knight, F. H. Risk, Uncertainty and Profit. New York: Sentry Press, 1964.

Krasner, S. "The Accomplishments of International Political Economy." In International Theory: Positivism and Beyond, edited by Steve Smith, Ken Booth and Marysia Zalewski. Cambridge: Cambridge University Press, 1996.

Laffey, M., and J. Weldis. "Beyond Belief: Ideas and Symbolic Technologies in the Study of International Relations." European Journal of International Relations 3, no. 2 (2000).

Langley, P. World Financial Orders: An Historical International Political Economy. London: Routledge, 2002.

—. "The Everyday Life of Global Finance." IPEG Papers in Global Political Economy (2003).

Larner, W. "Neo-liberalism: Policy, Ideology, Governmentality." Studies in Political Economy, no. 63 (2000): 5-25.

Lewis, M. Liar's Poker. London: Hodder and Stoughton, 1989. 
Ludger, H., and J. Clifford W. Smith. "Controlling Risks in Derivatives Markets." The Journal of Financial Engineering 4, no. 2 (1995).

MacKenzie, D. "Physics and Finance: s-terms and Modern Finance as a Topic for Science Studies." Science, Technology, and Human Values 26, no. 2 (2001): 115-144.

. "A Philosophical Investigation into Enron." Guardian, 22 May 2003.

Martin, P. How to Expect the Unexpected Financial Times, 13 March 2002 [cited 6 December 2004]. Available from http://specials.ft.com/enron/FT3SQT8M0XC.html.

Marx, K. Capital. Translated by David Fernbach. Vol. 3. New York: Vintage, 1981.

Maurer, B. "Repressed Futures: Financial Derivatives' Theological Unconscious." Economy and Society 31, no. 1 (2002): 15-36.

McGoun, E. "Hyperreal Finance." Critical Perspectives on Accounting 8, no. 1/2 (1997): 97-122.

Michaels, J. W. "Did the Babylonians have an SEC?" Forbes, August 15 1994, 10.

Milbank, J. Theology and Social Theory: Beyond Secular Reason. Cambridge, Massachusetts: Blackwell, 1990. Reprint, 1994.

Miller, P., and N. Rose. "Governing Economic Life." Economy and Society 19, no. 1 (1990): 1-31.

Neal, L. The Rise of Financial Capitalism: International Capital Markets in the Age of Reason. Cambridge: Cambridge University Press, 1990.

Nietzsche, F. On the Genealogy of Morals. Translated by Douglas Smith. Oxford and New York: Oxford University Press, 1996.

O'Brien, R., and M. Williams. Global Political Economy: Evolution and Dynamics. New York: Palgrave Macmillan, 2004. 
OED. [cited 21 October 2004]. Available from http://www.oed.com.

O'Malley, P. "Governable Catastrophes: A Comment on Bougen." Economy and Society 32, no. 2 (2003): 275-279.

Palan, R., ed. Global Political Economy: Contemporary Theories. London: Routledge, 2000.

Partnoy, F. Enron and Derivatives Obtained from Social Science Research Network Electronic Library, 24 January 2002 [cited 5 June 2004]. Available from http://ssrn.com/abstract=302332.

- A Revisionist View of Enron and the Sudden Death of 'May' Villanova University School of Law's Law Review Symposium Issue, 2003 [cited 1 June 2004]. Available from http://ssrn.com/abstract=417261.

Patomaki, H. Democratising Globalisation: The Leverage of the Tobin Tax. London: Zed, 2001.

Pauly, L. W. Who Elected the Bankers? Surveillance and Control in the World Economy. Ithaca and London: Cornell University Press, 1997.

Peterson, V. S. A Critical Rewriting of Global Political Economy: Integrating Reproductive, Productive, and Virtual Economies. London: Routledge, 2003.

Pettman, R. World Politics: Rationalism and Beyond. New York: Palgrave, 2001.

Piga, G. "Do Governments Use Financial Derivatives Appropriately? Evidence from Sovereign Borrowers in Developed Economies." International Finance 4, no. 2 (2001): 189(131).

Polanyi, K. The Great Transformation. New York and Toronto: Farrar and Rinehart, Inc, 1994.

Poovey, M. A History of the Modern Fact: Problems of Knowledge in the Sciences of Wealth and Society. Chicago and London: The University of Chicago Press, 1998. 
Porter, T. States, Markets and Regimes in Global Finance. Basingstoke: Macmillan, 1993.

—. "The Late-Modern Knowledge Structure and World Politics." In Approaches to Global Governance, edited by Martin Hewson and Timothy J. Sinclair. Albany: State University of New York Press, 1999.

Prashad, V. Fat Cats and Running Dogs: The Enron Stage of Capitalism. London: Zed Books, 2002.

Pryke, M., and J. Allen. "Monetized Time-Space: Derivatives - Money's 'New Imaginary'?" Economy and Society 29, no. 2 (2000): 264-284.

Rose, N. "Governing by Numbers: Figuring out Democracy." Accounting, Organizations and Society 16 (1991): 673-692.

Rosencrance, R. The Rise of the Trading State: Commerce and Conquest in the Modern World. New York: Basic Books Inc., 1986.

Ruggie, J. G. "International Regimes, Transactions, and Change: Embedded Liberalism in the Postwar Economic Order." International Organizations 36, no. 2 (1982): 331-351.

Sandor, R. "Observations on Enron." Environmental Finance, March 2002.

Scholte, J. A. "Global Trade and Finance." In The Globalization of World Politics, edited by John Baylis and Steve Smith. Oxford: Oxford University Press, 2001.

—. "Governing Global Finance." In Governing Globalization: Power, Authority and Global Governance, edited by David Held and Anthony McGrew. Cambridge: Polity, 2002.

Schumacher, E. F. Small Is Beautiful: A Study of Economics as if People Mattered. London: Vintage, 1973.

Sperry, P. Power For Sale: Huge Enron Loans Expose Taxpayers WorldNetDaily, 22 January 2002 [cited 5 July 2004]. Available from http://worldnetdaily.com/news/article.asp?ARTICLE ID=26159. 
Stiglitz, J. Globalization and its Discontents. London: Allen Lane, 2002.

Strange, S. Casino Capitalism. Oxford and New York: Basil Blackwell, 1986.

_. "Political Economy and International Relations." In International Relations Theory Today, edited by Ken Booth and Steve Smith, 154-174. Pennsylvania: The Pennsylvania State University Press, 1995.

- States and Markets: An Introduction to International Political Economy. 2nd ed. New York: Basil Blackwell, 1997.

Tickell, A. "Dangerous Derivatives: Controlling and Creating Risks in International Money." Geoforum 31 (2000): 87-99.

Tickell, A., and G. Clark. "New Architechtures or Liberal Logics? Interpretating Global Financial Reform." Future Governance Paper, no. No. 3 (2001).

Tobin, J. "Money." In The New Palgrave Dictionary of Money and Finance, edited by Peter Newmann, Murray Milgrage and John Eatwell, 770-779. London: The Macmillan Press Ltd., 1992.

Toulmin, S. Return to Reason. Cambridge, Massachusetts: Harvard University Press, 2001.

Warner, E. "As Derivatives Unravel, It's Your Lookout." Guardian, 1 December 2001.

Weiss, L. Myth of the Powerless State. Ithaca: Cornell University Press, 1998.

Woods, N. "Globalization and International Institutions." In The Political Economy of Globalization, edited by Ngaire Woods. New York: St Martins Press, 2000 .

"International Political Economy in an Age of Globalization." In The Globalization of World Politics, edited by John Baylis and Steve Smith. Oxford: Oxford University Press, 2001. 